Article

\title{
Design, Synthesis, and Biological Application of Novel Photoaffinity Probes of Dihydropyridine Derivatives, BAY R3401
}

\author{
Liying Zhang ${ }^{1, *}$, Zhiwei Yan ${ }^{1}$, Youde Wang ${ }^{1}$, Chengjun Song ${ }^{2}$ and Guangxin Miao ${ }^{1}$ \\ 1 Key Laboratory of Traditional Chinese Medicine Research and Development of Hebei Province, \\ Institute of Traditional Chinese Medicine, Chengde Medical University, Chengde 067000, China \\ 2 Department of Human Anatomy, Chengde Medical University, Chengde 067000, China \\ * Correspondence: zzzhangliying@126.com; Tel.: +86-314-229-1000
}

Academic Editor: Run Zhang, D. Amilan Jose, Hang Thu Ta and Mingqian Tan Received: 1 May 2019; Accepted: 28 June 2019; Published: 28 June 2019

\begin{abstract}
To explore the molecular mechanisms of BAY R3401, four types of novel photoaffinity probes bearing different secondary tags were synthesized. Their potency for glycogenolysis was evaluated in primary human liver HL-7702 cells and HepG2 cells. Probe $2 \mathrm{~d}$ showed the best activity in primary human liver HL-7702 cells and HepG2 cells, with IC 50 values of $4.45 \mu \mathrm{M}$ and $28.49 \mu \mathrm{M}$, respectively. Likewise, probe $5 \mathrm{~d}$ showed $\mathrm{IC}_{50}$ values of $6.46 \mu \mathrm{M}$ in primary human liver HL-7702 cells and 15.29 $\mu \mathrm{M}$ in HepG2 cells, respectively. Photoaffinity labeling experiments were also performed and protein bands larger than $170 \mathrm{kDa}$ were specifically tagged by probe $2 \mathrm{~d}$. The results suggest that the synthesized probe $2 \mathrm{~d}$ might be a very promising tool for the isolation of the target proteins of BAY R3401.
\end{abstract}

Keywords: BAY R3401; molecular mechanism; type 2 diabetes; photoaffinity probe; glycogenolysis; photoaffinity labeling; target proteins

\section{Introduction}

BAY R3401 is an orally bioavailable hypoglycemic agent for the treatment of type 2 diabetes, as reported by the Bayer Pharmaceutical Company [1]. This agent allows irreversible, nonselective suppression of hepatic glycogenolysis by inhibiting glycogen phosphorylase, which is the rate controlling enzyme of the glycogenolytic pathway [2]. The active metabolite, W1807, contributes significantly to its activity [3]. Nonetheless, much to the researchers' surprise, BAY R3401 inactivated glycogen phosphorylase by $63 \%$, but glucose output dropped by $83 \%$ in the perfused liver [4]. It is difficult to explain the effects based only on the reported mechanism. Therefore, the exact mode of action of BAY R3401 has not been established.

Photoaffinity labeling is one of the major methods to directly capture small-molecule binding proteins [5]. The conventional approach, however, usually relies on the synthesis of photoaffinity probes and the identification of photolabeled fragments in proteins [6]. In general, a typical photoaffinity probe contains three functional groups. A bioactive scaffold ferries the probe to the enzyme active site, a photoreactive group generates a covalent and irreversible linkage between the probe and its target macromolecule after UV irradiation, and a tag (such as biotin or fluorophore) detects and/or visualizes the modified target enzymes [7].

Herein, we report the synthesis and biological application of four types of photoaffinity probes based on BAY R3401, which contains both a benzophenone photophore for covalent labeling of target proteins and a secondary handle for the subsequent detection or manipulation of labeled proteins (Figure 1). Probes bearing different secondary tags were exploited, either by direct attachment 
of a dansyl fluorescent or a biotin tag for detection and enrichment. Moreover, we developed a dual-functional tag containing both a dansyl group and a biotin, which is suitable for both affinity purification and fluorescence applications. In order to avoid the sterically hindrance caused by the large tags, we designed another tag-free probe that employed an azide handle for downstream conjugation to the reporter tag via the click-chemistry reaction after proteome labeling. According to the previous primary structure-activity relationship of the dihydropyridine derivative, modification of the N1 position of BAY R3401 had little effect on its potency. However, the molecular size of the secondary tags is not very small compared to BAY R3401. Thus, it is not hard to speculate that hindrance might sterically occur due to interfere from the interaction between BAY R3401 and its target proteins when secondary tags are introduced to the N1 position of BAY R3401 directly. Therefore, appropriate linkages were designed to provide enough space between BAY R3401 and the secondary tags.

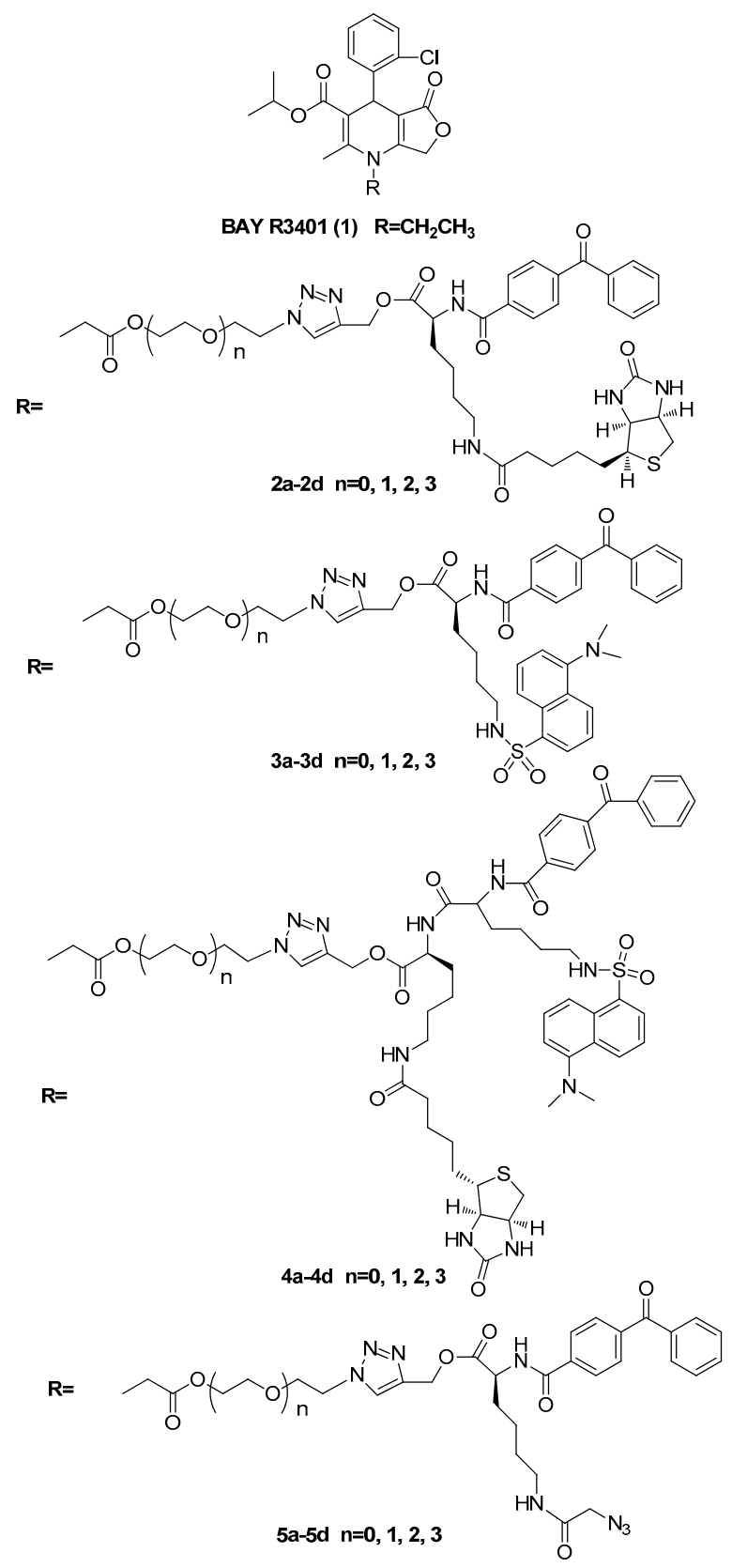

Figure 1. Structures of BAY R3401 (1), and synthetic photoaffinity probes possessing biotin (2a-2d), dansyl (3a-3d), a dual-functional tag (4a-4d), or azide (5a-5d). 


\section{Results and Discussion}

\subsection{Chemistry}

The general synthetic strategy employing a click reaction for the described activity probes is outlined in Figure 2.

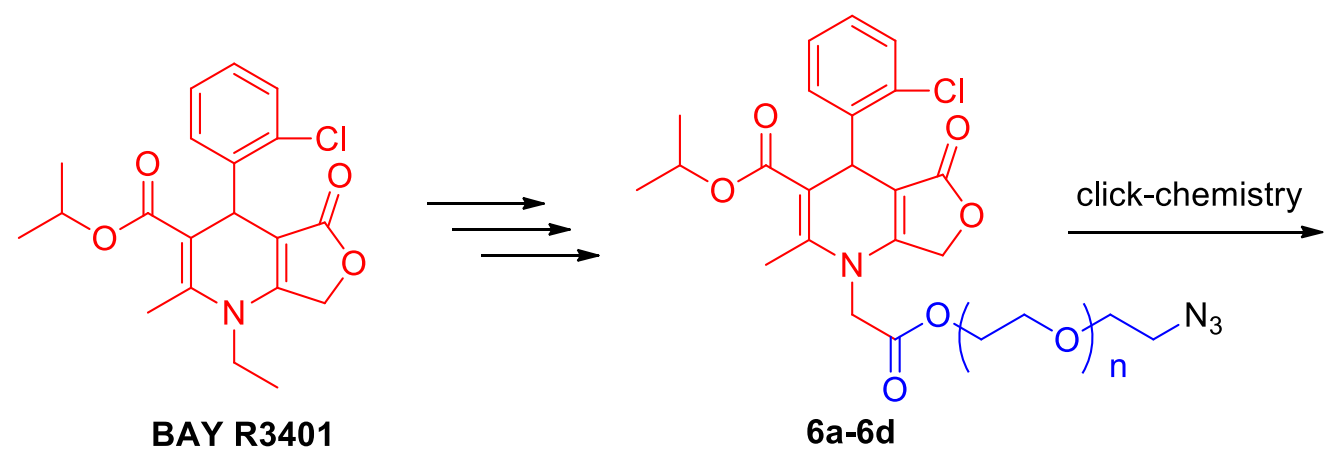

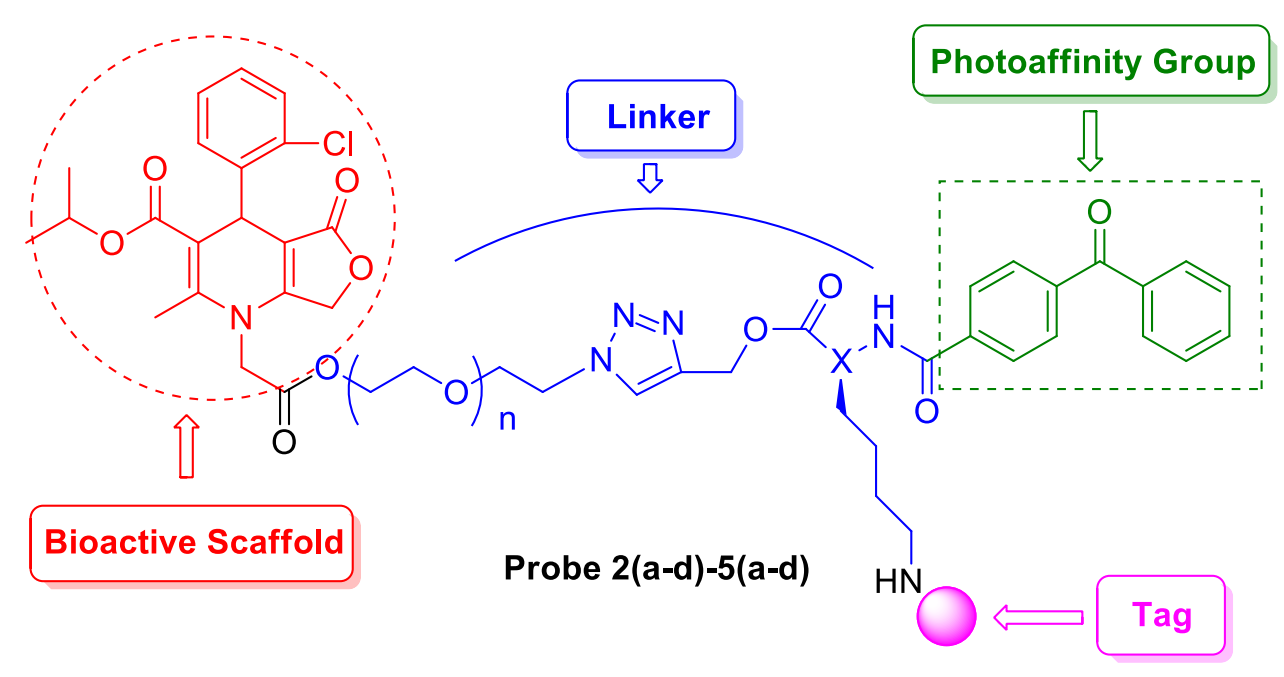

Figure 2. General synthetic strategy for photoaffinity probes by click-chemistry reaction.

To realize the click chemistry between BAY R3401 and the photoaffinity label moiety, azide functions were first introduced into the position of the ethyl branches based on previous SAR studies (Scheme 1) [8]. Treatment of 2-chlorobenzaldehyde 7 and ethyl 4-chloroacetoacetate 8 with excess isopropyl 3-aminocrotonate 9 in a one-pot reaction at reflux overnight in isopropanol yielded the 1,4-dihydropyridine nucleus 10 with a 17\% yield. The alkylation of 10 with tert-butyl chloroacetate produced 1-alkyl-1,4-dihydropyridine derivative $\mathbf{1 1}$ with a 40\% yield. Deprotection of 11 with trifluoroacetic acid (TFA) produced carboxylic acid 12 (46\%). Esterification of 12 with three different linker groups (such as 1,2-dibromoethane, 2,2'-Dibromodiethyl ether, and 1,2-Bis(2-bromoethoxy)ethane) yielded the corresponding bromides, 13a-13d (58-62\%), which were

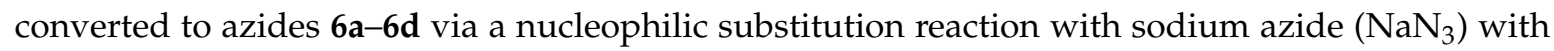
satisfactory yields (59-90\%). 


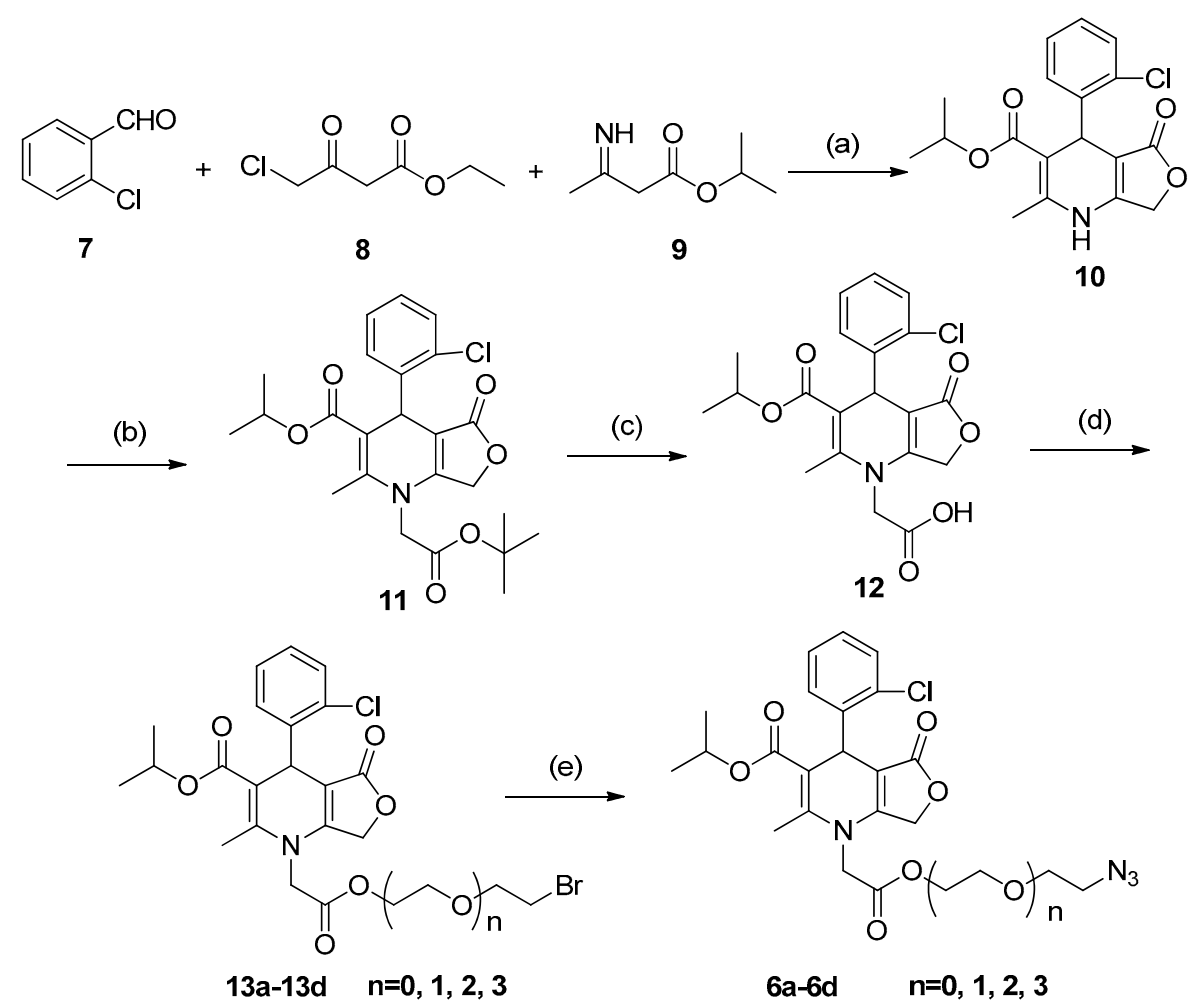

Scheme 1. Reagents and conditions: (a) isopropyl alcohol, reflux (17\%); (b) (i) $\mathrm{NaH}, 0{ }^{\circ} \mathrm{C}$ to $80{ }^{\circ} \mathrm{C}$; (ii) tert-butyl 2-chloroacetate, $80{ }^{\circ} \mathrm{C}$ ( $40 \%$ for 2 steps); (c) trifluoroacetic acid (TFA), $\mathrm{CH}_{2} \mathrm{Cl}_{2}, 0{ }^{\circ} \mathrm{C}$ to r.t. (46\%); (d) 1,2-dibromoethane or 2,2'-Dibromodiethyl ether or 1,2-Bis(2-bromoethoxy)ethane, $\mathrm{K}_{2} \mathrm{CO}_{3}$, anhydrous $\mathrm{CH}_{3} \mathrm{CN}, 0^{\circ} \mathrm{C}$ to $80{ }^{\circ} \mathrm{C}(58-62 \%)$; (e) $\mathrm{NaN}_{3}$, DMF, r.t. (59-90\%).

The key intermediates, 20-22, were prepared individually via procedures similar to those reported previously, with some modifications (Scheme 2) [9]. Treatment of Lys(Boc)-OMe with 4-benzoylbenzoic acid using EDCI/DMAP afforded compound 16, bearing a benzophenone photophore. Hydrolysis of 16 with aqueous $\mathrm{NaOH}$ yielded carboxylic acid 17, followed by an esterification with propargyl bromide to produce the alkyne 18. Subsequent deprotection of 18 using TFA gave amide 19, then coupling 19 with D-biotin in DMF in the presence of EDCI, HOBt, and DIPEA as condensing agents produced biotin conjugate 20 with a biotin tag. Treatment of amino 19 with dansyl chloride (DNS-Cl) gave the desired fluorescent derivative 21. Amidation of amino 19 with $\mathrm{ClCH}_{2} \mathrm{COCl}$ was carried out to produce chloroacetyl compound $\mathbf{2 2}$ for the next step of azide displacement.

The preparation of a dual-labeled moiety was accomplished as follows (Scheme 3). The synthesis cycle began with deprotection of $\mathbf{1 6}$ using TFA, producing amide 23 . Then, amidation with DNS-Cl gave compound 24. Hydrolysis of $\mathbf{2 4}$ with aqueous $\mathrm{LiOH}$ afforded carboxylic acid $\mathbf{2 5}$ with an $87 \%$ yield. Treatment of N-Cbz-N'-Boc-L-lysine with propargyl bromide gave alkyne 27. Subsequent deprotection of 27 using TFA, followed by coupling with D-biotin in DMF in the presence of isobutyl chloroformate and $\mathrm{Et}_{3} \mathrm{~N}$ as condensing agents, produced biotin conjugate 28 . The $\mathrm{N}-\mathrm{Cbz}$ group was hydrolyzed off in $30 \% \mathrm{HBr}$ in acetic acid at room temperature to give the amide compound 29. Reaction of 29 with carboxylic acid derivative $\mathbf{2 5}$ in the presence of HATU and DIPEA produced the dual label moiety with a $43 \%$ yield. 
Molecules 2019, 24, 2394

5 of 27

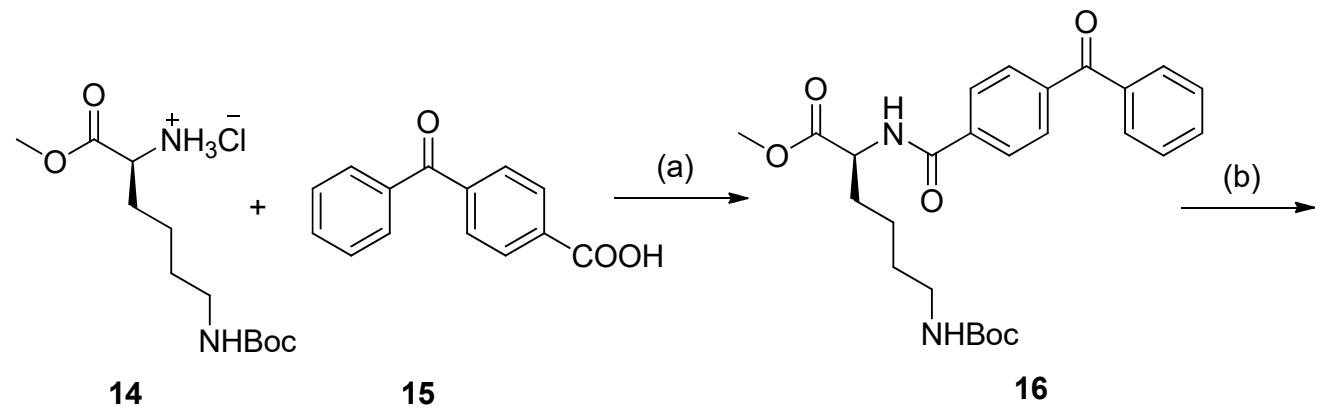<smiles>CC(C)(C)OC(=O)NCCCC[C@H](NC(=O)c1ccc(C(=O)c2ccccc2)cc1)C(=O)O</smiles>

17<smiles>C#CCOC(=O)[C@H](CCCCNC(=O)OCc1ccccc1)NC(=O)c1ccc(C(=O)c2ccccc2)cc1</smiles>

18<smiles>C#CCOC(=O)[C@H](CCCCN)NC(=O)c1ccc(C(=O)c2ccccc2)cc1</smiles>

(e)

19

(f)

(g)<smiles>C#CCOC(=O)[C@H](CCCCNC(=O)CCl)NC(=O)c1ccc(C(=O)c2ccccc2)cc1</smiles>

22

Scheme 2. Reagents and conditions: (a) EDCI, NMM, DMAP, DMF, r.t. (87\%); (b) $2 \mathrm{~N} \mathrm{NaOH}, \mathrm{CH}_{3} \mathrm{OH}$, $0{ }^{\circ} \mathrm{C}$ to r.t.; (c) 3-Bromopropyne, $\mathrm{K}_{2} \mathrm{CO}_{3}$, DMF, r.t. (68\%); (d) TFA, $\mathrm{CH}_{2} \mathrm{Cl}_{2}, 0{ }^{\circ} \mathrm{C}$ to r.t.; (e) D-biotin, $\mathrm{EDCI}$, $\mathrm{HOBt}, \mathrm{DIPEA}, \mathrm{DMF}(37 \%)$; (f) dansyl chloride (DNS-Cl), $\mathrm{Et}_{3} \mathrm{~N}, \mathrm{CH}_{2} \mathrm{Cl}_{2}$, r.t. (81\%); (g) $\mathrm{ClCH}_{2} \mathrm{COCl}$, $\mathrm{Et}_{3} \mathrm{~N}, \mathrm{CH}_{2} \mathrm{Cl}_{2}, 0^{\circ} \mathrm{C}$ to r.t. $(86 \%)$. 
<smiles>COC(=O)[C@H](CCCCN)NC(=O)c1ccc(C(=O)c2ccc(C(=O)N[C@@H](CCCCNC(=O)OC(C)(C)C)C(=O)OC)cc2)cc1</smiles>

16

23<smiles>COC(=O)[C@H](CCCCNS(=O)(=O)c1cccc2c(N(C)C)cccc12)NC(=O)c1ccc(C(=O)c2ccccc2)cc1</smiles>

24 (c)<smiles>CN(C)c1cccc2c(S(=O)(=O)NCCCCC(NC(=O)c3ccc(C(=O)c4ccccc4)cc3)C(=O)O)cccc12</smiles>

25<smiles>C#CCOC(=O)[C@H](CCCCNC(=O)OCc1ccccc1)NC(=O)OCc1ccccc1</smiles>

26

27<smiles>C#CCOC(=O)[C@H](N)CCCCNC(=O)CCCC[C@H]1SC[C@@H]2NC(=O)N[C@@H]21</smiles>

28

29<smiles>O=C(I)c1ccc(C(=O)c2ccccc2)cc1</smiles><smiles>C#CCOC(=O)[C@H](CCCCN)NC(=O)[C@H](CC)NC(C)=O</smiles>

$25+29 \stackrel{(g)}{\longrightarrow}$<smiles>CCCCNS(=O)(=O)c1cccc2c(N(C)C)cccc12</smiles><smiles>CC[C@H]1SC[C@@H]2NC(=O)N[C@@H]21</smiles>

30

Scheme 3. Reagents and conditions: (a) TFA, $\mathrm{CH}_{2} \mathrm{Cl}_{2}, 0{ }^{\circ} \mathrm{C}$ to r.t.; (b) DNS-Cl, $\mathrm{Et}_{3} \mathrm{~N}, \mathrm{CH}_{2} \mathrm{Cl}_{2}$, r.t. (67\%); (c) $6 \mathrm{~N} \mathrm{LiOH}, \mathrm{THF} / \mathrm{H}_{2} \mathrm{O}, 0{ }^{\circ} \mathrm{C}$ to r.t. (88\%); (d) 3-Bromopropyne, $\mathrm{K}_{2} \mathrm{CO}_{3}$, DMF, r.t. (72\%); (e) (i) TFA, $\mathrm{CH}_{2} \mathrm{Cl}_{2},{ }^{\circ} \mathrm{C}$ to r.t.; (ii) D-biotin, isobutyl chloroformate, $\mathrm{Et}_{3} \mathrm{~N}, \mathrm{DMF}(77 \%)$; (f) $\mathrm{HBr} / \mathrm{HOAC}, 0{ }^{\circ} \mathrm{C}$ to r.t.; (g) HATU, DIPEA, DMF, $0{ }^{\circ} \mathrm{C}$ to r.t. $(43 \%)$. 
Click chemistry was handled as shown in Scheme 4 . The corresponding azides and alkynes were dissolved in $\mathrm{CH}_{2} \mathrm{Cl}_{2}-\mathrm{H}_{2} \mathrm{O}$, followed by the addition of catalytic sodium ascorbate and $\mathrm{CuSO}_{4} \cdot 5 \mathrm{H}_{2} \mathrm{O}_{\text {. }}$ Reaction of the above azides $\mathbf{6 a - 6 d}$ with alkynes 20, 21, and $\mathbf{3 0}$ gave, respectively, probes $\mathbf{2 a - 2 d}$ $(21-25 \%), 3 a-3 \mathbf{d}(13-27 \%)$, and $\mathbf{4 a}-\mathbf{4 d}(13-27 \%)$. In a similar way, the conversion of $\mathbf{6 a}-\mathbf{6 d}$ to the corresponding chloroacetyl compounds, 31a-31d, was followed by a reaction with $\mathrm{NaN}_{3}$ to give probes $5 \mathbf{a}-5 d$.

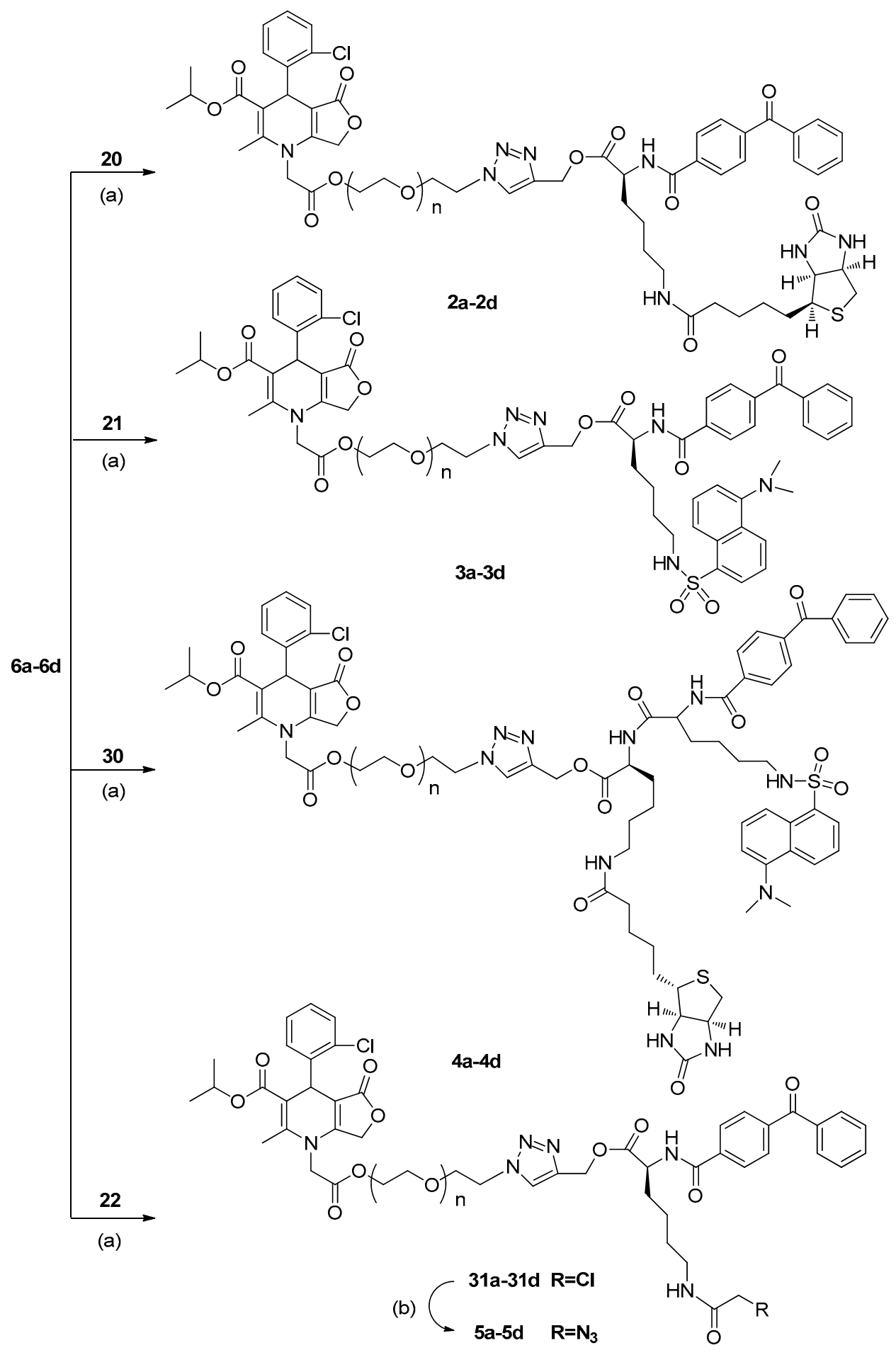

Scheme 4. Reagents and conditions: (a) $\mathrm{CuSO}_{4} \cdot 5 \mathrm{H}_{2} \mathrm{O}$, sodium ascorbate, $\mathrm{CH}_{2} \mathrm{Cl}_{2}-\mathrm{H}_{2} \mathrm{O}$, r.t.; (b) $\mathrm{NaN}_{3}$, DMF, r.t. 
The synthesis of control compounds 32 and 34, which lack the bioactive ligand BAY R3401 and only contain the photoaffinity and tag groups, is shown in Scheme 5 . The cycle was started with the deprotection step, as above, followed by amidation with D-biotin and $\mathrm{ClCH}_{2} \mathrm{COCl}$ to give the control compound 32, and intermediate haloester 33. Then, treatment of $\mathbf{3 3}$ with $\mathrm{NaN}_{3}$ produced the control compound 34 with a $77 \%$ yield.<smiles>COC(=O)[C@H](CCCCNC(=O)CCCC[C@H]1SC[C@@H]2NC(=O)N[C@H]21)NC(=O)c1ccc(C(=O)c2ccccc2)cc1</smiles>

32 (a)<smiles>[125In]</smiles>

(b)<smiles>[R]CC(=O)NCCCC[C@H](NC(=O)c1ccc(C(=O)c2ccccc2)cc1)C(=O)OC</smiles>

(c) $33 \mathrm{R}=\mathrm{Cl}$

$34 \mathrm{R}=\mathrm{N}_{3}$

Scheme 5. (a) i) TFA, $\mathrm{CH}_{2} \mathrm{Cl}_{2}, 0^{\circ} \mathrm{C}$ to r.t.; ii) D-biotin, $\mathrm{EDCI}, \mathrm{HOBt}$, DIPEA, DMF (51\%); (b) $\mathrm{ClCH}_{2} \mathrm{COCl}$, $\mathrm{Et}_{3} \mathrm{~N}, \mathrm{CH}_{2} \mathrm{Cl}_{2}, 0^{\circ} \mathrm{C}$ to r.t. $(68 \%) ;$ (c) $\mathrm{NaN}_{3}$, DMF, r.t. $(77 \%)$.

To confirm the efficacy of designed probes $\mathbf{5 a - 5 d}$ in combining the tag after protein labeling, the reaction of the tag-free probe $\mathbf{5 d}$ with the alkyne-coupled biotin derivative in a simple model system was also studied (Scheme 6). The biotin derivative 35 was prepared based on a previously reported procedure described in [10]. Treatment of probe $\mathbf{5 d}$ with alkyne-biotin $\mathbf{3 5}$ under typical click conditions ( $\mathrm{CuSO} \cdot 5 \mathrm{H}_{2} \mathrm{O}$, with sodium ascorbate as the reducing agent) in $\mathrm{CH}_{2} \mathrm{Cl}_{2}-\mathrm{H}_{2} \mathrm{O}$, the conjugate product 36 could be isolated with a $13 \%$ yield as a white solid. These results demonstrated that the azide handle of the tag-free probe can be subsequently conjugated with an alkyne-tag through biocompatible copper-catalyzed azide-alkyne cycloaddition.<smiles>C#CCOC(=O)CCCC[C@H]1SC[C@@H]2NC(=O)N[C@@H]21</smiles>

Scheme 6. (a) $\mathrm{CuSO}_{4} \cdot 5 \mathrm{H}_{2} \mathrm{O}$, sodium ascorbate, $\mathrm{CH}_{2} \mathrm{Cl}_{2}-\mathrm{H}_{2} \mathrm{O}$, r.t. (13\%). 


\subsection{Cell Assay and SAR Analysis.}

It is obviously important that the synthesized probes retain potency in bioassays. To evaluate the effects of all probes, the glycogenolysis assays were established in vitro, with primary human liver HL-7702 cells and HepG2 cells, based on the published method [11]. A well-known chloroindole inhibitor of glycogenolysis, CP-91149, was used as a positive control in these experiments.

The $\mathrm{IC}_{50}$ values of the tested derivatives are listed in Table 1 . Most of the newly synthesized probes maintained moderate inhibitory activity against glucagon-stimulated glycogenolysis in primary human liver HL-7702 cells and HepG2 cells. It is interesting to note that modification of dihydropyridine scaffold with bulky substituents resulted in a great increase in $\mathrm{IC}_{50}$ both in primary human liver HL-7702 cells and HepG2 cells (e.g., BAY R3401 vs. $\mathbf{2 b - 2 d}, \mathbf{3 b}-\mathbf{3 d}, \mathbf{5 a}, \mathbf{5 c}, \mathbf{5 d}, \mathbf{6 a}$ ). The results are consistent with the SAR analysis of W1807, the active metabolite in cells of BAY R3401, which revealed that the N1-substituent may productive van der Waals interactions between the substitutions and its target proteins [8]. With different linkers, SAR analysis in HepG2 cells shows that the distance between the BAY R3401 moiety and secondary tags' moiety is important-a longer linker led to better inhibitory activity (e.g., 2a vs. 2d, 3a vs. 3d, and 5a vs. 5d). However, data analysis indicated no clear SAR for the distance in primary human liver HL-7702 cells. Within this series of compounds, probe $\mathbf{2} \mathbf{d}$ showed the best activity in primary human liver HL-7702 cells and HepG2 cells, with $\mathrm{IC}_{50}$ values of $4.45 \mu \mathrm{M}$ and $28.49 \mu \mathrm{M}$, respectively. Likewise, probe $5 \mathrm{~d}$ showed an $\mathrm{IC}_{50}$ value of $6.46 \mu \mathrm{M}$ in primary human liver HL-7702 cells and $15.29 \mu \mathrm{M}$ in HepG2 cells, respectively. Therefore, probe $\mathbf{2} \mathbf{d}$ and $\mathbf{5} \mathbf{d}$ may be very promising tools for isolation of the target proteins of BAY R3401.

Table 1. Glycogenolysis inhibition assay for compounds 2(a-d)-6(a-d) in liver cells.

\begin{tabular}{|c|c|c|c|c|c|}
\hline Compound & $\begin{array}{c}\mathrm{IC}_{50}{ }^{\mathrm{a}}(\mu \mathrm{M}, \\
\mathrm{HL}-7702 \text { cells })\end{array}$ & $\begin{array}{c}\mathrm{IC}_{50}{ }^{\mathrm{a}}(\mu \mathrm{M}, \\
\text { HepG2 cells })\end{array}$ & Compound & $\begin{array}{c}\mathrm{IC}_{50}{ }^{\mathrm{a}}(\mu \mathrm{M}, \\
\mathrm{HL}-7702 \text { cells })\end{array}$ & $\begin{array}{r}\mathrm{IC}_{50}{ }^{\mathrm{a}}(\mu \mathrm{M}, \\
\text { HepG2 cells) }\end{array}$ \\
\hline $2 a$ & $6.23 \pm 2.86$ & $53.12 \pm 10.11$ & $4 d$ & $17.15 \pm 4.97$ & $\mathrm{NI}$ \\
\hline $2 b$ & $4.55 \pm 1.57$ & $37.69 \pm 1.76$ & $5 a$ & $2.96 \pm 0.57$ & $45.94 \pm 12.44$ \\
\hline $2 c$ & $5.22 \pm 1.17$ & $38.00 \pm 1.06$ & $5 b$ & $4.83 \pm 1.48$ & $59.89 \pm 19.75$ \\
\hline $2 d$ & $4.45 \pm 0.50$ & $28.49 \pm 3.38$ & $5 c$ & $15.22 \pm 3.29$ & $18.73 \pm 5.31$ \\
\hline $3 a$ & $4.86 \pm 1.22$ & $106.16 \pm 4.17$ & $5 d$ & $6.46 \pm 3.60$ & $15.29 \pm 4.31$ \\
\hline $3 b$ & $5.62 \pm 1.67$ & $44.75 \pm 7.20$ & $6 a$ & $19.36 \pm 2.00$ & $40.02 \pm 5.55$ \\
\hline $3 c$ & $2.56 \pm 0.59$ & $42.32 \pm 5.78$ & $6 b$ & $22.36 \pm 1.97$ & $54.38 \pm 13.73$ \\
\hline $3 d$ & $2.71 \pm 0.54$ & $33.71 \pm 1.23$ & $6 c$ & $22.35 \pm 24.36$ & NI \\
\hline $4 a$ & $27.22 \pm 4.94$ & $49.09 \pm 1.23$ & $6 d$ & $24.00 \pm 12.44$ & $40.05 \pm 3.99$ \\
\hline $4 b$ & $27.32 \pm 9.27$ & $96.71 \pm 36.04$ & BAY R3401 & $27.06 \pm 9.63$ & $52.83 \pm 8.93$ \\
\hline $4 c$ & $15.22 \pm 3.29$ & $\mathrm{NI}^{\mathrm{b}}$ & CP-91149 $\mathrm{c}$ & $2.53 \pm 0.78$ & $3.08 \pm 1.16$ \\
\hline
\end{tabular}

\subsection{Application of Activity-Based Profiling to Target Discovery}

Based on the results of the potency in cell assay, probe $2 \mathbf{d}$ was selected for photolabeling studies to detect the binding proteins of BAY R3401 by PAGE and chemiluminescence [12]. The soluble proteomes prepared from HepG2 cells, were incubated with the $10 \mu \mathrm{M}$ probe $\mathbf{2 d}$, exposed to UV light for $30 \mathrm{~min}$, followed by SDS-PAGE electrophoresis, and then transfer onto a PVDF membrane for detection with streptavidin-HRP [10]. Samples were prepared by incubating $2.0 \mathrm{mg} / \mathrm{mL}$ proteomes at different conditions: (Lane 1 and 6) marker; (Lane 2) with the $10 \mu \mathrm{M}$ probe $\mathbf{2} \mathbf{d}$ and exposed to UV light for $30 \mathrm{~min}$; (Lane 3) with the $10 \mu \mathrm{M}$ probe $\mathbf{2 d}$ and BAY R3401, and then exposed to UV light for $30 \mathrm{~min}$; (Lane 4) With the $10 \mu \mathrm{M}$ control compound 32 and exposed to UV light for $30 \mathrm{~min}$; and (Lane 5) with the $0 \mu \mathrm{M}$ probe $\mathbf{2} \mathbf{d}$ and exposed to UV light for $30 \mathrm{~min}$. 
The results showed that a protein band larger than $170 \mathrm{kDa}$ was seen in samples incubated with 2d. This labeling was specific since it was completed by BAY R3401, and no such labeling was seen when samples were incubated with control compound $\mathbf{3 2}$ rather than $\mathbf{2 d}$ (Figure 3 ). These data demonstrate that the synthesized probe $\mathbf{2 d}$ can efficiently and specifically identify the binding protein(s) of BAY R3401 and suggest that 2d will be suitable for isolating the binding protein(s) of BAY R3401 by avidin-agarose chromatography.

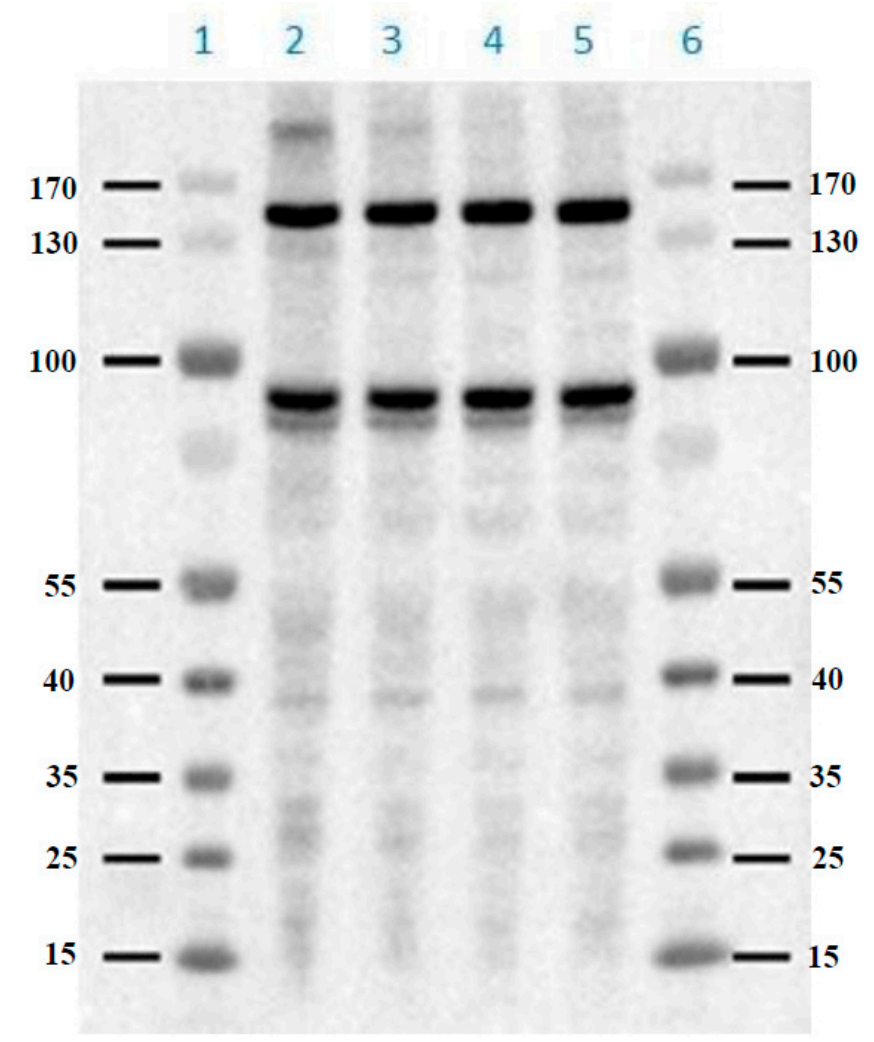

Figure 3. Results of SDS-PAGE analysis of photoaffinity labeling of experiment by synthesized probe 2d.

Then, we used a more detailed proteomic analysis, with a mass spectrometric analysis method, to detect the protein band larger than $170 \mathrm{kDa}$. Several proteins have been identified, and some of the results are summarized in Table 2. We hypothesise that the PH-interacting protein, histone H4, hexokinase-2 and solute carrier family 2 might be the target proteins of BAY R3401 based on the protein probability scores in MaxQuant. We are now in the process of verifying these proteins. A comparison between the streptavidin blot analysis and Coomassie brilliant blue (CBB) staining was carried out. The detailed information of CBB is in Supplementary information. The results also showed that the streptavidin blot analysis was specific since the protein labeled by probe $\mathbf{2 d}$ is clearly shown after the streptavidin blot analysis while CBB staining had a strong background with the gel image under identical staining conditions. 
Table 2. Comparative analysis of the protein groups identified by LC-MS/MS.

\begin{tabular}{|c|c|c|c|}
\hline Description & Accession $^{a}$ & Score ${ }^{b}$ & $\mathrm{MW}^{\mathrm{c}}[\mathrm{kDa}]$ \\
\hline Carbamoyl-phosphate synthase [ammonia] & P31327 & 703.64 & 164.83 \\
\hline Myoferlin & Q9NZM1 & 491.05 & 234.56 \\
\hline Coatomer subunit alpha & P53621 & 338.49 & 138.26 \\
\hline Keratin, type II cytoskeletal 1 & P04264 & 332.99 & 66.0 \\
\hline Vigilin & Q00341 & 325.29 & 141.37 \\
\hline $\begin{array}{l}\text { Sodium/potassium-transporting ATPase subunit } \\
\text { alpha-1 }\end{array}$ & P05023 & 169.27 & 112.82 \\
\hline Inositol 1,4,5-trisphosphate receptor type 3 & Q14573 & 146.90 & 303.91 \\
\hline Epidermal growth factor receptor & P00533 & 110.92 & 134.19 \\
\hline PH-interacting protein & Q8WWQ0 & 46.67 & 206.56 \\
\hline Nuclear pore complex protein Nup153 & P49790 & 29.84 & 153.84 \\
\hline Histone $\mathrm{H} 4$ & P62805 & 27.37 & 11.36 \\
\hline Hexokinase-2 & E9PB90 & 26.18 & 98.91 \\
\hline DNA (cytosine-5)-methyltransferase 1 & P26358 & 26.13 & 183.05 \\
\hline U2 snRNP-associated SURP motif-containing protein & O15042 & 25.91 & 118.22 \\
\hline Histone-lysine $N$-methyltransferase EHMT2 & A0A0G2JIS2 & 24.46 & 128.95 \\
\hline Keratin, type II cytoskeletal 72 & Q14CN4 & 24.37 & 55.84 \\
\hline $\begin{array}{l}\text { 1-phosphatidylinositol 4,5-bisphosphate } \\
\text { phosphodiesterase beta-3 }\end{array}$ & Q01970 & 22.73 & 138.71 \\
\hline $\begin{array}{l}\text { Solute carrier family } 2 \text {, facilitated glucose transporter } \\
\text { member } 1\end{array}$ & P11166 & 20.46 & 54.05 \\
\hline Inositol 1,4,5-trisphosphate receptor type 2 & Q14571 & 20.32 & 307.87 \\
\hline Low-density lipoprotein receptor & P01130 & 18.50 & 95.31 \\
\hline $\begin{array}{c}\text { Phosphatidylinositol 4-phosphate 3-kinase C2 } \\
\text { domain-containing subunit alpha }\end{array}$ & O00443 & 16.86 & 190.56 \\
\hline Inositol 1,4,5-trisphosphate receptor type 1 & Q14643 & 15.87 & 313.73 \\
\hline Receptor tyrosine-protein kinase erbB-2 (Fragment) & J3KTI5 & 13.12 & 27.76 \\
\hline Apolipoprotein B-100 & P04114 & 11.42 & 515.28 \\
\hline Rho-associated protein kinase 2 & O75116 & 10.68 & 160.80 \\
\hline Histone-lysine $N$-methyltransferase EHMT1 & A0A1B0GV09 & 10.33 & 138.17 \\
\hline
\end{tabular}

\section{Materials and Methods}

\subsection{Chemistry}

NMR experiments were performed on a Bruker Avance III $400 \mathrm{MHz}$ and a Bruker Fourier $300 \mathrm{MHz}$. The spectra are referenced internally according to the residual solvent signals of TMS $(\delta=0.00 \mathrm{ppm})$. Positive or negative ion LCMS data were obtained at $303 \mathrm{~K}$ by a quadrupole Mass Spectrometer on Agilent LC/MSD 1200 Series using a $50 \times 4.6 \mathrm{~mm}(5 \mu \mathrm{m})$ ODS column. Prep-HPLC experiments were performed by flash welchrom C18 column $(150 \times 20 \mathrm{~mm})$ chromatography. 
3.1.1. Isopropyl 2-methyl-4-(2-chlorophenyl)-5-oxo-1,4,5,7-tetrahydrofuro [3,4-b]pyridine-3-carboxylate (10)

A mixture of $9(224.9 \mathrm{~mL}, 1.55 \mathrm{~mol})$, ethyl 4-chloro-3-oxobutanoate $(209.4 \mathrm{~mL}, 1.55 \mathrm{~mol})$ and 2-chlorobenzaldehyde $(174.4 \mathrm{~mL}, 1.55 \mathrm{~mol})$ in isopropyl alcohol $(1.5 \mathrm{~L})$ was stirred at reflux temperature overnight. After cooling to r.t. overnight, the mixture was filtered. The residue was purified by recrystallized from isopropyl ether to give product $10(90.0 \mathrm{~g}, 17 \%)$ as a yellow solid. HPLC analysis: 100.0\%. M.p. $225-227{ }^{\circ} \mathrm{C} .{ }^{1} \mathrm{H}-\mathrm{NMR}\left(400 \mathrm{MHz}, d_{6}\right.$-DMSO): $0.71(\mathrm{~d}, J=8.4 \mathrm{~Hz}, 3 \mathrm{H}), 1.12(\mathrm{~d}, \mathrm{~J}=8.4 \mathrm{~Hz}$, $3 \mathrm{H}), 2.30(\mathrm{~s}, 3 \mathrm{H}), 4.68-4.76(\mathrm{~m}, 1 \mathrm{H}), 4.79(\mathrm{~s}, 2 \mathrm{H}), 5.16(\mathrm{~s}, 1 \mathrm{H}), 7.12-7.18(\mathrm{~m}, 1 \mathrm{H}), 7.25-7.32(\mathrm{~m}, 3 \mathrm{H}), 9.79$ (s, 1H). ${ }^{13} \mathrm{C}$-NMR (100 MHz, $d_{6}$-DMSO): 171.5, 166.3, 156.7, 146.6, 144.3, 132.4, 131.4, 129.2, 128.2, 127.7, $103.4,100.7,66.5,65.5,34.8,22.0,21.3,19.2$. ESI (MS) $m / z: 348.1(M+H)^{+}$. HRMS (ESI-TOF) calculated for $\mathrm{C}_{18} \mathrm{H}_{18} \mathrm{ClNNaO}_{4}(M+\mathrm{Na})^{+}$: 370.08166; found: 370.08298 .

3.1.2. Isopropyl 2-methyl-4-(2-chlorophenyl)-1-(2-tert-butoxy-2-oxoethyl)-5-oxo-1,4,5,7-tetrahydrofuro [3,4-b]pyridine-3-carboxylate (11)

To a solution of $\mathbf{1 0}(62.60 \mathrm{~g}, 0.18 \mathrm{~mol})$ in anhydrous DMF $(1.5 \mathrm{~L})$ was added a $\mathrm{NaH}(60 \%$ dispersion in mineral oil, $8.85 \mathrm{~g}, 0.22 \mathrm{~mol}$ ) at $0{ }^{\circ} \mathrm{C}$ under a $\mathrm{N}_{2}$ atmosphere. The mixture was heated at $80{ }^{\circ} \mathrm{C}$ for $2 \mathrm{~h}$ and then tert-butyl 2-chloroacetate $(36.10 \mathrm{~g}, 0.24 \mathrm{~mol})$ was added slowly dropwise at r.t.. The mixture was stirred at $80^{\circ} \mathrm{C}$ for $1 \mathrm{~h}$. After cooling to r.t., the mixture was diluted with water $(2.5 \mathrm{~L})$ and extracted by EtOAc $(1 \mathrm{~L} \times 3)$. The combined organic phase was washed with brine $(1 \mathrm{~L} \times 2)$, dried over anhydrous $\mathrm{Na}_{2} \mathrm{SO}_{4}$, and evaporated. The residue was purified by being recrystallized with EtOAc $(200 \mathrm{~mL})$ to give product $11(33.0 \mathrm{~g}, 40 \%)$ as a white solid. HPLC analysis: 90.3\%. M.p. 174-176 ${ }^{\circ} \mathrm{C} .{ }^{1} \mathrm{H}-\mathrm{NMR}\left(400 \mathrm{MHz}, \mathrm{CDCl}_{3}\right): 0.85(\mathrm{~d}, J=8.4 \mathrm{~Hz}, 3 \mathrm{H}), 1.22(\mathrm{~d}, J=6.4 \mathrm{~Hz}, 3 \mathrm{H}), 1.55(\mathrm{~s}, 9 \mathrm{H})$, $2.42(\mathrm{~s}, 3 \mathrm{H}), 4.07(\mathrm{dd}, J=42.8,18.4 \mathrm{~Hz}, 2 \mathrm{H}), 4.68(\mathrm{~s}, 2 \mathrm{H}), 4.84-4.93(\mathrm{~m}, 1 \mathrm{H}), 5.47(\mathrm{~s}, 1 \mathrm{H}), 7.11(\mathrm{td}, J=7.6$, $1.6 \mathrm{~Hz}, 1 \mathrm{H}), 7.21(\mathrm{td}, J=7.6,1.2 \mathrm{~Hz}, 1 \mathrm{H}), 7.31(\mathrm{dd}, J=8.0,1.2 \mathrm{~Hz}, 1 \mathrm{H}), 7.42(\mathrm{dd}, J=8.0,1.6 \mathrm{~Hz}, 1 \mathrm{H})$. ${ }^{13} \mathrm{C}-\mathrm{NMR}\left(100 \mathrm{MHz}, \mathrm{CDCl}_{3}\right): 171.1,166.9,166.8,156.4,144.9,142.2,133.2,131.1,129.4,127.9,127.0$, 109.0, 103.3, 84.0, 67.8, 65.0, 48.1, 35.0, 28.0, 21.7, 20.9, 15.1. ESI (MS) $m / z: 462.0(M+\mathrm{H})^{+}$. HRMS (ESI-TOF) calculated for $\mathrm{C}_{24} \mathrm{H}_{29} \mathrm{ClNO}_{6}(M+\mathrm{H})^{+}: 462.16779$; found: 462.16878 .

3.1.3. 2-[2-Methyl-3-isopropoxycarbonyl-4-(2-chlorophenyl)-5-oxo-furo[3,4-b]pyridine-1 $(4 H, 5 H, 7 H)$-yl]acetic acid (12)

To a solution of $\mathbf{1 1}(10.0 \mathrm{~g}, 21.65 \mathrm{mmol})$ in DCM $(100 \mathrm{~mL})$ under a $\mathrm{N}_{2}$ atmosphere, TFA $(15.0 \mathrm{~mL}$, $0.20 \mathrm{~mol}$ ) was added, dropwise, at $0{ }^{\circ} \mathrm{C}$. The mixture was stirred at $0{ }^{\circ} \mathrm{C}$ for $2 \mathrm{~h}$ and then quenched with $\mathrm{KHCO}_{3}$ aq $(3 \mathrm{~N})$. The aqueous layer was acidified with acetic acid to $\mathrm{pH}=2$ and extracted by EtOAc $(100 \mathrm{~mL} \times 5)$. The combined organic phase was washed with brine $(200 \mathrm{~mL} \times 2)$, dried over anhydrous $\mathrm{Na}_{2} \mathrm{SO}_{4}$, and concentrated. The residue was purified by flash silica gel column chromatography $\left[\mathrm{CH}_{2} \mathrm{Cl}_{2}-\mathrm{MeOH}(100: 1)\right]$ to obtain a white solid product 12 (4.0 g, 45\%). HPLC analysis: 92.6\%. M.p. 155-157 ${ }^{\circ} \mathrm{C} .{ }^{1} \mathrm{H}-\mathrm{NMR}\left(400 \mathrm{MHz}, d_{6}\right.$-DMSO): 0.79 (d, $\left.J=6.0 \mathrm{~Hz}, 3 \mathrm{H}\right), 1.14(\mathrm{~d}, J=6.4 \mathrm{~Hz}, 3 \mathrm{H}), 2.32$ (s, $3 \mathrm{H}), 4.27(\mathrm{q}, J=18.4 \mathrm{~Hz}, 2 \mathrm{H}), 4.71-4.78(\mathrm{~m}, 1 \mathrm{H}), 4.87(\mathrm{dd}, J=42.8,16.4 \mathrm{~Hz}, 2 \mathrm{H}), 5.22(\mathrm{~s}, 1 \mathrm{H}), 7.17(\mathrm{td}$, $J=7.6,1.6 \mathrm{~Hz}, 1 \mathrm{H}), 7.27(\mathrm{td}, J=7.2,0.8 \mathrm{~Hz}, 1 \mathrm{H}), 7.32(\mathrm{dd}, J=7.6,0.8 \mathrm{~Hz}, 1 \mathrm{H}), 7.49(\mathrm{dd}, J=7.6,0.8 \mathrm{~Hz}$, 1H). ${ }^{13} \mathrm{C}-\mathrm{NMR}\left(100 \mathrm{MHz}, d_{6}\right.$-DMSO): 171.5, 170.9, 166.9, 159.1, 146.9, 143.7, 132.3, 131.6, 129.1, 128.4, $127.8,107.4,101.1,67.2,66.0,48.6,34.6,21.9,21.2,15.3$. ESI (MS) $m / z: 405.9(M+\mathrm{H})^{+}$. HRMS (ESI-TOF) calculated for $\mathrm{C}_{20} \mathrm{H}_{20} \mathrm{ClNNaO}_{6}(\mathrm{M}+\mathrm{Na})^{+}$: 428.08714 ; found: 428.08765 .

\subsubsection{General Procedure for Synthesis of compounds 13a-13d}

To a solution of $12(12.20 \mathrm{~g}, 0.03 \mathrm{~mol})$ in anhydrous acetonitrile $(120 \mathrm{~mL})$ was added $\mathrm{K}_{2} \mathrm{CO}_{3}$ $(12.50 \mathrm{~g}, 0.09 \mathrm{~mol})$ in groups, and then Bromo-PEG(n)-bromide $(0.15 \mathrm{~mol})$ was added to the reaction mixture slowly under an ice bath, and the temperature was raised to $80^{\circ} \mathrm{C}$ for $1.5 \mathrm{~h}$. After cooling to r.t., the mixture was diluted with water $(150 \mathrm{~mL})$ and extracted by EtOAc $(100 \mathrm{~mL} \times 2)$. The combined organic phase was washed with brine $(100 \mathrm{~mL} \times 2)$, dried over anhydrous $\mathrm{Na}_{2} \mathrm{SO}_{4}$, and evaporated. 
The residue was purified by flash column chromatography [petroleum ether-EtOAc (1:1)] to give the products 13a-13d.

Isopropyl 1-[2-(2-bromoethoxy)-2-oxoethyl]-4-(2-chlorophenyl)-2-methyl-5-oxo-1, 4, 5, 7-tetrahydrofuro[3,4-b] pyridine-3-carboxylate (13a). HPLC analysis: $96.8 \%$. M.p. $154-156{ }^{\circ} \mathrm{C} .{ }^{1} \mathrm{H}-\mathrm{NMR}\left(400 \mathrm{MHz}, \mathrm{CDCl}_{3}\right)$ : $0.85(\mathrm{~d}, J=6.4 \mathrm{~Hz}, 3 \mathrm{H}), 1.20(\mathrm{~d}, J=6.4 \mathrm{~Hz}, 3 \mathrm{H}), 2.41(\mathrm{~s}, 3 \mathrm{H}), 3.58(\mathrm{t}, J=6.0 \mathrm{~Hz}, 2 \mathrm{H}), 4.25(\mathrm{dd}, J=57.6$, $18.8 \mathrm{~Hz}, 2 \mathrm{H}), 4.57(\mathrm{t}, J=5.6 \mathrm{~Hz}, 2 \mathrm{H}), 4.69(\mathrm{~s}, 2 \mathrm{H}), 4.85-4.91(\mathrm{~m}, 1 \mathrm{H}), 5.44(\mathrm{~s}, 1 \mathrm{H}), 7.11(\mathrm{td}, J=8.0,1.6 \mathrm{~Hz}$, $1 \mathrm{H}), 7.21(\mathrm{t}, J=7.6, \mathrm{~Hz}, 1 \mathrm{H}), 7.30(\mathrm{~d}, J=7.6,1 \mathrm{H}), 7.41(\mathrm{dd}, J=7.6,1.6 \mathrm{~Hz}, 1 \mathrm{H}) .{ }^{13} \mathrm{C}-\mathrm{NMR}(100 \mathrm{MHz}$, $\left.\mathrm{CDCl}_{3}\right):$ 171.0, 167.6, 166.7, 156.2, 144.4, 141.9, 133.3, 131.1, 129.4, 127.9, 127.0, 109.4, 103.6, 67.9, 65.3, 65.0, 47.2, 35.1, 28.3, 21.7, 20.9, 15.2. ESI (MS) $m / z: 513.8(M+\mathrm{H})^{+}$. HRMS (ESI-TOF) calculated for $\mathrm{C}_{22} \mathrm{H}_{24} \mathrm{BrClNO}_{6}(M+\mathrm{H})^{+}:$512.047; found: 512.04884 .

Isopropyl 1-\{2-[2-(2-bromoethoxy)ethoxy]-2-oxoethyl\}-4-(2-chlorophenyl)-2-methyl-5-oxo-1, 4, 5, 7-tetrahydrofuro [3, 4-b]pyridine-3-carboxylate (13b). HPLC analysis: 90.0\%. M.p. $113-115{ }^{\circ} \mathrm{C} .{ }^{1} \mathrm{H}-\mathrm{NMR}(400 \mathrm{MHz}$, $\left.\mathrm{CDCl}_{3}\right): 0.85(\mathrm{~d}, J=6.4 \mathrm{~Hz}, 3 \mathrm{H}), 1.21(\mathrm{~d}, J=6.4 \mathrm{~Hz}, 3 \mathrm{H}), 2.42(\mathrm{~s}, 3 \mathrm{H}), 3.47(\mathrm{t}, J=6.0 \mathrm{~Hz}, 2 \mathrm{H}), 3.78(\mathrm{t}$, $J=4.8 \mathrm{~Hz}, 2 \mathrm{H}), 3.82(\mathrm{t}, J=5.6 \mathrm{~Hz}, 2 \mathrm{H}), 4.24(\mathrm{dd}, J=51.2,18.8 \mathrm{~Hz}, 2 \mathrm{H}), 4.43-4.46(\mathrm{~m}, 2 \mathrm{H}), 4.70(\mathrm{~s}, 2 \mathrm{H})$, $4.83-4.93(\mathrm{~m}, 1 \mathrm{H}), 5.45(\mathrm{~s}, 1 \mathrm{H}), 7.11(\mathrm{td}, J=8.0,1.6 \mathrm{~Hz}, 1 \mathrm{H}), 7.21(\mathrm{td}, J=7.6,1.2 \mathrm{~Hz}, 1 \mathrm{H}), 7.31(\mathrm{dd}$, $J=7.6,1.2 \mathrm{~Hz}, 1 \mathrm{H}), 7.41(\mathrm{dd}, J=7.6,1.6 \mathrm{~Hz}, 1 \mathrm{H}) .{ }^{13} \mathrm{C}-\mathrm{NMR}\left(100 \mathrm{MHz}, \mathrm{CDCl}_{3}\right): 171.1,167.9,166.8,156.4$, 144.6, 142.0, 133.2, 131.1, 129.4, 127.9, 127.0, 109.3, 103.5, 71.0, 68.5, 67.9, 65.1, 64.8, 47.3, 35.0, 30.3, 21.7, 20.9, 15.2. ESI (MS) $m / z$ : $557.9(M+\mathrm{H})^{+}$. HRMS (ESI-TOF) calculated for $\mathrm{C}_{24} \mathrm{H}_{28} \mathrm{BrClNO}_{7}(M+\mathrm{H})^{+}$: 556.07322; found: 556.07444 .

Isopropyl 1-(2-\{2-[2-(2-bromoethoxy)ethoxy]ethoxy\}-2-oxoethyl)-4-(2-chlorophenyl)-2-methyl-5-oxo-1,4,5,7tetrahydrofuro[3,4-b]pyridine-3-carboxylate (13c). HPLC analysis: 94.9\%. M.p. $77-78{ }^{\circ} \mathrm{C} .{ }^{1} \mathrm{H}-\mathrm{NMR}$ $\left(400 \mathrm{MHz}, \mathrm{CDCl}_{3}\right): 0.85(\mathrm{~d}, J=6.0 \mathrm{~Hz}, 3 \mathrm{H}), 1.21(\mathrm{~d}, J=6.4 \mathrm{~Hz}, 3 \mathrm{H}), 2.42(\mathrm{~s}, 3 \mathrm{H}), 3.49(\mathrm{t}, J=6.0 \mathrm{~Hz}, 2 \mathrm{H})$, $3.67(\mathrm{~s}, 4 \mathrm{H}), 3.77-3.82(\mathrm{~m}, 4 \mathrm{H}), 4.24(\mathrm{dd}, J=51.2,18.8 \mathrm{~Hz}, 2 \mathrm{H}), 4.43-4.45(\mathrm{~m}, 2 \mathrm{H}), 4.71(\mathrm{~s}, 2 \mathrm{H}), 4.84-4.93$ $(\mathrm{m}, 1 \mathrm{H}), 5.46(\mathrm{~s}, 1 \mathrm{H}), 7.11(\mathrm{td}, J=7.6,1.6 \mathrm{~Hz}, 1 \mathrm{H}), 7.21(\mathrm{td}, J=7.6,0.8 \mathrm{~Hz}, 1 \mathrm{H}), 7.31(\mathrm{dd}, J=8.0,0.8 \mathrm{~Hz}$, 1H), $7.41(\mathrm{dd}, J=7.6,1.6 \mathrm{~Hz}, 1 \mathrm{H}) .{ }^{13} \mathrm{C}-\mathrm{NMR}\left(100 \mathrm{MHz}, \mathrm{CDCl}_{3}\right): 171.1,167.9,166.8,156.4,144.7,142.0$, $133.3,131.1,129.4,127.9,127.0,109.3,103.6,71.2,70.5,68.8,67.9,65.1,47.3,35.1,30.5,21.7,20.9,15.2$. ESI (MS) $m / z: 602.0(M+\mathrm{H})^{+}$. HRMS (ESI-TOF) calculated for $\mathrm{C}_{26} \mathrm{H}_{31} \mathrm{BrClNNaO}_{8}(M+\mathrm{Na})^{+}$: 622.08138; found: 622.08153 .

Isopropyl 1-(14-bromo-2-oxo-3,6,9,12-tetraoxatetradecyl)-4- (2-chlorophenyl)-2-methyl-5-oxo-1,4,5,7tetrahydrofuro[3,4-b]pyridine-3-carboxylate (13d). HPLC analysis: $92.7 \% .{ }^{1} \mathrm{H}-\mathrm{NMR}\left(400 \mathrm{MHz}, \mathrm{CDCl}_{3}\right)$ : $0.85(\mathrm{~d}, J=6.0 \mathrm{~Hz}, 3 \mathrm{H}), 1.21(\mathrm{~d}, J=6.4 \mathrm{~Hz}, 3 \mathrm{H}), 2.41(\mathrm{~s}, 3 \mathrm{H}), 3.49(\mathrm{t}, J=6.4 \mathrm{~Hz}, 2 \mathrm{H}), 3.63-3.69(\mathrm{~m}, 8 \mathrm{H})$, $3.76(\mathrm{t}, J=4.8 \mathrm{~Hz}, 2 \mathrm{H}), 3.81(\mathrm{t}, J=6.4 \mathrm{~Hz}, 2 \mathrm{H}), 4.24(\mathrm{dd}, J=48.8,18.4 \mathrm{~Hz}, 2 \mathrm{H}), 4.42-4.44(\mathrm{~m}, 2 \mathrm{H}), 4.71(\mathrm{~s}$, $2 \mathrm{H}), 4.83-4.92(\mathrm{~m}, 1 \mathrm{H}), 5.45(\mathrm{~s}, 1 \mathrm{H}), 7.11(\mathrm{td}, J=8.0,1.6 \mathrm{~Hz}, 1 \mathrm{H}), 7.21(\mathrm{td}, J=7.6,1.2 \mathrm{~Hz}, 1 \mathrm{H}), 7.31(\mathrm{dd}$, $J=7.6,1.2 \mathrm{~Hz}, 1 \mathrm{H}), 7.41(\mathrm{dd}, J=7.6,1.6 \mathrm{~Hz}, 1 \mathrm{H}) .{ }^{13} \mathrm{C}-\mathrm{NMR}\left(100 \mathrm{MHz}, \mathrm{CDCl}_{3}\right): 171.1,167.9,166.8$, 156.5, 144.7, 142.1, 133.2, 131.1, 129.3, 127.9, 127.0, 109.2, 103.5, 71.1, 70.6, 70.5, 70.4, 68.7, 67.8, 65.1, 65.0, 47.3, 35.0, 30.5, 21.7, 20.9, 15.2. ESI (MS) $m / z: 646.1(M+H)^{+}$. HRMS (ESI-TOF) calculated for $\mathrm{C}_{28} \mathrm{H}_{35} \mathrm{BrClNNaO}_{9}(\mathrm{M}+\mathrm{Na})^{+}$: 666.10759; found: 666.10903.

\subsubsection{General Procedure for Synthesis of Compounds $6 \mathbf{a}-\mathbf{6 d}$}

A mixture of 13a-13d (1.0 equiv.) and $\mathrm{NaN}_{3}$ (1.5 equiv.) in DMF $(20 \mathrm{~mL})$ was stirred at r.t. for $26 \mathrm{~h}$. The mixture was diluted with ice water $(100 \mathrm{~mL})$ and extracted by EtOAc $(100 \mathrm{~mL} \times 2)$. The combined organic phase was washed with brine $(100 \mathrm{~mL} \times 2)$, dried over anhydrous $\mathrm{Na}_{2} \mathrm{SO}_{4}$, and concentrated. The residue was purified by flash column chromatography [petroleum ether-EtOAc (2:1)] to give products $\mathbf{6 a}-\mathbf{6} \mathbf{d}$ as white solids.

1-[2-(2-Azidoethoxy)-2-oxoethyl]-4-(2-chlorophenyl)-2-methyl-5-oxo-1, 4, 5, 7-tetrahydrofuro[3,4-b]pyridine3-carboxylate (6a). HPLC analysis: 94.2\%. M.p. $142-144{ }^{\circ} \mathrm{C} .{ }^{1} \mathrm{H}-\mathrm{NMR}\left(400 \mathrm{MHz}, \mathrm{CDCl}_{3}\right): 0.86(\mathrm{~d}$, $J=6.0 \mathrm{~Hz}, 3 \mathrm{H}), 1.21(\mathrm{~d}, J=6.4 \mathrm{~Hz}, 3 \mathrm{H}), 2.42(\mathrm{~s}, 3 \mathrm{H}), 3.59(\mathrm{t}, J=4.8 \mathrm{~Hz}, 2 \mathrm{H}), 4.25(\mathrm{dd}, J=54.0,18.4 \mathrm{~Hz}$, $2 \mathrm{H}), 4.44(\mathrm{t}, J=4.8 \mathrm{~Hz}, 2 \mathrm{H}), 4.69(\mathrm{~s}, 2 \mathrm{H}), 4.84-4.93(\mathrm{~m}, 1 \mathrm{H}), 5.46(\mathrm{~s}, 1 \mathrm{H}), 7.12(\mathrm{td}, J=7.6,1.6 \mathrm{~Hz}, 1 \mathrm{H}), 7.22$ 
$(\mathrm{t}, J=7.6,1 \mathrm{H}), 7.31(\mathrm{~d}, J=7.6, \mathrm{~Hz}, 1 \mathrm{H}), 7.42(\mathrm{dd}, J=7.6,1.2 \mathrm{~Hz}, 1 \mathrm{H}) .{ }^{13} \mathrm{C}-\mathrm{NMR}\left(100 \mathrm{MHz}, \mathrm{CDCl}_{3}\right): 171.0$, 167.8, 166.7, 156.2, 144.4, 141.9, 133.3, 131.1, 129.4, 127.9, 127.0, 109.5, 103.7, 67.9, 65.0, 64.6, 49.5, 47.1, 35.1, 21.7, 20.9, 15.2. ESI (MS) $m / z: 474.9(M+\mathrm{H})^{+}$. HRMS (ESI-TOF) calculated for $\mathrm{C}_{22} \mathrm{H}_{24} \mathrm{ClN}_{4} \mathrm{O}_{6}$ $(M+\mathrm{H})^{+}$: 475.13789; found: 475.13970 .

Isopropyl 1-\{2-[2-(2-azidoethoxy)ethoxy]-2-oxoethyl\}-4-(2-chlorophenyl)-2-methyl-5-oxo-1, 4, 5, 7-tetrahydrofuro [3,4-b]pyridine-3-carboxylate (6b). HPLC analysis: 96.8\%. M.p. $118-120{ }^{\circ} \mathrm{C} .{ }^{1} \mathrm{H}-\mathrm{NMR}(400 \mathrm{MHz}$, $\left.\mathrm{CDCl}_{3}\right): 0.84(\mathrm{~d}, J=6.4 \mathrm{~Hz}, 3 \mathrm{H}), 1.19(\mathrm{~d}, J=6.4 \mathrm{~Hz}, 3 \mathrm{H}), 2.39(\mathrm{~s}, 3 \mathrm{H}), 3.37(\mathrm{t}, J=4.8 \mathrm{~Hz}, 2 \mathrm{H}), 3.68(\mathrm{t}$, $J=4.8 \mathrm{~Hz}, 2 \mathrm{H}), 3.75(\mathrm{t}, J=4.4 \mathrm{~Hz}, 2 \mathrm{H}), 4.22(\mathrm{dd}, J=57.2,18.8 \mathrm{~Hz}, 2 \mathrm{H}), 4.42(\mathrm{t}, J=7.6 \mathrm{~Hz}, 2 \mathrm{H}), 4.66$ $(\mathrm{s}, 2 \mathrm{H}), 4.82-4.91(\mathrm{~m}, 1 \mathrm{H}), 5.44(\mathrm{~s}, 1 \mathrm{H}), 7.10(\mathrm{td}, J=8.0,1.6 \mathrm{~Hz}, 1 \mathrm{H}), 7.20(\mathrm{t}, J=7.6 \mathrm{~Hz}, 1 \mathrm{H}), 7.29(\mathrm{~d}$, $J=7.2 \mathrm{~Hz}, 1 \mathrm{H}), 7.41(\mathrm{dd}, J=7.6,1.2 \mathrm{~Hz}, 1 \mathrm{H}) .{ }^{13} \mathrm{C}-\mathrm{NMR}\left(100 \mathrm{MHz}, \mathrm{CDCl}_{3}\right): 171.2,168.0,166.8,156.6$, 144.7, 142.2, 133.2, 131.2, 129.3, 127.9, 127.1, 109.2, 103.4, 70.2, 68.6, 67.8, 65.1, 64.9, 50.5, 47.2, 35.0, 21.7, 20.9, 15.2. ESI (MS) $m / z: 518.9(M+\mathrm{H})^{+}$. HRMS (ESI-TOF) calculated for $\mathrm{C}_{24} \mathrm{H}_{28} \mathrm{ClN}_{4} \mathrm{O}_{7}(M+\mathrm{H})^{+}$: 519.1641; found: 519.16577 .

Isopropyl 1-(2-\{2-[2-(2- azidoethoxy)ethoxy]ethoxy\}-2-oxoethyl)-4-(2-chlorophenyl)-2-methyl-5-oxo-1, 4, 5, 7-tetrahydrofuro[3, 4-b]pyridine-3-carboxylate (6c). HPLC analysis: $94.0 \%$. M.p. $44-45{ }^{\circ} \mathrm{C} .{ }^{1} \mathrm{H}-\mathrm{NMR}$ $\left(400 \mathrm{MHz}, \mathrm{CDCl}_{3}\right): 0.85(\mathrm{~d}, J=6.0 \mathrm{~Hz}, 3 \mathrm{H}), 1.21(\mathrm{~d}, J=6.4 \mathrm{~Hz}, 3 \mathrm{H}), 2.42(\mathrm{~s}, 3 \mathrm{H}), 3.39(\mathrm{t}, J=4.8 \mathrm{~Hz}, 2 \mathrm{H})$, $3.63-3.68(\mathrm{~m}, 6 \mathrm{H}), 3.78(\mathrm{t}, J=4.8 \mathrm{~Hz}, 2 \mathrm{H}), 4.23(\mathrm{dd}, J=51.6,18.8 \mathrm{~Hz}, 2 \mathrm{H}), 4.43-4.45(\mathrm{~m}, 2 \mathrm{H}), 4.70(\mathrm{~s}$, $2 \mathrm{H}), 4.83-4.93(\mathrm{~m}, 1 \mathrm{H}), 5.46(\mathrm{~s}, 1 \mathrm{H}), 7.11(\mathrm{td}, J=7.6,1.6 \mathrm{~Hz}, 1 \mathrm{H}), 7.21(\mathrm{td}, J=7.6,1.2 \mathrm{~Hz}, 1 \mathrm{H}), 7.31(\mathrm{dd}$, $J=7.6,1.2 \mathrm{~Hz}, 1 \mathrm{H}), 7.41(\mathrm{dd}, J=7.6,1.6 \mathrm{~Hz}, 1 \mathrm{H}) .{ }^{13} \mathrm{C}-\mathrm{NMR}\left(100 \mathrm{MHz}, \mathrm{CDCl}_{3}\right): 171.1,167.9,166.8,156.4$, 144.7, 142.0, 133.3, 131.1, 129.4, 127.9, 127.0, 109.3, 103.5, 70.7, 70.6, 70.1, 68.8, 67.8, 65.1, 65.0, 50.6, 47.3, 35.1, 21.7, 20.9, 15.2. ESI (MS) $m / z: 563.1(M+\mathrm{H})^{+}$. HRMS (ESI-TOF) calculated for $\mathrm{C}_{26} \mathrm{H}_{31} \mathrm{ClN}_{4} \mathrm{NaO}_{8}$ $(M+\mathrm{Na})^{+}: 585.17226$; found: 585.17324 .

Isopropyl 1-(14-azido-2-oxo-3,6,9,12-tetraoxatetradecyl)-4-(2-chlorophenyl)-2-methyl-5-oxo-1,4,5,7-tetrahydrofuro [3,4-b]pyridine-3-carboxylate (6d). HPLC analysis: $94.3 \%$. M.p. $37-38{ }^{\circ} \mathrm{C} .{ }^{1} \mathrm{H}-\mathrm{NMR}\left(400 \mathrm{MHz}, \mathrm{CDCl}_{3}\right)$ : $0.84(\mathrm{~d}, J=6.4 \mathrm{~Hz}, 3 \mathrm{H}), 1.20(\mathrm{~d}, J=6.4 \mathrm{~Hz}, 3 \mathrm{H}), 2.41(\mathrm{~s}, 3 \mathrm{H}), 3.39(\mathrm{t}, J=4.8 \mathrm{~Hz}, 2 \mathrm{H}), 3.65-3.68(\mathrm{~m}, 10 \mathrm{H})$, $3.75(\mathrm{t}, J=4.4 \mathrm{~Hz}, 2 \mathrm{H}), 4.22(\mathrm{dd}, J=50.4,18.4 \mathrm{~Hz}, 2 \mathrm{H}), 4.41-4.43(\mathrm{~m}, 2 \mathrm{H}), 4.70(\mathrm{~s}, 2 \mathrm{H}), 4.84-4.90(\mathrm{~m}$, $1 \mathrm{H}), 5.45(\mathrm{~s}, 1 \mathrm{H}), 7.11(\mathrm{td}, J=7.6,1.6 \mathrm{~Hz}, 1 \mathrm{H}), 7.21(\mathrm{td}, J=7.6,1.2 \mathrm{~Hz}, 1 \mathrm{H}), 7.30(\mathrm{~d}, J=8.0 \mathrm{~Hz}, 1 \mathrm{H})$, $7.41(\mathrm{dd}, J=7.6,1.2 \mathrm{~Hz}, 1 \mathrm{H}) .{ }^{13} \mathrm{C}-\mathrm{NMR}\left(100 \mathrm{MHz}, \mathrm{CDCl}_{3}\right): 171.1,167.9,166.8,156.5,144.7,142.1,133.2$, 131.1, 129.3, 127.9, 127.0, 109.2, 103.5, 70.7, 70.6, 70.5, 70.4, 70.0, 68.7, 67.8, 65.1, 65.0, 50.7, 47.3, 35.0, 21.7, 20.9, 15.2. ESI (MS) $m / z: 607.1(M+\mathrm{H})^{+}$. HRMS (ESI-TOF) calculated for $\mathrm{C}_{28} \mathrm{H}_{35} \mathrm{ClN}_{4} \mathrm{NaO}_{9}(M+\mathrm{Na})^{+}$: 629.19848; found: 629.19933 .

3.1.6. (S)-Methyl 2-(4-benzoylbenzamido)-6-(tert-butoxycarbonylamino)hexanoate (16)

Lys(Boc)-OMe $\mathrm{HCl}(0.20 \mathrm{~g}, 0.67 \mathrm{mmol})$ was dissolved in $20 \mathrm{~mL}$ of DMF, to which 4-benzoylbenzoic acid $(0.15 \mathrm{~g}, 0.67 \mathrm{mmol}), \mathrm{N}$-[3-(dimethylamino)propyl]-N-ethylcarbodiimide hydrochloride (EDCI, $0.15 \mathrm{~g}, 0.78 \mathrm{mmol}$ ), 4-(dimethylamino)pyridine (DMAP, $0.097 \mathrm{~g}, 0.79 \mathrm{mmol}$ ), and $\mathrm{N}$-methylmorpholine (NMM, $0.26 \mathrm{~mL}, 2.36 \mathrm{mmol}$ ) were added. The reaction mixture was stirred at r.t. overnight and then poured into ice water $(50 \mathrm{~mL})$. The aqueous layer was extracted with EtOAc $(50 \mathrm{~mL} \times 2)$. The combined organic layer was washed with saturated brine $(50 \mathrm{~mL} \times 2)$, dried over anhydrous $\mathrm{Na}_{2} \mathrm{SO}_{4}$, filtered, and concentrated. The residue was purified by flash silica gel column chromatography [petroleum ether-EtOAc (4:1)] to give benzophenone-Lys(Boc)-OMe as a transparent solid (0.28 g, 89\%). HPLC analysis: $98.6 \%$. M.p. $66-67^{\circ} \mathrm{C} .{ }^{1} \mathrm{H}-\mathrm{NMR}\left(400 \mathrm{MHz}, \mathrm{CDCl}_{3}\right): 1.40(\mathrm{~s}, 9 \mathrm{H}), 1.45-1.58(\mathrm{~m}, 4 \mathrm{H}), 1.83-2.04$ $(\mathrm{m}, 2 \mathrm{H}), 3.06-3.18(\mathrm{~m}, 2 \mathrm{H}), 3.80(\mathrm{~s}, 3 \mathrm{H}), 4.64(\mathrm{br} \mathrm{s}, 1 \mathrm{H}), 4.79-4.84(\mathrm{~m}, 1 \mathrm{H}), 6.97(\mathrm{~d}, J=5.6 \mathrm{~Hz}, 1 \mathrm{H})$, $7.50(\mathrm{t}, J=7.6 \mathrm{~Hz}, 2 \mathrm{H}), 7.62(\mathrm{t}, J=7.2 \mathrm{~Hz}, 1 \mathrm{H}), 7.80(\mathrm{~d}, J=7.6 \mathrm{~Hz}, 2 \mathrm{H}), 7.85(\mathrm{~d}, J=8.0 \mathrm{~Hz}, 2 \mathrm{H}), 7.94$ $(\mathrm{d}, J=8.4 \mathrm{~Hz}, 2 \mathrm{H}) .{ }^{13} \mathrm{C}-\mathrm{NMR}\left(100 \mathrm{MHz}, \mathrm{CDCl}_{3}\right): 195.9,172.9,166.4,156.2,140.3,137.1,137.0,132.9$, $130.1,128.4,127.2,79.2,52.64,52.59,40.0,32.0,29.7,28.4,22.5$. ESI (MS) $m / z: 491.2(M+\mathrm{Na})^{+}$. HRMS (ESI-TOF) calculated for $\mathrm{C}_{26} \mathrm{H}_{32} \mathrm{~N}_{2} \mathrm{NaO}_{6}(M+\mathrm{Na})^{+}$: 491.2158; found: 491.2164. 


\subsection{7. (S)-Prop-2-ynyl 2-(4-benzoylbenzamido)-6-(tert-butoxycarbonylamino)hexanoate (18)}

To a solution of $16(0.50 \mathrm{~g}, 1.07 \mathrm{mmol})$ in $\mathrm{MeOH}(10 \mathrm{~mL})$, a $\mathrm{NaOH}$ aqueous $(2 \mathrm{~N}, 10 \mathrm{~mL})$ was added under an ice bath. The reaction mixture was stirred at r.t. for $3 \mathrm{~h}$ and then concentrated in vacuo. The residue was redissolved in $\mathrm{H}_{2} \mathrm{O}(20 \mathrm{~mL})$, and then the aqueous was adjusted to $\mathrm{pH}=2$ with $\mathrm{HCl}$ aqueous $(1 \mathrm{~N})$, the suspension was extracted with EtOAc $(20 \mathrm{~mL} \times 3)$, and the combined organic layer was dried over anhydrous $\mathrm{Na}_{2} \mathrm{SO}_{4}$, filtered, and concentrated to give a white solid product $(0.37 \mathrm{~g}, 76 \%)$, which was used directly in the next reaction without further purification. The above product $17(10.0 \mathrm{~g}, 22.0 \mathrm{mmol})$ and $\mathrm{K}_{2} \mathrm{CO}_{3}(6.08 \mathrm{~g}, 44.0 \mathrm{mmol})$ in anhydrous DMF $(120 \mathrm{~mL})$ were slowly added to 3-Bromopropyne $(2.85 \mathrm{~mL}, 33.04 \mathrm{mmol}, 80 \%$ in toluene). The reaction mixture was stirred at r.t. overnight and then filtered. The filtrate was diluted with water $(200 \mathrm{~mL})$ and extracted with EtOAc $(200 \mathrm{~mL} \times 2)$. The combined organic layer was washed with $1 \mathrm{~N} \mathrm{HCl}$ aqueous solution $(200 \mathrm{~mL})$, saturated $\mathrm{NaHCO}_{3}$ solution $(200 \mathrm{~mL})$, and saturated brine $(200 \mathrm{~mL})$, dried over anhydrous $\mathrm{Na}_{2} \mathrm{SO}_{4}$ and evaporated. The mixture was purified by column chromatography on silica gel [petroleum ether-EtOAc (4:1)] to give 18 (9.70 g, 90\%) of a white solid. HPLC analysis: 98.6\%. M.p. 79-81 ${ }^{\circ} \mathrm{C}$. ${ }^{1} \mathrm{H}-\mathrm{NMR}\left(400 \mathrm{MHz}, \mathrm{CDCl}_{3}\right): 1.40(\mathrm{~s}, 8 \mathrm{H}), 1.53$ (ddd, $\left.J=26.4,14.9,7.2 \mathrm{~Hz}, 4 \mathrm{H}\right), 1.89$ (dt, $J=13.2,8.4 \mathrm{~Hz}$, $1 \mathrm{H}), 1.96-2.10(\mathrm{~m}, 1 \mathrm{H}), 2.53(\mathrm{~s}, 1 \mathrm{H}), 3.13(\mathrm{~s}, 2 \mathrm{H}), 4.61(\mathrm{~s}, 1 \mathrm{H}), 4.74(\mathrm{dd}, J=15.4,2.2 \mathrm{~Hz}, 1 \mathrm{H}), 4.85(\mathrm{dt}$, $J=11.2,4.0 \mathrm{~Hz}, 2 \mathrm{H}), 6.94(\mathrm{~d}, J=6.0 \mathrm{~Hz}, 1 \mathrm{H}), 7.50(\mathrm{t}, J=7.6 \mathrm{~Hz}, 2 \mathrm{H}), 7.62(\mathrm{t}, J=7.4 \mathrm{~Hz}, 1 \mathrm{H}), 7.80(\mathrm{~d}$, $J=7.6 \mathrm{~Hz}, 2 \mathrm{H}), 7.85(\mathrm{~d}, J=8.0 \mathrm{~Hz}, 2 \mathrm{H}), 7.94(\mathrm{~d}, J=8.2 \mathrm{~Hz}, 2 \mathrm{H}) .{ }^{13} \mathrm{C}-\mathrm{NMR}\left(100 \mathrm{MHz}, \mathrm{CDCl}_{3}\right): 195.9$, 171.7, 166.5, 156.2, 140.4, 137.1, 137.0, 132.9, 130.1, 128.5, 127.2, 79.2, 75.6, 52.9, 52.6, 39.9, 31.8, 29.7, 28.4, 22.4. ESI (MS) m/z: $515.2(M+\mathrm{Na})^{+}$. HRMS (ESI-TOF) calculated for $\mathrm{C}_{28} \mathrm{H}_{32} \mathrm{~N}_{2} \mathrm{NaO}_{6}(M+\mathrm{Na})^{+}$: 515.2158; found: 515.2165 .

\subsubsection{General Procedure for Synthesis of compounds 20 and 32}

The crude product 19 or $23(12.80 \mathrm{mmol})$ and D-Biotin $(19.50 \mathrm{mmol})$ were dissolved in $200 \mathrm{~mL}$ of anhydrous DMF, to which EDCI $(0.69 \mathrm{mmol})$, HOBt $(0.69 \mathrm{mmol})$, and DIPEA $(1.38 \mathrm{mmol})$ were added at $0{ }^{\circ} \mathrm{C}$. The mixture was stirred at r.t. overnight under a $\mathrm{N}_{2}$ atmosphere and then diluted with water $(10 \mathrm{~mL})$ and extracted with EtOAc $(10 \mathrm{~mL} \times 3)$. The combined organic layer was washed with brine $(10 \mathrm{~mL} \times 2)$, dried over $\mathrm{Na}_{2} \mathrm{SO}_{4}$, filtered, and concentrated in vacuo. The crude product was purified by column chromatography over silica gel $\left[\mathrm{CH}_{2} \mathrm{Cl}_{2}-\mathrm{MeOH}(40: 1)\right]$ to give target products 20 and 32 as white solids.

(S)-Prop-2-ynyl 2-(4-benzoylbenzamido)-6-(5-\{(3aS,4S,6aR)-2-oxohexahydro-1H-thieno[3,4-d]imidazole-4-yl $\}$ pentanamido)hexanoate (20). HPLC analysis: 95.4\%. M.p. $130-132{ }^{\circ} \mathrm{C}$. ${ }^{1} \mathrm{H}-\mathrm{NMR}\left(400 \mathrm{MHz}, d_{6}\right.$-DMSO): 1.30-1.59 (m, 10H), 1.83 (br s, 2H), $2.04(\mathrm{t}, J=5.6 \mathrm{~Hz}, 2 \mathrm{H}), 2.57$ (d, J = 12.4 Hz, 1H), 2.80-2.83 (m, 1H), 3.05 (br s, 3H), $3.63(\mathrm{~d}, J=36.0 \mathrm{~Hz}, 1 \mathrm{H}), 4.12$ (br s, 1H), 4.30 (br s, 1H), 4.44-4.49 (m, 1H), 4.77 (br s, 2H), 6.35 (br s, 1H), 6.40 (br s, 1H), 7.55-7.64 (m, 2H), 7.72-7.84 (m, 5H), $8.06(\mathrm{~d}, J=7.2 \mathrm{~Hz}, 1 \mathrm{H})$, $8.97(\mathrm{~d}, J=6.4 \mathrm{~Hz}, 1 \mathrm{H}) .{ }^{13} \mathrm{C}-\mathrm{NMR}\left(100 \mathrm{MHz}, d_{6}\right.$-DMSO): 195.4, 171.9, 171.4, 162.7, 139.4, 136.9, 136.6, 133.0, 129.7, 129.4, 128.7, 127.7, 78.2, 77.9, 61.0, 59.2, 55.4, 52.7, 52.2, 38.0, 35.2, 29.9, 28.7, 28.2, 28.0, 25.3, 23.1, 23.0. ESI (MS) m/z: $641.2(M+\mathrm{H})^{+}$. HRMS (ESI-TOF) calculated for $\mathrm{C}_{33} \mathrm{H}_{38} \mathrm{~N}_{4} \mathrm{NaO}_{6}(M+\mathrm{Na})^{+}$: 641.2410; found: 641.2418 .

(S)-Methyl 2-(4-benzoylbenzamido)-6-(5-\{(3aS,4S,6aR)-2-oxohexahydro-1H-thieno[3,4-d]imidazole-4-yl\} pentanamido)hexanoate (32). HPLC analysis: 90.2\%. M.p. $148-150{ }^{\circ} \mathrm{C} .{ }^{1} \mathrm{H}-\mathrm{NMR}\left(400 \mathrm{MHz}, \mathrm{CDCl}_{3}\right)$ : $1.34-1.62(\mathrm{~m}, 10 \mathrm{H}), 1.92-1.95(\mathrm{~m}, 2 \mathrm{H}), 2.16-2.18(\mathrm{~m}, 2 \mathrm{H}), 2.69(\mathrm{~d}, J=12.4 \mathrm{~Hz}, 1 \mathrm{H}), 2.84-2.85(\mathrm{~m}, 1 \mathrm{H})$, 3.07-3.08 (m, 1H), 3.24 (br s, 2H), $3.77(\mathrm{~s}, 3 \mathrm{H}), 4.22-4.29(\mathrm{~m}, 1 \mathrm{H}), 4.44-4.50(\mathrm{~m}, 1 \mathrm{H}), 4.73(\mathrm{dd}, J=13.2$, $8.0 \mathrm{~Hz}, 1 \mathrm{H}), 6.40$ (br $s, 1 \mathrm{H}), 6.65$ (br s, 1H), $7.49(\mathrm{t}, J=8.0 \mathrm{~Hz}, 2 \mathrm{H}), 7.59-7.66(\mathrm{~m}, 2 \mathrm{H}), 7.80$ (dd, J = 16.8, $7.2 \mathrm{~Hz}, 4 \mathrm{H}), 8.03(\mathrm{~d}, J=8.0 \mathrm{~Hz}, 2 \mathrm{H}) .{ }^{13} \mathrm{C}-\mathrm{NMR}$ (100 MHz, $d_{6}$-DMSO): 195.4, 172.6, 171.9, 165.9, 162.7, 139.4, 137.0, 136.6, 133.0, 129.7, 129.4, 128.7, 127.7, 61.0, 59.1, 55.4, 52.8, 51.9, 38.0, 35.2, 33.5, 30.1, 28.7, 28.0, 25.3, 24.5, 23.1. ESI (MS) $m / z: 595.3(M+\mathrm{H})^{+}$. HRMS (ESI-TOF) calculated for $\mathrm{C}_{31} \mathrm{H}_{39} \mathrm{~N}_{4} \mathrm{O}_{6} \mathrm{~S}$ $(M+\mathrm{H})^{+}:$595.2590; found: 595.2598. 


\subsubsection{General Procedure for Synthesis of Compounds 21 and 24}

To a solution of 16 or $18(21.34 \mathrm{mmol})$ in anhydrous $\mathrm{CH}_{2} \mathrm{Cl}_{2}(50 \mathrm{~mL})$, trifluoroacetic acid (TFA, $32 \mathrm{~mL}, 0.43 \mathrm{~mol}$ ) was added. The reaction mixture was stirred at $0{ }^{\circ} \mathrm{C}$ for $2 \mathrm{~h}$. Then, the reaction mixture was concentrated in vacuo. The residue was redissolved in EtOAc $(20 \mathrm{~mL})$ and washed with saturated $\mathrm{NaHCO}_{3}(20 \mathrm{~mL}), 1 \mathrm{~N} \mathrm{HCl}$ aqueous $(20 \mathrm{~mL})$, and brine $(20 \mathrm{~mL})$, dried over $\mathrm{Na}_{2} \mathrm{SO}_{4}$, filtered, and concentrated to give the crude target product $\mathbf{1 9}$ or $\mathbf{2 3}$ as a white solid, which was used for the next reaction without further purification. To a mixture of the above crude product 19 or 23 (21.71 mmol) and $\mathrm{Et}_{3} \mathrm{~N}(4.75 \mathrm{~mL}, 34.22 \mathrm{mmol})$ in anhydrous $\mathrm{CH}_{2} \mathrm{Cl}_{2} / \mathrm{CH}_{3} \mathrm{OH}(1: 1, v / v, 200 \mathrm{~mL})$ were slowly added dansyl chloride $(9.23 \mathrm{~g}, 34.22 \mathrm{mmol})$ in groups under an ice bath. The reaction mixture was stirred at r.t. overnight. After the solvent was removed in vacuo, the residue was redissolved in $\mathrm{CH}_{2} \mathrm{Cl}_{2}(20 \mathrm{~mL})$ and washed with brine $(2 \times 20 \mathrm{~mL})$, dried over anhydrous $\mathrm{Na}_{2} \mathrm{SO}_{4}$, and evaporated. The mixture was purified by column chromatography on silica gel $\left[\mathrm{CH}_{2} \mathrm{Cl}_{2}=100 \%\right]$ to give target the products 21 and 24 as pale yellow solids.

(S)-Prop-2-ynyl-6-dansylamide-2-(4-benzoylbenzamido)hexanoate (21). HPLC analysis: 100.0\%. M.p. 76-78 ${ }^{\circ} \mathrm{C} .{ }^{1} \mathrm{H}-\mathrm{NMR}\left(400 \mathrm{MHz}, \mathrm{CDCl}_{3}\right): 1.43-1.56(\mathrm{~m}, 4 \mathrm{H}), 1.73-1.82(\mathrm{~m}, 1 \mathrm{H}), 1.85-1.92(\mathrm{~m}, 1 \mathrm{H}), 2.52(\mathrm{t}$, $J=6.4 \mathrm{~Hz}, 1 \mathrm{H}), 2.88(\mathrm{~s}, 6 \mathrm{H}), 2.90-2.94(\mathrm{~m}, 2 \mathrm{H}), 4.69-4.83(\mathrm{~m}, 3 \mathrm{H}), 5.05(\mathrm{br} \mathrm{t}, J=6.0 \mathrm{~Hz}, 1 \mathrm{H}), 6.97(\mathrm{~d}$, $J=7.6 \mathrm{~Hz}, 1 \mathrm{H}), 7.16(\mathrm{~d}, J=7.2 \mathrm{~Hz}, 1 \mathrm{H}), 7.46-7.52(\mathrm{~m}, 4 \mathrm{H}), 7.60(\mathrm{tt}, J=7.6,1.2 \mathrm{~Hz}, 1 \mathrm{H}), 7.77-7.83(\mathrm{~m}$, $4 \mathrm{H}), 7.94(\mathrm{~d}, J=8.4 \mathrm{~Hz}, 2 \mathrm{H}), 8.20(\mathrm{dd}, J=7.2,0.8 \mathrm{~Hz}, 1 \mathrm{H}), 8.28(\mathrm{~d}, J=8.4 \mathrm{~Hz}, 1 \mathrm{H}), 8.54(\mathrm{~d}, J=8.4 \mathrm{~Hz}$, 1H). ${ }^{13} \mathrm{C}-\mathrm{NMR}\left(100 \mathrm{MHz}, \mathrm{CDCl}_{3}\right):$ 195.9, 171.6, 166.6, 140.4, 137.0, 136.8, 134.8, 132.9, 130.4, 130.1, 129.9, 129.6, 129.5, 128.5, 128.4, 127.3, 123.2, 115.3, 77.0, 75.7, 52.9, 52.5, 45.4, 42.6, 31.5, 28.8, 22.0. ESI (MS) $m / z: 648.2(M+\mathrm{Na})^{+}$. HRMS (ESI-TOF) calculated for $\mathrm{C}_{35} \mathrm{H}_{35} \mathrm{~N}_{3} \mathrm{NaO}_{6} \mathrm{~S}(M+\mathrm{Na})^{+}: 648.2144$; found: 648.2152 .

(S)-Methyl-6-dansylamide-2-(4-benzoylbenzamido)hexanoate (24). HPLC analysis: 98.1\%. M.p. 69-71 ${ }^{\circ} \mathrm{C}$. ${ }^{1} \mathrm{H}-\mathrm{NMR}\left(400 \mathrm{MHz}, \mathrm{CDCl}_{3}\right): 1.39-1.55(\mathrm{~m}, 4 \mathrm{H}), 1.70-1.79(\mathrm{~m}, 1 \mathrm{H}), 1.82-1.90(\mathrm{~m}, 1 \mathrm{H}), 2.88-2.92(\mathrm{~m}, 8 \mathrm{H})$, $3.76(\mathrm{~s}, 3 \mathrm{H}), 4.71-4.76(\mathrm{~m}, 1 \mathrm{H}), 5.13(\mathrm{br} \mathrm{t}, J=5.6 \mathrm{~Hz}, 1 \mathrm{H}), 6.99(\mathrm{~d}, J=7.6 \mathrm{~Hz}, 1 \mathrm{H}), 7.16(\mathrm{~d}, J=7.2 \mathrm{~Hz}$, $1 \mathrm{H}), 7.47-7.52(\mathrm{~m}, 4 \mathrm{H}), 7.61(\mathrm{t}, J=7.6 \mathrm{~Hz}, 1 \mathrm{H}), 7.78(\mathrm{~d}, J=7.2 \mathrm{~Hz}, 2 \mathrm{H}), 7.83(\mathrm{~d}, J=8.0 \mathrm{~Hz}, 2 \mathrm{H}), 7.95(\mathrm{~d}$, $J=8.4 \mathrm{~Hz}, 2 \mathrm{H}), 8.21(\mathrm{dd}, J=7.2,0.8 \mathrm{~Hz}, 1 \mathrm{H}), 8.29(\mathrm{~d}, J=8.8 \mathrm{~Hz}, 1 \mathrm{H}), 8.53(\mathrm{~d}, J=8.4 \mathrm{~Hz}, 1 \mathrm{H}) .{ }^{13} \mathrm{C}-\mathrm{NMR}$ $\left(100 \mathrm{MHz}_{1} \mathrm{CDCl}_{3}\right):$ 196.0, 172.8, 166.5, 140.3, 137.0, 136.9, 134.8, 132.9, 130.4, 130.1, 129.8, 129.6, 129.5, 128.5, 128.4, 127.3, 123.2, 115.3, 52.6, 52.5, 45.4, 42.6, 31.7, 28.9, 22.1. ESI (MS) $m / z: 602.3(M+\mathrm{H})^{+}$. HRMS (ESI-TOF) calculated for $\mathrm{C}_{33} \mathrm{H}_{35} \mathrm{~N}_{3} \mathrm{NaO}_{6} \mathrm{~S}(M+\mathrm{Na})^{+}$: 624.2144; found: 624.2152 .

\subsubsection{General Procedure for Synthesis of Compounds 22 and 33}

To a solution of 16 or $18(15.0 \mathrm{~g}, 30.45 \mathrm{mmol})$ in anhydrous $\mathrm{CH}_{2} \mathrm{Cl}_{2}(150 \mathrm{~mL})$, trifluoroacetic acid (TFA, $46.0 \mathrm{~mL}, 0.62 \mathrm{~mol}$ ) was added. The reaction mixture was stirred at $0{ }^{\circ} \mathrm{C}$ for $2 \mathrm{~h}$. Then, the reaction mixture was concentrated in vacuo. The residue was redissolved in EtOAc $(150 \mathrm{~mL})$ and was washed with saturated $\mathrm{NaHCO}_{3}(200 \mathrm{~mL} \times 2), 1 \mathrm{~N} \mathrm{HCl}$ aqueous solution $(200 \mathrm{~mL} \times 2)$, and brine $(200 \mathrm{~mL}$ $\times 2$ ), and dried over $\mathrm{Na}_{2} \mathrm{SO}_{4}$, filtered, and concentrated to give the crude target product as a white solid, which was used for next reaction without further purification. To a mixture of the above crude product 19 or $23(0.26 \mathrm{mmol})$ and $\mathrm{Et}_{3} \mathrm{~N}(0.36 \mathrm{mmol})$ in anhydrous $\mathrm{CH}_{2} \mathrm{Cl}_{2} / \mathrm{CH}_{3} \mathrm{OH}(1: 1, v / v, 20 \mathrm{~mL})$, was slowly added acyl chloride $(0.36 \mathrm{mmol})$ in groups under an ice bath. The reaction mixture was stirred at r.t. for another $12 \mathrm{~h}$. After the solvent was removed in vacuo, the residue was redissolved in $\mathrm{CH}_{2} \mathrm{Cl}_{2}(20 \mathrm{~mL})$ and washed with brine $(2 \times 20 \mathrm{~mL})$, dried over anhydrous $\mathrm{Na}_{2} \mathrm{SO}_{4}$, and evaporated. The mixture was purified by column chromatography on silica gel $\left[\mathrm{CH}_{2} \mathrm{Cl}_{2}=100 \%\right.$ ] to give target products 22 and 33 as pale yellow solids.

(S)-Prop-2-ynyl-2-(4-benzoylbenzamido)-6-(2-chloroacetamido)hexanoate (22). HPLC analysis: 99.5\%. M.p. 123-124 ${ }^{\circ} \mathrm{C} .{ }^{1} \mathrm{H}-\mathrm{NMR}\left(400 \mathrm{MHz}, \mathrm{CDCl}_{3}\right): 1.47$ (ddd, $\left.J=29.2,15.8,6.8 \mathrm{~Hz}, 2 \mathrm{H}\right), 1.65(\mathrm{tt}, J=13.6,6.8 \mathrm{~Hz}$, $2 \mathrm{H}), 1.87-1.98(\mathrm{~m}, 1 \mathrm{H}), 2.05(\mathrm{qd}, J=10.6,5.4 \mathrm{~Hz}, 1 \mathrm{H}), 2.53(\mathrm{t}, J=2.2 \mathrm{~Hz}, 1 \mathrm{H}), 3.26-3.43(\mathrm{~m}, 2 \mathrm{H}), 3.94-4.06$ $(\mathrm{m}, 2 \mathrm{H}), 4.75(\mathrm{dd}, J=15.4,2.4 \mathrm{~Hz}, 1 \mathrm{H}), 4.84(\mathrm{ddd}, J=13.2,5.4,2.6 \mathrm{~Hz}, 2 \mathrm{H}), 6.67(\mathrm{~s}, 1 \mathrm{H}), 6.98(\mathrm{~d}, J=7.4 \mathrm{~Hz}$, 
$1 \mathrm{H}), 7.50(\mathrm{t}, J=7.6 \mathrm{~Hz}, 2 \mathrm{H}), 7.62(\mathrm{t}, J=7.4 \mathrm{~Hz}, 1 \mathrm{H}), 7.79(\mathrm{~d}, J=7.4 \mathrm{~Hz}, 2 \mathrm{H}), 7.85(\mathrm{~d}, J=8.2 \mathrm{~Hz}, 2 \mathrm{H})$, $7.96(\mathrm{~d}, J=8.2 \mathrm{~Hz}, 2 \mathrm{H}) .{ }^{13} \mathrm{C}-\mathrm{NMR}\left(100 \mathrm{MHz}, \mathrm{CDCl}_{3}\right): 195.9,171.6,166.5,166.3,140.4,137.0,136.8,132.9$, $130.1,128.5,127.2,77.0,75.6,53.0,52.5,42.6,39.1,31.5,28.9,22.3$. ESI (MS) $m / z: 491.1(M+\mathrm{Na})^{+}$. HRMS (ESI-TOF) calculated for $\mathrm{C}_{25} \mathrm{H}_{25} \mathrm{ClN}_{2} \mathrm{NaO}_{5}(M+\mathrm{Na})^{+}$: 491.1350; found: 491.1356 .

(S)-Methyl-2-(4-benzoylbenzamido)-6-(2-chloroacetamido)hexanoate (33). HPLC analysis: 99.6\%. M.p. 129-130 ${ }^{\circ} \mathrm{C} .{ }^{1} \mathrm{H}-\mathrm{NMR}\left(400 \mathrm{MHz}, \mathrm{CDCl}_{3}\right)$ : $1.39-1.67(\mathrm{~m}, 4 \mathrm{H}), 1.84-2.06(\mathrm{~m}, 2 \mathrm{H}), 3.25-3.41(\mathrm{~m}, 2 \mathrm{H}), 3.80$ $(\mathrm{s}, 3 \mathrm{H}), 3.95-4.06(\mathrm{~m}, 2 \mathrm{H}), 4.81(\mathrm{td}, J=7.6,5.0 \mathrm{~Hz}, 1 \mathrm{H}), 6.66(\mathrm{~s}, 1 \mathrm{H}), 6.96(\mathrm{~d}, J=7.4 \mathrm{~Hz}, 1 \mathrm{H}), 7.50(\mathrm{t}$, $J=7.6 \mathrm{~Hz}, 2 \mathrm{H}), 7.62(\mathrm{t}, J=7.4 \mathrm{~Hz}, 1 \mathrm{H}), 7.80(\mathrm{~d}, J=7.2 \mathrm{~Hz}, 2 \mathrm{H}), 7.85(\mathrm{~d}, J=8.2 \mathrm{~Hz}, 2 \mathrm{H}), 7.96(\mathrm{~d}, J=8.2 \mathrm{~Hz}$, 2H). ${ }^{13} \mathrm{C}-\mathrm{NMR}\left(100 \mathrm{MHz}, \mathrm{CDCl}_{3}\right):$ 195.9, 172.8, 166.4, 166.2, 140.4, 137.0, 136.9, 132.9, 130.1, 128.5, 127.2, 52.6, 52.5, 42.6, 39.1, 31.8, 28.9, 22.4. ESI (MS) $m / z$ : $443.1(M-\mathrm{H})^{-}$. HRMS (ESI-TOF) calculated for $\mathrm{C}_{23} \mathrm{H}_{24} \mathrm{ClN}_{2} \mathrm{O}_{5}(\mathrm{M}-\mathrm{H})^{-}$: 443.1374; found: 443.1380 .

\subsubsection{1. (S)-6-Dansylamide-2-(4-benzoylbenzamido)hexanoic acid (25)}

To a solution of $24(5.30 \mathrm{~g}, 8.81 \mathrm{mmol})$ in THF $(50 \mathrm{~mL}), \mathrm{LiOH} \cdot \mathrm{H}_{2} \mathrm{O}(6 \mathrm{~N}, 3.0 \mathrm{~mL})$ was added under an ice bath. The reaction mixture was stirred at r.t. for $3 \mathrm{~h}$ and then concentrated in vacuo. The residue was redissolved in $\mathrm{H}_{2} \mathrm{O}(50 \mathrm{~mL})$, and then the aqueous solution was adjusted to $\mathrm{pH}=2$ with $1 \mathrm{~N} \mathrm{HCl}$ aqueous solution, and the suspension was extracted with EtOAc $(50 \mathrm{~mL} \times 3)$. The combined organic layer was dried over anhydrous $\mathrm{Na}_{2} \mathrm{SO}_{4}$, filtered, and concentrated. The residue was purified by flash silica gel column chromatography $\left[\mathrm{CH}_{2} \mathrm{Cl}_{2}-\mathrm{MeOH}(40: 1)\right]$ to obtain the pale yellow solid product 25 (4.50 g, 87\%). HPLC analysis: $99.5 \%$. M.p. $83-85^{\circ} \mathrm{C} .{ }^{1} \mathrm{H}-\mathrm{NMR}\left(400 \mathrm{MHz}, \mathrm{CDCl}_{3}\right): 1.40-1.51(\mathrm{~m}, 4 \mathrm{H})$, 1.84-2.06 (m, 2H), 2.90-2.97 (m, 8H), 4.75-4.81 (m, 2H), $6.85(\mathrm{~d}, J=6.8 \mathrm{~Hz}, 1 \mathrm{H}), 7.18(\mathrm{~d}, J=10.0 \mathrm{~Hz}$, $1 \mathrm{H}), 7.52(\mathrm{dd}, J=20.4,10.0 \mathrm{~Hz}, 4 \mathrm{H}), 7.63(\mathrm{t}, J=9.6 \mathrm{~Hz}, 1 \mathrm{H}), 7.82(\mathrm{~d}, J=9.6 \mathrm{~Hz}, 2 \mathrm{H}), 7.92(\mathrm{dd}, J=32.8$, $11.2 \mathrm{~Hz}, 4 \mathrm{H}), 8.26(\mathrm{dd}, J=15.2,10.4 \mathrm{~Hz}, 2 \mathrm{H}), 8.55(\mathrm{~d}, J=11.2 \mathrm{~Hz}, 1 \mathrm{H}) .{ }^{13} \mathrm{C}-\mathrm{NMR}\left(100 \mathrm{MHz}, \mathrm{CDCl}_{3}\right)$ : 196.0, 167.3, 151.6, 140.2, 136.9, 136.6, 134.9, 132.9, 130.3, 130.1, 129.9, 129.8, 129.6, 129.2, 128.4, 128.3, $127.5,123.2,119.0,115.3,45.4,42.6,31.1,28.9,22.3$. ESI (MS) $m / z: 588.3(M+\mathrm{H})^{+}$. HRMS (ESI-TOF) calculated for $\mathrm{C}_{32} \mathrm{H}_{33} \mathrm{~N}_{3} \mathrm{NaO}_{6} \mathrm{~S}(M+\mathrm{Na})^{+}$: 610.19823; found: 610.20065 .

\subsubsection{Prop-2-ynylN-Cbz-N'-Boc-L-lysine (27)}

To a stirred solution of $26(3.81 \mathrm{~g}, 10.0 \mathrm{mmol})$ in anhydrous DMF $(20 \mathrm{~mL}), \mathrm{K}_{2} \mathrm{CO}_{3}(2.10 \mathrm{~g}$, $15.19 \mathrm{mmol}$ ) was added at r.t. After $0.5 \mathrm{~h}, 3$-Bromopropyne $(1.72 \mathrm{~mL}, 0.02 \mathrm{~mol} \mathrm{mmol}, 80 \%$ in toluene) was slowly added dropwise. The reaction mixture was stirred at r.t. overnight and then filtered. The filtrate was diluted with water $(40 \mathrm{~mL})$ and extracted with EtOAc $(40 \mathrm{~mL} \times 3)$. The combined organic layer was washed with $1 \mathrm{~N} \mathrm{HCl}$ aqueous $(40 \mathrm{~mL} \times 2)$, saturated $\mathrm{NaHCO}_{3}(40 \mathrm{~mL} \times 2)$ and brine $(40 \mathrm{~mL} \times 2)$, dried over anhydrous $\mathrm{Na}_{2} \mathrm{SO}_{4}$, filtered, and evaporated. Purified by column chromatography on silica gel [petroleum ether-EtOAc (8:1)] to give product 27 (3.0 g, 72\%) as a white solid. HPLC analysis: $96.5 \%$. M.p. $119-121{ }^{\circ} \mathrm{C} .{ }^{1} \mathrm{H}-\mathrm{NMR}\left(400 \mathrm{MHz}, \mathrm{CDCl}_{3}\right): 1.37-1.48(\mathrm{~m}, 13 \mathrm{H})$, 1.70-1.91 (m, 2H), $2.51(\mathrm{~s}, 1 \mathrm{H}), 2.98-3.16(\mathrm{~m}, 2 \mathrm{H}), 4.37-4.42(\mathrm{~m}, 1 \mathrm{H}), 4.62(\mathrm{br} \mathrm{s}, 1 \mathrm{H}), 4.73$ (ddd, $J=37.2$, 15.6, $1.6 \mathrm{~Hz}, 2 \mathrm{H}), 5.10(\mathrm{~s}, 2 \mathrm{H}), 5.49(\mathrm{br} \mathrm{d}, J=6.8 \mathrm{~Hz}, 1 \mathrm{H}), 7.29-7.36(\mathrm{~m}, 5 \mathrm{H}) .{ }^{13} \mathrm{C}-\mathrm{NMR}\left(100 \mathrm{MHz}, \mathrm{CDCl}_{3}\right)$ : 171.7, 156.0, 155.9, 136.1, 128.4, 128.1, 128.0, 79.1, 75.4, 67.0, 53.6, 52.6, 39.8, 31.8, 29.5, 28.3, 22.1. ESI (MS) $m / z: 419.2(M+\mathrm{H})^{+}$. HRMS (ESI-TOF) calculated for $\mathrm{C}_{22} \mathrm{H}_{30} \mathrm{~N}_{2} \mathrm{NaO}_{6}(M+\mathrm{Na})^{+}:$441.19961; found: 441.20100.

3.1.13. Prop-2-ynylN-Cbz- $N^{\prime}-(5-\{(3 a S, 4 S, 6 a R)-2-o x o h e x a h y d r o-1 H$-thieno[3,4-d]imidazol-4-yl $\}$ pentanoyl)-L-lysine (28)

To a solution of $27(6.48 \mathrm{~g}, 15.50 \mathrm{mmol})$ in $\mathrm{CH}_{2} \mathrm{Cl}_{2}(20 \mathrm{~mL})$, trifluoroacetic acid (TFA, $10 \mathrm{~mL}$, $0.14 \mathrm{~mol}$ ) was added, and the reaction mixture was stirred at $0{ }^{\circ} \mathrm{C}$ for $2 \mathrm{~h}$. Then, the reaction mixture was concentrated in vacuo. The residue was redissolved in EtOAc $(20 \mathrm{~mL})$ and washed with saturated $\mathrm{NaHCO}_{3}(20 \mathrm{~mL} \times 2), 1 \mathrm{M} \mathrm{HCl}$ aqueous $(20 \mathrm{~mL} \times 2)$, and brine $(20 \mathrm{~mL} \times 2)$, dried over $\mathrm{Na}_{2} \mathrm{SO}_{4}$, and concentrated to give crude Prop-2-ynyl $\mathrm{N}$-Cbz-L-lysine as a colorless oil, which was used for 
next reaction without further purification. To a stirred solution of D-biotin $(3.79 \mathrm{~g}, 15.50 \mathrm{mmol})$ and $\mathrm{Et}_{3} \mathrm{~N}(2.57 \mathrm{~mL}, 18.60 \mathrm{mmol})$ in anhydrous DMF $(20 \mathrm{~mL})$, isobutyl chloroformate $(2.12 \mathrm{~g}, 15.50 \mathrm{mmol})$ was slowly added at $0{ }^{\circ} \mathrm{C}$ under nitrogen. After $2 \mathrm{~h}$, the reaction mixture was added successively to Prop-2-ynyl N-Cbz-L-lysine $(5.50 \mathrm{~g}, 15.50 \mathrm{mmol})$ in anhydrous DMF $(10 \mathrm{~mL})$ and $\mathrm{Et}_{3} \mathrm{~N}(3.10 \mathrm{~g}$, $0.03 \mathrm{~mol})$. The reaction mixture was stirred at r.t. overnight, and then poured into ice water $(100 \mathrm{~mL})$. The aqueous layer was extracted with EtOAc $(50 \mathrm{~mL} \times 3)$. The combined organic layer was washed with $1 \mathrm{~N} \mathrm{KHSO}_{4}(50 \mathrm{~mL} \times 2), 1 \mathrm{~N} \mathrm{NaHCO}_{3}$ solution $(50 \mathrm{~mL} \times 2)$ and saturated brine $(50 \mathrm{~mL} \times 2)$, dried over anhydrous $\mathrm{Na}_{2} \mathrm{SO}_{4}$, filtered, and concentrated. The residue was purified by flash silica gel column chromatography $\left[\mathrm{CH}_{2} \mathrm{Cl}_{2}-\mathrm{MeOH}(8: 1)\right]$ to give 28 as a white solid (6.50 g, 77\%). HPLC analysis: 95.4\%. M.p. 120-121 ${ }^{\circ} \mathrm{C} .{ }^{1} \mathrm{H}-\mathrm{NMR}\left(400 \mathrm{MHz}, \mathrm{CD}_{3} \mathrm{OD}\right): 1.28-1.79(\mathrm{~m}, 12 \mathrm{H}), 2.09(\mathrm{t}, J=7.2 \mathrm{~Hz}$, 2H), $2.59(\mathrm{~d}, J=12.8 \mathrm{~Hz}, 1 \mathrm{H}), 2.82(\mathrm{dd}, J=12.8,5.2 \mathrm{~Hz}, 1 \mathrm{H}), 2.86(\mathrm{t}, J=2.4 \mathrm{~Hz}, 1 \mathrm{H}), 3.05-3.11(\mathrm{~m}, 3 \mathrm{H})$, 4.08-4.12 (m, 1H), 4.17-4.20 (m, 1H), 4.36-4.39 (m, 1H), $4.64(\mathrm{ddd}, J=26.8,15.6,2.4 \mathrm{~Hz}, 2 \mathrm{H}), 5.00$ (s, 2H), 7.18-7.26 (m, 5H), 7.85 (br t, $J=4.4 \mathrm{~Hz}, 1 \mathrm{H}) .{ }^{13} \mathrm{C}-\mathrm{NMR}\left(100 \mathrm{MHz}, \mathrm{CD}_{3} \mathrm{OD}\right): 176.0,173.3,166.1,158.7$, 138.2, 129.5, 129.0, 128.8, 78.5, 76.6, 67.7, 63.4, 61.6, 57.0, 55.4, 53.4, 41.0, 40.0, 36.8, 32.1, 29.9, 29.8, 29.5, 26.9, 24.2. ESI (MS) $m / z: 545.3(M+\mathrm{H})^{+}$. HRMS (ESI-TOF) calculated for $\mathrm{C}_{27} \mathrm{H}_{36} \mathrm{~N}_{4} \mathrm{NaO}_{6} \mathrm{~S}(M+\mathrm{Na})^{+}$: 567.22478; found: 567.22561.

3.1.14. (S)-Prop-2-ynyl-2-[(S)-6-dansylamide-2-(4-benzoylbenzamido)hexanamido] -6-(5- $\{(3 \mathrm{a} S, 4 S, 6 \mathrm{a} R)-2-o x o h e x a h y d r o-1 H$-thieno[3,4-d]imidazol-4-yl\}pentanamido)hexanoate (30)

Compound $28(5.60 \mathrm{~g}, 10.28 \mathrm{mmol})$ was dissolved in a mixed solution of $30 \% \mathrm{HBr} / \mathrm{HOAC}$ $(30.0 \mathrm{~mL})$. The reaction mixture was stirred at r.t. for $1 \mathrm{~h}$, and then concentrated in vacuo to give a colorless oil, which was almost a pure product and was used for the next reaction without further purification. The $29(4.19 \mathrm{~g}, 10.20 \mathrm{mmol})$ was dissolved in anhydrous DMF (50 mL), to which O-(7-Azabenzotriazol-1-yl)- $N, N, N^{\prime}, N^{\prime}$-tetraMethyluronium hexafluorophosphate (HATU, 3.88 g, $10.21 \mathrm{mmol})$, DIPEA $(5.05 \mathrm{~mL}, 30.56 \mathrm{mmol})$ was added at $0{ }^{\circ} \mathrm{C}$. After the mixture was stirred for $5 \mathrm{~min}$ at r.t., 25 (6.00 g, $10.21 \mathrm{mmol})$ was added. The mixture was stirred at r.t. overnight. The mixture was diluted with water $(100 \mathrm{~mL})$ and extracted by EtOAc $(100 \mathrm{~mL} \times 2)$. The combined organic layer was washed with $1 \mathrm{~N} \mathrm{KHSO}_{4}(100 \mathrm{~mL} \times 2)$, saturated $\mathrm{NaHCO}_{3}$ solution $(100 \mathrm{~mL} \times 2)$, and saturated brine $(100 \mathrm{~mL} \times 2)$, dried over anhydrous $\mathrm{Na}_{2} \mathrm{SO}_{4}$, filtered, and concentrated. The residue was purified by preparative-reverse phase HPLC to give $30(4.30 \mathrm{~g}, 43 \%)$ as a white solid. HPLC analysis: $95.1 \%$. M.p. $105-108{ }^{\circ} \mathrm{C} .{ }^{1} \mathrm{H}-\mathrm{NMR}\left(400 \mathrm{MHz}, \mathrm{CDCl}_{3}\right)$ : 1.43-1.88 (m, 18H), 2.05 (s, 2H), 2.49 (s, $\left.1 \mathrm{H}\right), 2.71$ (d, $J=12.8 \mathrm{~Hz}, 1 \mathrm{H}), 2.84(\mathrm{~s}, 6 \mathrm{H}), 2.94(\mathrm{~s}, 2 \mathrm{H}), 3.09(\mathrm{~s}, 1 \mathrm{H}), 3.21(\mathrm{~s}, 2 \mathrm{H}), 3.46(\mathrm{~s}, 1 \mathrm{H}), 4.32(\mathrm{~s}, 1 \mathrm{H}), 4.49-4.53(\mathrm{~m}$, $2 \mathrm{H}), 4.63-4.66(\mathrm{~m}, 2 \mathrm{H}), 4.73-4.76(\mathrm{~m}, 1 \mathrm{H}), 5.78(\mathrm{~s}, 1 \mathrm{H}), 6.66-6.71(\mathrm{~m}, 2 \mathrm{H}), 6.85(\mathrm{~s}, 1 \mathrm{H}), 7.10(\mathrm{~d}, J=6.4 \mathrm{~Hz}$, 1H), 7.40-7.49 (m, 4H),7.58-7.60 (m, 1H), $7.80(\mathrm{dd}, J=17.6,7.2 \mathrm{~Hz}, 4 \mathrm{H}), 7.91(\mathrm{~d}, J=5.2 \mathrm{~Hz}, 1 \mathrm{H}), 8.00$ $(\mathrm{d}, J=7.2 \mathrm{~Hz}, 2 \mathrm{H}), 8.18(\mathrm{~d}, J=6.0 \mathrm{~Hz}, 1 \mathrm{H}), 8.34(\mathrm{~d}, J=6.4 \mathrm{~Hz}, 2 \mathrm{H}), 8.48(\mathrm{~d}, J=8.0 \mathrm{~Hz}, 1 \mathrm{H}) .{ }^{13} \mathrm{C}-\mathrm{NMR}$ $\left(100 \mathrm{MHz}_{1} \mathrm{CDCl}_{3}\right)$ : 196.0, 173.7, 173.0, 171.6, 167.2, 164.3, 151.8, 140.3, 137.0, 136.8, 135.4, 132.9, 130.1, $129.9,129.6,129.1,128.5,128.1,127.4,123.2,119.1,115.1,77.2,75.6,62.1,60.2,55.8,54.2,52.8,52.3,50.7$, $45.4,42.0,40.6,38.7,35.3,31.2,30.7,28.6,28.5,27.8,25.3,22.4,22.2$. ESI (MS) $m / z: 980.0(M+\mathrm{H})^{+}$. HRMS (ESI-TOF) calculated for $\mathrm{C}_{51} \mathrm{H}_{61} \mathrm{~N}_{7} \mathrm{NaO}_{9} \mathrm{~S}_{2}(M+\mathrm{Na})^{+}$: 1002.38644 ; found: 1002.38858 .

\subsubsection{General Procedure for Synthesis of compounds $\mathbf{2 a}-\mathbf{2 d}, \mathbf{3 a}-\mathbf{3 d}$, and $\mathbf{3 1 a} \mathbf{- 3 1 d}$}

To a solution of $\mathbf{6}(0.32 \mathrm{mmol})$ and $\mathbf{2 0}, \mathbf{2 1}$, or $22(0.32 \mathrm{mmol})$ in $\mathrm{CH}_{2} \mathrm{Cl}_{2}(1.5 \mathrm{~mL})$ and $\mathrm{H}_{2} \mathrm{O}(1.5 \mathrm{~mL})$, $\mathrm{CuSO}_{4} \cdot 5 \mathrm{H}_{2} \mathrm{O}(0.39 \mathrm{mmol})$ and sodium ascorbate $(0.51 \mathrm{mmol})$ were added. The resulting solution was stirred at r.t. overnight. The solvent was evaporated in vacuo, and then the residue was redissolved in EtOAc $(10 \mathrm{~mL})$, washed with water $(10 \mathrm{~mL} \times 3)$, and dried over anhydrous $\mathrm{Na}_{2} \mathrm{SO}_{4}$. The organic layer was evaporated, and the residue was purified by preparative-reverse phase HPLC to give target products $\mathbf{2 a - 2 d}, \mathbf{3 a}-\mathbf{3 d}$, and $\mathbf{3 1 a}-\mathbf{3 1 d}$ as white solids.

Isopropyl 1-(2-\{2-[4-(\{[(S)-2-(4-benzoylbenzamido)-6-(5-\{(3aS,4S,6aR)-2-oxohexahydro-1H-thieno[3,4-d]imidazol -4-yllpentanamido)hexanoylloxy methyl)-1H-1,2,3-triazol-1-yl]ethoxy\}-2-oxoethyl)-4-(2-chlorophenyl)-2-methyl5-oxo-1,4,5,7-tetrahydrofuro[3,4-b]pyridine-3-carboxylate (2a). HPLC analysis: 98.5\%. M.p. $128-130{ }^{\circ} \mathrm{C}$. 
${ }^{1} \mathrm{H}-\mathrm{NMR}\left(400 \mathrm{MHz}, d_{6}\right.$-DMSO): $0.76(\mathrm{~d}, J=6.4 \mathrm{~Hz}, 3 \mathrm{H}), 1.11(\mathrm{~d}, J=6.4 \mathrm{~Hz}, 3 \mathrm{H}), 1.23-1.48(\mathrm{~m}, 10 \mathrm{H})$, $1.79-1.84(\mathrm{~m}, 2 \mathrm{H}), 2.03(\mathrm{t}, J=6.4 \mathrm{~Hz}, 2 \mathrm{H}), 2.23(\mathrm{~s}, 3 \mathrm{H}), 2.55(\mathrm{~d}, J=12.8 \mathrm{~Hz}, 1 \mathrm{H}), 2.80(\mathrm{dd}, J=12.0,4.4 \mathrm{~Hz}$, $1 \mathrm{H}), 3.00-3.08(\mathrm{~m}, 3 \mathrm{H}), 4.08-4.11(\mathrm{~m}, 1 \mathrm{H}), 4.26-4.30(\mathrm{~m}, 1 \mathrm{H}), 4.38-4.50(\mathrm{~m}, 3 \mathrm{H}), 4.59-4.63(\mathrm{~m}, 2 \mathrm{H})$, 4.72-4.92 (m, 5H), $5.18(\mathrm{~s}, 3 \mathrm{H}), 6.34(\mathrm{br} \mathrm{s}, 1 \mathrm{H}), 6.40(\mathrm{br} \mathrm{s}, 1 \mathrm{H}), 7.17(\mathrm{t}, J=6.4 \mathrm{~Hz}, 1 \mathrm{H}), 7.26(\mathrm{t}, J=7.2 \mathrm{~Hz}$, $1 \mathrm{H}), 7.31(\mathrm{~d}, J=7.6 \mathrm{~Hz}, 1 \mathrm{H}), 7.35(\mathrm{~d}, J=7.6 \mathrm{~Hz}, 1 \mathrm{H}), 7.58(\mathrm{t}, J=7.6 \mathrm{~Hz}, 2 \mathrm{H}), 7.71(\mathrm{t}, J=7.2 \mathrm{~Hz}, 1 \mathrm{H}), 7.76$ $(\mathrm{d}, J=7.2 \mathrm{~Hz}, 3 \mathrm{H}), 7.81(\mathrm{~d}, J=8.4 \mathrm{~Hz}, 2 \mathrm{H}), 8.03(\mathrm{~d}, J=8.0 \mathrm{~Hz}, 2 \mathrm{H}), 8.22(\mathrm{~s}, 1 \mathrm{H}), 8.94(\mathrm{~d}, J=7.2 \mathrm{~Hz}, 1 \mathrm{H})$. ${ }^{13} \mathrm{C}-\mathrm{NMR}$ (100 MHz, $d_{6}$-DMSO): 195.8, 172.4, 172.3, 171.3, 168.9, 166.7, 166.5, 163.2, 158.5, 146.1, 143.3, 142.3, 139.9, 137.4, 137.1, 133.5, 132.5, 131.3, 130.2, 129.9, 129.2, 129.1,128.5, 128.2, 127.8, 125.8, 107.9, 101.7, 67.4, 65.9,64.1, 61.5, 59.7, 58.2, 55.9, 53.4, 48.9, 47.6, 38.5, 35.7, 34.6, 30.4, 29.2, 28.7, 28.5, 25.8, 23.6, 21.8, 21.1, 15.2. ESI (MS) $m / z: 1093.4(M+\mathrm{H})^{+}$. HRMS (ESI-TOF) calculated for $\mathrm{C}_{55} \mathrm{H}_{61} \mathrm{ClN}_{8} \mathrm{NaO}_{12} \mathrm{~S}$ $(M+\mathrm{Na})^{+}:$1115.3716; found 1115.3710 .

Isopropyl 1-[2-(2-\{2-[4-(\{[(S)-2-(4-benzoylbenzamido)-6-(5-\{(3aS,4S,6aR)-2-oxohexahydro-1H-thieno[3,4-d] imidazol-4-yl\}pentanamido)hexanoyl]oxy\}methyl)-1H-1,2,3-triazol-1-yl]ethoxy\}ethoxy)-2-oxoethyl]-4-(2-

chlorophenyl)-2-methyl-5-oxo-1,4,5,7-tetrahydrofuro[3,4-b]pyridine-3-carboxylate (2b). HPLC analysis: 98.5\%. M.p. $103-105{ }^{\circ} \mathrm{C} .{ }^{1} \mathrm{H}-\mathrm{NMR}\left(400 \mathrm{MHz}, d_{6}\right.$-DMSO): 0.76 (d, $\left.J=6.4 \mathrm{~Hz}, 3 \mathrm{H}\right), 1.10(\mathrm{~d}, J=6.4 \mathrm{~Hz}$, $3 \mathrm{H}), 1.23-1.63(\mathrm{~m}, 10 \mathrm{H}), 1.77-1.83(\mathrm{~m}, 2 \mathrm{H}), 2.03(\mathrm{t}, J=7.2 \mathrm{~Hz}, 2 \mathrm{H}), 2.28(\mathrm{~s}, 3 \mathrm{H}), 2.55(\mathrm{~d}, J=10.4 \mathrm{~Hz}$, $1 \mathrm{H}), 2.79(\mathrm{dd}, J=15.2,8.0 \mathrm{~Hz}, 1 \mathrm{H}), 3.00-3.08(\mathrm{~m}, 3 \mathrm{H}), 3.66(\mathrm{t}, J=5.2 \mathrm{~Hz}, 2 \mathrm{H}), 3.84(\mathrm{t}, J=5.2 \mathrm{~Hz}, 2 \mathrm{H})$, $4.08-4.11(\mathrm{~m}, 1 \mathrm{H}), 4.29(\mathrm{t}, J=4.0 \mathrm{~Hz}, 3 \mathrm{H}), 4.40-4.61(\mathrm{~m}, 5 \mathrm{H}), 4.70-4.77(\mathrm{~m}, 1 \mathrm{H}), 4.89(\mathrm{dd}, J=36.4$, $16.4 \mathrm{~Hz}, 2 \mathrm{H}), 5.20(\mathrm{~s}, 1 \mathrm{H}), 5.21(\mathrm{~s}, 2 \mathrm{H}), 6.36(\mathrm{br} \mathrm{s}, 1 \mathrm{H}), 6.42(\mathrm{br} \mathrm{s}, 1 \mathrm{H}), 7.17(\mathrm{td}, J=7.6,1.6 \mathrm{~Hz}, 1 \mathrm{H}), 7.27$ $(\mathrm{td}, J=7.2,0.8 \mathrm{~Hz}, 1 \mathrm{H}), 7.32(\mathrm{dd}, J=8.0,1.2 \mathrm{~Hz}, 1 \mathrm{H}), 7.40(\mathrm{~d}, J=7.2 \mathrm{~Hz}, 1 \mathrm{H}), 7.58(\mathrm{t}, J=8.0 \mathrm{~Hz}, 2 \mathrm{H})$, $7.71(\mathrm{tt}, J=7.2,1.2 \mathrm{~Hz}, 1 \mathrm{H}), 7.76(\mathrm{~d}, J=7.2 \mathrm{~Hz}, 3 \mathrm{H}), 7.82(\mathrm{~d}, J=8.4 \mathrm{~Hz}, 2 \mathrm{H}), 8.03(\mathrm{~d}, J=8.4 \mathrm{~Hz}, 2 \mathrm{H}), 8.13$ (s, $1 \mathrm{H}), 8.95(\mathrm{~d}, J=7.2 \mathrm{~Hz}, 1 \mathrm{H}) .{ }^{13} \mathrm{C}-\mathrm{NMR}\left(100 \mathrm{MHz}, d_{6}\right.$-DMSO): 195.3, 171.9, 171.8, 170.8, 168.7, 166.2, 166.1, 162.7, 158.2, 145.6, 142.8, 141.6, 139.4, 137.0, 136.6, 133.0, 132.0, 130.9, 129.7, 129.4, 128.7, 128.6, 128.0, 127.6, 127.3, 125.0, 107.5, 101.2, 68.5, 67.9, 66.9, 65.4, 64.4, 61.0, 59.2, 57.8, 55.4, 52.9, 49.3, 47.3, 38.0, 35.2, 34.2, 30.0, 28.7, 28.2, 28.0, 25.3, 23.1, 21.3, 20.6, 14.7. ESI (MS) $m / z: 1137.4(M+\mathrm{H})^{+}$. HRMS (ESI-TOF) calculated for $\mathrm{C}_{57} \mathrm{H}_{65} \mathrm{ClN}_{8} \mathrm{NaO}_{13} \mathrm{~S}(M+\mathrm{Na})^{+}$: 1159.3978; found: 1159.3973 .

Isopropyl 1-\{2-[2-(2-\{2-[4-(\{[(S)-2-(4-benzoylbenzamido)-6-(5-\{(3aS, 4S,6aR)-2-oxohexahydro-1H-thieno[3,4-d] imidazol-4-yljpentanamido)hexanoyl]oxy\}methyl)-1H-1,2,3-triazol-1-yl]ethoxy\}ethoxy)ethoxy]-2-oxoethyl\}-4-(2 -chlorophenyl)-2-methyl-5-oxo-1,4,5,7-tetrahydrofuro[3,4-b]pyridine-3-carboxylate (2c). HPLC analysis: 95.2\%. M.p. $77-79{ }^{\circ} \mathrm{C} .{ }^{1} \mathrm{H}-\mathrm{NMR}\left(400 \mathrm{MHz}, d_{6}\right.$-DMSO): $0.76(\mathrm{~d}, J=6.4 \mathrm{~Hz}, 3 \mathrm{H}), 1.11(\mathrm{~d}, J=6.4 \mathrm{~Hz}, 3 \mathrm{H})$, $1.23-1.63(\mathrm{~m}, 10 \mathrm{H}), 1.78-1.83(\mathrm{~m}, 2 \mathrm{H}), 2.03(\mathrm{t}, J=7.2 \mathrm{~Hz}, 2 \mathrm{H}), 2.30(\mathrm{~s}, 3 \mathrm{H}), 2.55(\mathrm{~d}, J=12.4 \mathrm{~Hz}, 1 \mathrm{H}), 2.79$ $(\mathrm{dd}, J=12.4,5.2 \mathrm{~Hz}, 1 \mathrm{H}), 2.98-3.08(\mathrm{~m}, 3 \mathrm{H}), 3.49(\mathrm{~s}, 4 \mathrm{H}), 3.61(\mathrm{t}, J=4.8 \mathrm{~Hz}, 2 \mathrm{H}), 3.79(\mathrm{t}, J=7.2 \mathrm{~Hz}, 2 \mathrm{H})$, $4.08-4.11(\mathrm{~m}, 1 \mathrm{H}), 4.27-4.30(\mathrm{~m}, 3 \mathrm{H}), 4.41-4.61(\mathrm{~m}, 5 \mathrm{H}), 4.71-4.77(\mathrm{~m}, 1 \mathrm{H}), 4.89(\mathrm{dd}, J=33.6,16.4 \mathrm{~Hz}$, $2 \mathrm{H}), 5.20(\mathrm{~s}, 3 \mathrm{H}), 6.34(\mathrm{br} \mathrm{s}, 1 \mathrm{H}), 6.40(\mathrm{br} \mathrm{s}, 1 \mathrm{H}), 7.17(\mathrm{td}, J=7.6,1.6 \mathrm{~Hz}, 1 \mathrm{H}), 7.27(\mathrm{t}, J=7.6 \mathrm{~Hz}, 1 \mathrm{H}), 7.32$ $(\mathrm{d}, J=7.6 \mathrm{~Hz}, 1 \mathrm{H}), 7.40(\mathrm{~d}, J=7.6 \mathrm{~Hz}, 1 \mathrm{H}), 7.58(\mathrm{t}, J=7.6 \mathrm{~Hz}, 2 \mathrm{H}), 7.73(\mathrm{t}, J=8.0 \mathrm{~Hz}, 1 \mathrm{H}), 7.76(\mathrm{~d}$, $J=7.2 \mathrm{~Hz}, 3 \mathrm{H}), 7.82(\mathrm{~d}, J=8.4 \mathrm{~Hz}, 2 \mathrm{H}), 8.03(\mathrm{~d}, J=8.0 \mathrm{~Hz}, 2 \mathrm{H}), 8.12(\mathrm{~s}, 1 \mathrm{H}), 8.94(\mathrm{~d}, J=7.2 \mathrm{~Hz}, 1 \mathrm{H})$. ${ }^{13} \mathrm{C}-\mathrm{NMR}$ (100 MHz, $d_{6}$-DMSO): 195.4, 171.9, 171.9, 170.8, 168.7, 166.2, 166.0, 162.7, 158.2, 145.6, 142.8, 141.6, 139.4, 137.0, 136.6, 133.0, 132.0, 130.9, 129.7, 129.4, 128.7, 128.6, 128.0, 127.7, 127.3, 125.0, 107.5, $101.1,69.5,68.6,68.1,66.9,65.4,64.5,61.0,59.2,57.8,55.4,52.9,49.4,47.4,38.0,35.2,34.2,29.9,28.7$, 28.2, 28.0, 25.3, 23.1, 21.3, 20.7, 14.7. ESI (MS) $m / z: 1181.5(\mathrm{M}+\mathrm{H})^{+}$. HRMS (ESI-TOF) calculated for $\mathrm{C}_{59} \mathrm{H}_{69} \mathrm{ClN}_{8} \mathrm{NaO}_{14} \mathrm{~S}(M+\mathrm{Na})^{+}:$1203.4240; found: 1203.4235 .

Isopropyl 1-\{14-[4-(\{[(S)-2-(4-benzoylbenzamido)-6-(5-\{(3aS,4S,6aR)-2-oxohexahydro-1H-thieno[3,4-d]imidazol -4-yl\}pentanamido)hexanoyl]oxy\}methyl)-1H-1,2,3-triazol-1-yl]-2-oxo-3,6,9,12-tetraoxatetradecyl\}-4-(2-

chlorophenyl)-2-methyl-5-oxo-1,4,5,7-tetrahydrofuro[3,4-b]pyridine-3-carboxylate (2d). HPLC analysis: 97.4\%. M.p. $61-63{ }^{\circ} \mathrm{C} .{ }^{1} \mathrm{H}-\mathrm{NMR}\left(400 \mathrm{MHz}, d_{6}\right.$-DMSO): $0.77(\mathrm{~d}, J=6.0 \mathrm{~Hz}, 3 \mathrm{H}), 1.11(\mathrm{~d}, J=6.0 \mathrm{~Hz}, 3 \mathrm{H})$, $1.38-1.56(\mathrm{~m}, 10 \mathrm{H}), 1.78-1.82(\mathrm{~m}, 2 \mathrm{H}), 2.03(\mathrm{t}, J=7.2 \mathrm{~Hz}, 2 \mathrm{H}), 2.30(\mathrm{~s}, 3 \mathrm{H}), 2.55(\mathrm{~d}, J=9.2 \mathrm{~Hz}, 1 \mathrm{H})$, $2.80(\mathrm{dd}, J=12.4,5.2 \mathrm{~Hz}, 1 \mathrm{H}), 2.99-3.08(\mathrm{~m}, 3 \mathrm{H}), 3.44-3.52(\mathrm{~m}, 8 \mathrm{H}), 3.64(\mathrm{t}, J=4.0 \mathrm{~Hz}, 2 \mathrm{H}), 3.80(\mathrm{t}$, $J=5.2 \mathrm{~Hz}, 2 \mathrm{H}), 4.08-4.11(\mathrm{~m}, 1 \mathrm{H}), 4.27-4.32(\mathrm{~m}, 3 \mathrm{H}), 4.40-4.61(\mathrm{~m}, 5 \mathrm{H}), 4.71-4.77(\mathrm{~m}, 1 \mathrm{H}), 4.85(\mathrm{dd}$, $J=32.0,15.2 \mathrm{~Hz}, 2 \mathrm{H}), 5.20(\mathrm{~s}, 2 \mathrm{H}), 5.21(\mathrm{~s}, 1 \mathrm{H}), 6.40(\mathrm{br} \mathrm{s}, 2 \mathrm{H}), 7.17(\mathrm{t}, J=8.4 \mathrm{~Hz}, 1 \mathrm{H}), 7.27(\mathrm{t}, J=8.4 \mathrm{~Hz}$, 
$1 \mathrm{H}), 7.32(\mathrm{~d}, J=8.0 \mathrm{~Hz}, 1 \mathrm{H}), 7.40(\mathrm{~d}, J=8.0 \mathrm{~Hz}, 1 \mathrm{H}), 7.58(\mathrm{t}, J=7.6 \mathrm{~Hz}, 2 \mathrm{H}), 7.71(\mathrm{t}, J=7.2 \mathrm{~Hz}, 1 \mathrm{H}), 7.76$ $(\mathrm{d}, J=7.2 \mathrm{~Hz}, 3 \mathrm{H}), 7.82(\mathrm{~d}, J=8.0 \mathrm{~Hz}, 2 \mathrm{H}), 8.03(\mathrm{~d}, J=8.0 \mathrm{~Hz}, 2 \mathrm{H}), 8.12(\mathrm{~s}, 1 \mathrm{H}), 8.94(\mathrm{~d}, J=7.2 \mathrm{~Hz}, 1 \mathrm{H})$. ${ }^{13}$ C-NMR (100 MHz, $d_{6}$-DMSO): 195.4, 171.9, 171.8, 170.8, 168.7, 166.2, 166.0, 162.7, 158.2, 145.7, 142.8, 141.5, 139.4, 137.0, 136.6, 133.0, 132.0, 130.9, 129.7, 129.4, 128.7, 128.6, 128.0, 127.7, 127.3, 125.1, 107.4, 101.1, 69.7, 69.6, 69.5, 69.4, 68.6, 68.1, 66.9, 65.4, 64.5, 61.0, 59.2, 57.8, 55.4, 52.9, 49.4, 47.3, 38.0, 35.2, 34.2, 30.0, 28.7, 28.2, 28.0, 25.3, 23.1, 21.3, 20.6, 14.7. ESI (MS) $m / z: 1225.5(M+\mathrm{H})^{+}$. HRMS (ESI-TOF) calculated for $\mathrm{C}_{61} \mathrm{H}_{73} \mathrm{ClN}_{8} \mathrm{NaO}_{15} \mathrm{~S}(\mathrm{M}+\mathrm{Na})^{+}$: 1247.4502; found: 1247.4497 .

Isopropyl 1-(2-\{2-[4-(\{[(S)-6-dansylamide-2-(4-benzoylbenzamido)hexanoyl]oxy\}methyl)-1H-1,2,3-triazol-1-yl] ethoxy\}-2-oxoethyl)-4-(2-chlorophenyl)-2-methyl-5-oxo-1,4,5,7-tetrahydrofuro[3,4-b]pyridine-3-carboxylate (3a). HPLC analysis: $91.8 \%$. M.p. $119-121{ }^{\circ} \mathrm{C} .{ }^{1} \mathrm{H}-\mathrm{NMR}\left(400 \mathrm{MHz}, d_{6}\right.$-DMSO): $0.75(\mathrm{~d}, J=6.4 \mathrm{~Hz}, 3 \mathrm{H})$, $1.10(\mathrm{~d}, J=6.4 \mathrm{~Hz}, 3 \mathrm{H}), 1.22-1.34(\mathrm{~m}, 4 \mathrm{H}), 1.63-1.69(\mathrm{~m}, 2 \mathrm{H}), 2.22(\mathrm{~s}, 3 \mathrm{H}), 2.73-2.79(\mathrm{~m}, 2 \mathrm{H}), 2.82(\mathrm{~s}$, $6 \mathrm{H}), 4.29-4.54(\mathrm{~m}, 3 \mathrm{H}), 4.59-4.61(\mathrm{~m}, 2 \mathrm{H}), 4.70-4.92(\mathrm{~m}, 5 \mathrm{H}), 5.15(\mathrm{~d}, J=3.6 \mathrm{~Hz}, 2 \mathrm{H}), 5.18(\mathrm{~s}, 1 \mathrm{H}), 7.16$ $(\mathrm{tt}, J=8.0,1.6 \mathrm{~Hz}, 1 \mathrm{H}), 7.25(\mathrm{t}, J=6.8 \mathrm{~Hz}, 2 \mathrm{H}), 7.33(\mathrm{dd}, J=8.0,14.8 \mathrm{~Hz}, 2 \mathrm{H}), 7.55-7.62(\mathrm{~m}, 4 \mathrm{H}), 7.71$ $(\mathrm{t}, J=7.2 \mathrm{~Hz}, 1 \mathrm{H}), 7.76(\mathrm{~d}, J=8.0 \mathrm{~Hz}, 2 \mathrm{H}), 7.80(\mathrm{~d}, J=8.4 \mathrm{~Hz}, 2 \mathrm{H}), 7.89(\mathrm{t}, J=7.6 \mathrm{~Hz}, 1 \mathrm{H}), 7.99(\mathrm{~d}$, $J=8.0 \mathrm{~Hz}, 2 \mathrm{H}), 8.08(\mathrm{~d}, J=8.0 \mathrm{~Hz}, 1 \mathrm{H}), 8.20(\mathrm{~s}, 1 \mathrm{H}), 8.29(\mathrm{~d}, J=8.8 \mathrm{~Hz}, 1 \mathrm{H}), 8.44(\mathrm{~d}, J=8.0 \mathrm{~Hz}, 1 \mathrm{H})$, $8.87(\mathrm{~d}, J=7.2 \mathrm{~Hz}, 1 \mathrm{H}) .{ }^{13} \mathrm{C}-\mathrm{NMR}\left(100 \mathrm{MHz}, d_{6}\right.$-DMSO): 195.3, 171.7, 170.7, 168.4, 166.1, 166.0, 158.0, $150.7,145.5,142.7,141.7,139.3,136.9,136.6,136.1,133.0,132.0,130.8,129.6,129.4,129.1,129.0,128.8$, 128.7, 128.6, 128.1, 128.0, 127.7, 127.6, 127.2, 125.2, 123.6, 119.4, 115.3, 107.4, 101.1, 66.8, 65.3, 63.5, 57.6, $52.7,48.4,47.0,45.0,42.1,34.1,29.7,28.7,22.7,21.3,20.6,14.6$. ESI (MS) $m / z: 1100.5(M+\mathrm{H})^{+}$. HRMS (ESI-TOF) calculated for $\mathrm{C}_{57} \mathrm{H}_{59} \mathrm{ClN}_{7} \mathrm{O}_{12} \mathrm{~S}(M+\mathrm{H})^{+}:$1100.3631; found: 1100.3625 .

Isopropyl 1-[2-(2-\{2-[4-(\{[(S)-6-dansylamide-2-(4-benzoylbenzamido)hexanoyl]oxy\}methyl)-1H-1,2,3-triazol-1-yl] ethoxy\}ethoxy)-2-oxoethyl]-4-(2-chlorophenyl)-2-methyl-5-oxo-1,4,5,7-tetrahydrofuro[3,4-b]pyridine-3-carboxylate (3b). HPLC analysis: $96.6 \%$. M.p. $124-126{ }^{\circ} \mathrm{C} .{ }^{1} \mathrm{H}-\mathrm{NMR}\left(400 \mathrm{MHz}, \mathrm{d}_{6}\right.$-DMSO): $0.76(\mathrm{~d}, J=6.0 \mathrm{~Hz}, 3 \mathrm{H})$, $1.10(\mathrm{~d}, J=6.4 \mathrm{~Hz}, 3 \mathrm{H}), 1.23-1.32(\mathrm{~m}, 4 \mathrm{H}), 1.62-1.68(\mathrm{~m}, 2 \mathrm{H}), 2.27(\mathrm{~s}, 3 \mathrm{H}), 2.73-2.78(\mathrm{~m}, 2 \mathrm{H}), 2.82(\mathrm{~s}$, $6 \mathrm{H}), 3.65(\mathrm{t}, J=5.2 \mathrm{~Hz}, 2 \mathrm{H}), 3.83(\mathrm{t}, J=5.2 \mathrm{~Hz}, 2 \mathrm{H}), 4.26-4.32(\mathrm{~m}, 3 \mathrm{H}), 4.46-4.59(\mathrm{~m}, 4 \mathrm{H}), 4.70-4.76(\mathrm{~m}$, $1 \mathrm{H}), 4.88(\mathrm{dd}, J=36.4,16.8 \mathrm{~Hz}, 2 \mathrm{H}), 5.18(\mathrm{~s}, 2 \mathrm{H}), 5.20(\mathrm{~s}, 1 \mathrm{H}), 7.16(\mathrm{td}, J=7.6,1.2 \mathrm{~Hz}, 1 \mathrm{H}), 7.23-7.27$ $(\mathrm{m}, 2 \mathrm{H}), 7.31(\mathrm{~d}, J=8.0 \mathrm{~Hz}, 1 \mathrm{H}), 7.40(\mathrm{~d}, J=8.0 \mathrm{~Hz}, 1 \mathrm{H}), 7.54-7.62(\mathrm{~m}, 4 \mathrm{H}), 7.71(\mathrm{t}, J=7.2 \mathrm{~Hz}, 1 \mathrm{H})$, $7.76(\mathrm{~d}, J=7.2 \mathrm{~Hz}, 2 \mathrm{H}), 7.80(\mathrm{~d}, J=8.4 \mathrm{~Hz}, 2 \mathrm{H}), 7.88(\mathrm{t}, J=6.0 \mathrm{~Hz}, 1 \mathrm{H}), 7.99(\mathrm{~d}, J=8.0 \mathrm{~Hz}, 2 \mathrm{H}), 8.08$ $(\mathrm{d}, J=11.2 \mathrm{~Hz}, 1 \mathrm{H}), 8.10(\mathrm{~s}, 1 \mathrm{H}), 8.29(\mathrm{~d}, J=9.2 \mathrm{~Hz}, 1 \mathrm{H}), 8.44(\mathrm{~d}, J=8.4 \mathrm{~Hz}, 1 \mathrm{H}), 8.86(\mathrm{~d}, J=6.8 \mathrm{~Hz}$, 1H). ${ }^{13}$ C-NMR (100 MHz, $d_{6}$-DMSO): 195.4, 171.8, 170.8, 168.7, 166.2, 166.0, 158.2, 150.9, 145.6, 142.8, 141.6, 139.4, 136.9, 136.6, 136.2, 133.0, 132.0, 130.9, 129.7, 129.4, 129.2, 129.1, 128.9, 128.7, 128.6, 128.2, 128.0, 127.7, 127.6, 127.3, 125.0, 123.6, 119.4, 115.2, 107.5, 101.1, 68.5, 67.8, 66.9, 65.4, 64.4, 57.7, 52.8, 49.3, 47.3, 45.1, 42.2, 34.2, 29.8, 28.8, 22.7, 21.3, 20.6, 14.7. ESI (MS) $m / z: 1144.5(M+\mathrm{H})^{+}$. HRMS (ESI-TOF) calculated for $\mathrm{C}_{59} \mathrm{H}_{63} \mathrm{ClN}_{7} \mathrm{O}_{13} \mathrm{~S}(M+\mathrm{H})^{+}$: 1144.3893; found: 1144.3888 .

Isopropyl 1-\{2-[2-(2-\{2-[4-(\{[(S)-6-dansylamide-2-(4-benzoylbenzamido)hexanoyl]oxy\}methyl)-1H-1,2,3-triazol1-yl]ethoxy\}ethoxy)ethoxy]-2-oxoethyl\}-4-(2-chlorophenyl)-2-methyl-5-oxo-1,4,5,7-tetrahydrofuro[3,4-b]pyridine -3-carboxylate (3c). HPLC analysis: 97.8\%. M.p. 96-98 ${ }^{\circ} \mathrm{C} .{ }^{1} \mathrm{H}-\mathrm{NMR}\left(400 \mathrm{MHz}, d_{6}\right.$-DMSO): $0.76(\mathrm{~d}$, $J=7.2 \mathrm{~Hz}, 3 \mathrm{H}), 1.10(\mathrm{~d}, J=6.4 \mathrm{~Hz}, 3 \mathrm{H}), 1.23-1.37(\mathrm{~m}, 4 \mathrm{H}), 1.62-1.67(\mathrm{~m}, 2 \mathrm{H}), 2.29(\mathrm{~s}, 3 \mathrm{H}), 2.73-2.78(\mathrm{~m}$, $2 \mathrm{H}), 2.82(\mathrm{~s}, 6 \mathrm{H}), 3.48(\mathrm{~s}, 4 \mathrm{H}), 3.59(\mathrm{t}, J=5.6 \mathrm{~Hz}, 2 \mathrm{H}), 3.78(\mathrm{t}, J=5.2 \mathrm{~Hz}, 2 \mathrm{H}), 4.27-4.33(\mathrm{~m}, 3 \mathrm{H}), 4.48-4.61$ $(\mathrm{m}, 4 \mathrm{H}), 4.70-4.76(\mathrm{~m}, 1 \mathrm{H}), 4.89(\mathrm{dd}, J=34.0,16.4 \mathrm{~Hz}, 2 \mathrm{H}), 5.17(\mathrm{~s}, 2 \mathrm{H}), 5.20(\mathrm{~s}, 1 \mathrm{H}), 7.16(\mathrm{td}, J=7.6$, $1.2 \mathrm{~Hz}, 1 \mathrm{H}), 7.23-7.28(\mathrm{~m}, 2 \mathrm{H}), 7.31(\mathrm{~d}, J=7.6 \mathrm{~Hz}, 1 \mathrm{H}), 7.40(\mathrm{~d}, J=8.0 \mathrm{~Hz}, 1 \mathrm{H}), 7.54-7.62(\mathrm{~m}, 4 \mathrm{H}), 7.71$ $(\mathrm{t}, J=7.6 \mathrm{~Hz}, 1 \mathrm{H}), 7.76(\mathrm{~d}, J=8.0 \mathrm{~Hz}, 2 \mathrm{H}), 7.80(\mathrm{~d}, J=8.4 \mathrm{~Hz}, 2 \mathrm{H}), 7.88(\mathrm{t}, J=4.8 \mathrm{~Hz}, 1 \mathrm{H}), 7.99(\mathrm{~d}$, $J=8.4 \mathrm{~Hz}, 2 \mathrm{H}), 8.08(\mathrm{~d}, J=7.2 \mathrm{~Hz}, 1 \mathrm{H}), 8.10(\mathrm{~s}, 1 \mathrm{H}), 8.29(\mathrm{~d}, J=8.8 \mathrm{~Hz}, 1 \mathrm{H}), 8.44(\mathrm{~d}, J=9.2 \mathrm{~Hz}, 1 \mathrm{H}), 8.86$ (d, $J=7.6 \mathrm{~Hz}, 1 \mathrm{H}) .{ }^{13} \mathrm{C}-\mathrm{NMR}$ (100 MHz, $d_{6}$-DMSO): 195.4, 171.8, 170.8, 168.7, 166.2, 166.0, 158.2, 150.6, 145.6, 142.8, 141.5, 139.4, 136.9, 136.6, 136.2, 133.0, 132.0, 130.9, 129.7, 129.4, 129.1, 129.0, 128.9, 128.7, 128.6, 128.2, 128.0, 127.7, 127.6, 127.3, 125.0, 123.7, 119.5, 115.3, 107.5, 101.1, 69.5, 68.6, 68.1, 66.9, 65.4, 64.5, 57.7, 52.8, 49.4, 47.3, 45.1, 42.2, 34.2, 29.8, 28.8, 22.7, 21.3, 20.6, 14.7. ESI (MS) $m / z: 1188.5(M+\mathrm{H})^{+}$. HRMS (ESI-TOF) calculated for $\mathrm{C}_{61} \mathrm{H}_{67} \mathrm{ClN}_{7} \mathrm{O}_{14} \mathrm{~S}(M+\mathrm{H})^{+}$: 1188.4155; found: 1188.4150 . 
Isopropyl 1-\{14-[4-(\{[(S)-6-dansylamide-2-(4-benzoylbenzamido)hexanoyl]oxy\}methyl)-1H-1,2,3-triazol-1-yl]-2 -oxo-3,6,9,12-tetraoxatetradecyl\}-4-(2-chlorophenyl)-2-methyl-5-oxo-1,4,5,7-tetrahydrofuro[3,4-b]pyridine-3carboxylate (3d). HPLC analysis: 96.9\%. M.p. 84-86 ${ }^{\circ} \mathrm{C} .{ }^{1} \mathrm{H}-\mathrm{NMR}\left(400 \mathrm{MHz}, d_{6}\right.$-DMSO): 0.76 (d, $J=6.0 \mathrm{~Hz}, 3 \mathrm{H}), 1.10(\mathrm{~d}, J=6.0 \mathrm{~Hz}, 3 \mathrm{H}), 1.23-1.37(\mathrm{~m}, 4 \mathrm{H}), 1.61-1.67(\mathrm{~m}, 2 \mathrm{H}), 2.29(\mathrm{~s}, 3 \mathrm{H}), 2.72-2.78(\mathrm{~m}$, $2 \mathrm{H}), 2.82(\mathrm{~s}, 6 \mathrm{H}), 3.42-3.51(\mathrm{~m}, 8 \mathrm{H}), 3.63(\mathrm{t}, J=6.0 \mathrm{~Hz}, 2 \mathrm{H}), 3.79(\mathrm{t}, J=5.2 \mathrm{~Hz}, 2 \mathrm{H}), 4.28-4.33(\mathrm{~m}, 3 \mathrm{H})$, 4.49-4.61 (m, 4H), 4.70-4.77 (m,1H), $4.89(\mathrm{dd}, J=32.8,16.4 \mathrm{~Hz}, 2 \mathrm{H}), 5.17(\mathrm{~s}, 2 \mathrm{H}), 5.21(\mathrm{~s}, 1 \mathrm{H}), 7.16(\mathrm{td}$, $J=9.2,1.6 \mathrm{~Hz}, 1 \mathrm{H}), 7.25(\mathrm{t}, J=7.6 \mathrm{~Hz}, 2 \mathrm{H}), 7.30(\mathrm{t}, J=8.0 \mathrm{~Hz}, 1 \mathrm{H}), 7.39(\mathrm{~d}, J=7.6 \mathrm{~Hz}, 1 \mathrm{H}), 7.54-7.62(\mathrm{~m}$, $4 \mathrm{H}), 7.71(\mathrm{t}, J=7.6 \mathrm{~Hz}, 1 \mathrm{H}), 7.76(\mathrm{~d}, J=6.8 \mathrm{~Hz}, 2 \mathrm{H}), 7.80(\mathrm{~d}, J=8.4 \mathrm{~Hz}, 2 \mathrm{H}), 7.88(\mathrm{t}, J=5.2 \mathrm{~Hz}, 1 \mathrm{H}), 7.99$ $(\mathrm{d}, J=8.0 \mathrm{~Hz}, 2 \mathrm{H}), 8.07(\mathrm{~d}, J=6.8 \mathrm{~Hz}, 1 \mathrm{H}), 8.10(\mathrm{~s}, 1 \mathrm{H}), 8.29(\mathrm{~d}, J=8.4 \mathrm{~Hz}, 1 \mathrm{H}), 8.44(\mathrm{~d}, J=8.8 \mathrm{~Hz}, 1 \mathrm{H})$, $8.86(\mathrm{~d}, J=6.8 \mathrm{~Hz}, 1 \mathrm{H}) .{ }^{13} \mathrm{C}-\mathrm{NMR}\left(100 \mathrm{MHz}, d_{6}\right.$-DMSO): 195.4, 171.8, 170.8, 168.7, 166.2, 166.0, 158.2, $150.8,145.6,142.8,141.5,139.4,136.9,136.6,136.2,133.0,132.0,130.9,129.7,129.4,129.1,129.0,128.9$, 128.7, 128.6, 128.2, 128.0, 127.7, 127.6, 127.3, 125.0, 123.6, 119.4, 115.3, 107.4, 101.1, 69.7, 69.6, 69.5, 69.4, 68.6, 68.1, 66.9, 65.4, 64.5, 57.7, 52.8, 49.4, 47.3, 45.1, 42.2, 34.2, 29.8, 28.8, 22.7, 21.3, 20.7, 14.7. ESI (MS) $m / z: 1232.5(M+H)^{+}$. HRMS (ESI-TOF) calculated for $\mathrm{C}_{63} \mathrm{H}_{70} \mathrm{ClN}_{7} \mathrm{NaO}_{15} \mathrm{~S}(\mathrm{M}+\mathrm{Na})^{+}:$1254.4237; found: 1254.4231 .

Isopropyl 1-(2-\{2-[4-(\{[(S)-6-(2-chloroacetamido)-2-(4-benzoylbenzamido)hexanoyl]oxy\}methyl)-1H-1,2,3-triazol -1-yl]ethoxy\}-2-oxoethyl)-4-(2-chlorophenyl)-2-methyl-5-oxo-1,4,5,7-tetrahydrofuro[3,4-b]pyridine-3-carboxylate (31a). HPLC analysis: 90.9\%. M.p. 89-91 ${ }^{\circ} \mathrm{C} .{ }^{1} \mathrm{H}-\mathrm{NMR}\left(400 \mathrm{MHz}, \mathrm{CDCl}_{3}\right): 0.81(\mathrm{~d}, J=6.4 \mathrm{~Hz}, 3 \mathrm{H})$, $1.16(\mathrm{dd}, J=6.0,1.6 \mathrm{~Hz}, 3 \mathrm{H}), 1.38-1.60(\mathrm{~m}, 4 \mathrm{H}), 1.82-1.99(\mathrm{~m}, 2 \mathrm{H}), 2.32(\mathrm{~s}, 3 \mathrm{H}), 3.24-3.33(\mathrm{~m}, 2 \mathrm{H})$, 3.93-4.02 (m, 2H), 4.11-4.29 (m, 2H), 4.61-4.69 (m, 7H), 4.80-4.87 (m, 1H), 5.29-5.34 (m, 2H), $5.38(\mathrm{~s}$, $1 \mathrm{H}), 6.80-6.83(\mathrm{~m}, 1 \mathrm{H}), 7.06(\mathrm{tt}, J=7.6,1.6 \mathrm{~Hz}, 1 \mathrm{H}), 7.15(\mathrm{t}, J=6.4 \mathrm{~Hz}, 1 \mathrm{H}), 7.24-7.34(\mathrm{~m}, 3 \mathrm{H}), 7.50(\mathrm{t}$, $J=7.6 \mathrm{~Hz}, 2 \mathrm{H}), 7.62(\mathrm{t}, J=7.6 \mathrm{~Hz}, 1 \mathrm{H}), 7.77-7.83(\mathrm{~m}, 5 \mathrm{H}), 7.95(\mathrm{dd}, J=8.4,2.8 \mathrm{~Hz}, 2 \mathrm{H}) .{ }^{13} \mathrm{C}-\mathrm{NMR}$ $\left(100 \mathrm{MHz}_{,} \mathrm{CDCl}_{3}\right):$ 196.0, 172.1, 171.4, 167.8, 166.8, 166.7, 166.6, 156.7, 144.4, 141.9, 140.4, 137.0, 136.8, 133.3, 133.0, 131.1, 130.1, 130.0, 129.4, 128.5, 128.0, 127.3, 127.0, 124.4, 109.4, 103.3, 68.0, 65.2, 63.6, 58.4, 53.0, 48.8, 47.1, 42.7, 38.9, 35.1, 30.8, 28.8, 22.5, 21.6, 20.9, 15.2. ESI (MS) $m / z: 945.1(M+\mathrm{H})^{+}$. HRMS (ESI-TOF) calculated for $\mathrm{C}_{47} \mathrm{H}_{49} \mathrm{Cl}_{2} \mathrm{~N}_{6} \mathrm{O}_{11}(M+\mathrm{H})^{+}$: 943.28364; found: 943.2932 .

Isopropyl 1-[2-(2-\{2-[4-(\{[(S)-6-(2-chloroacetamido)-2-(4-benzoylbenzamido)hexanoyl]oxy\}methyl)-1H-1,2,3triazol-1-yl]ethoxy\}ethoxy)-2-oxoethyl]-4-(2-chlorophenyl)-2-methyl-5-oxo-1,4,5,7-tetrahydrofuro[3,4-b]pyridine -3-carboxylate (31b). HPLC analysis: 93.5\%. M.p. $64-66{ }^{\circ} \mathrm{C} .{ }^{1} \mathrm{H}-\mathrm{NMR}\left(400 \mathrm{MHz}, \mathrm{CDCl}_{3}\right): 0.81$ (d, $J=6.0 \mathrm{~Hz}, 3 \mathrm{H}), 1.18(\mathrm{~d}, J=6.4 \mathrm{~Hz}, 3 \mathrm{H}), 1.41-1.67(\mathrm{~m}, 4 \mathrm{H}), 1.88-1.97(\mathrm{~m}, 2 \mathrm{H}), 2.38(\mathrm{~s}, 3 \mathrm{H}), 3.25-3.32$ $(\mathrm{m}, 2 \mathrm{H}), 3.68(\mathrm{t}, J=4.0 \mathrm{~Hz}, 2 \mathrm{H}), 3.88(\mathrm{t}, J=5.2 \mathrm{~Hz}, 2 \mathrm{H}), 3.94-4.03(\mathrm{~m}, 2 \mathrm{H}), 4.20-4.37(\mathrm{~m}, 4 \mathrm{H}), 4.51$ $(\mathrm{t}, J=5.2 \mathrm{~Hz}, 2 \mathrm{H}), 4.72-4.76(\mathrm{~m}, 3 \mathrm{H}), 4.83-4.88(\mathrm{~m}, 1 \mathrm{H}), 5.32(\mathrm{~s}, 2 \mathrm{H}), 5.42(\mathrm{~s}, 1 \mathrm{H}), 6.72-6.78(\mathrm{~m}, 1 \mathrm{H})$, 7.06-7.18 (m, 3H), 7.25-7.29 (m, 1H), $7.37(\mathrm{dt}, J=7.6,1.2 \mathrm{~Hz}, 1 \mathrm{H}), 7.50(\mathrm{t}, J=7.6 \mathrm{~Hz}, 2 \mathrm{H}), 7.62(\mathrm{t}$, $J=7.6 \mathrm{~Hz}, 1 \mathrm{H}), 7.74(\mathrm{~s}, 1 \mathrm{H}), 7.82(\mathrm{dd}, J=17.2,8.8 \mathrm{~Hz}, 4 \mathrm{H}), 7.95(\mathrm{t}, J=8.4 \mathrm{~Hz}, 2 \mathrm{H}) .{ }^{13} \mathrm{C}-\mathrm{NMR}(100 \mathrm{MHz}$, $\left.\mathrm{CDCl}_{3}\right):$ 195.0,171.1, 170.5, 167.2, 165.8, 165.7, 165.6, 156.2, 143.7,141.2, 139.3, 135.9, 135.8, 132.2, 132.0, $130.1,129.1,129.0,128.2,127.5,126.9,126.3,126.1,108.3,102.1,68.1,67.5,66.9,64.4,63.7,57.5,52.0,49.1$, 46.4, 41.7, 38.0, 33.9, 30.0, 27.7, 21.5, 20.6, 19.9, 14.2. ESI (MS) m/z: $987.1(M+\mathrm{H})^{+}$. HRMS (ESI-TOF) calculated for $\mathrm{C}_{49} \mathrm{H}_{52} \mathrm{Cl}_{2} \mathrm{~N}_{6} \mathrm{NaO}_{12}(M+\mathrm{Na})^{+}$: 1009.29125; found: 1009.29266.

Isopropyl 1-\{2-[2-(2-\{2-[4-(\{[(S)-6-(2-chloroacetamido)-2-(4-benzoylbenzamido)hexanoyl]oxy\}methyl)-1H-1,2,3triazol-1-yl]ethoxy\}ethoxy)ethoxy]-2-oxoethyl\}-4-(2-chlorophenyl)-2-methyl-5-oxo-1,4,5,7-tetrahydrofuro[3,4-b] pyridine-3-carboxylate (31c). HPLC analysis: $91.1 \%$. M.p. $51-52{ }^{\circ} \mathrm{C} .{ }^{1} \mathrm{H}-\mathrm{NMR}\left(400 \mathrm{MHz}, \mathrm{CDCl}_{3}\right): 0.82$ $(\mathrm{d}, J=6.4 \mathrm{~Hz}, 3 \mathrm{H}), 1.18(\mathrm{~d}, J=6.0 \mathrm{~Hz}, 3 \mathrm{H}), 1.41-1.59(\mathrm{~m}, 4 \mathrm{H}), 1.83-1.99(\mathrm{~m}, 2 \mathrm{H}), 2.39(\mathrm{~s}, 3 \mathrm{H}), 3.21-3.34$ $(\mathrm{m}, 2 \mathrm{H}), 3.55(\mathrm{~s}, 4 \mathrm{H}), 3.65(\mathrm{t}, J=4.8 \mathrm{~Hz}, 2 \mathrm{H}), 3.84(\mathrm{t}, J=4.8 \mathrm{~Hz}, 2 \mathrm{H}), 3.95-4.04(\mathrm{~m}, 2 \mathrm{H}), 4.19-4.32(\mathrm{~m}, 2 \mathrm{H})$, $4.37-4.39(\mathrm{~m}, 2 \mathrm{H}), 4.51(\mathrm{t}, J=4.8 \mathrm{~Hz}, 2 \mathrm{H}), 4.73(\mathrm{~s}, 2 \mathrm{H}), 4.74-4.78(\mathrm{~m}, 1 \mathrm{H}), 4.82-4.88(\mathrm{~m}, 1 \mathrm{H}), 5.32(\mathrm{~s}, 2 \mathrm{H})$, $5.42(\mathrm{~s}, 1 \mathrm{H}), 6.78(\mathrm{t}, J=7.2 \mathrm{~Hz}, 1 \mathrm{H}), 7.06-7.16(\mathrm{~m}, 3 \mathrm{H}), 7.25-7.28(\mathrm{~m}, 1 \mathrm{H}), 7.38(\mathrm{dd}, J=7.6,1.6 \mathrm{~Hz}, 1 \mathrm{H})$, $7.50(\mathrm{t}, J=8.0 \mathrm{~Hz}, 2 \mathrm{H}), 7.62(\mathrm{t}, J=7.2 \mathrm{~Hz}, 1 \mathrm{H}), 7.79(\mathrm{~s}, 1 \mathrm{H}), 7.83(\mathrm{t}, J=8.0 \mathrm{~Hz}, 4 \mathrm{H}), 7.95(\mathrm{t}, J=8.8 \mathrm{~Hz}$, 2H). ${ }^{13} \mathrm{C}-\mathrm{NMR}\left(100 \mathrm{MHz}, \mathrm{CDCl}_{3}\right):$ 195.9, 172.1, 171.3, 168.0, 166.8, 166.6, 166.4, 156.9, 144.7, 142.1, 140.4, $137.0,136.9,133.2,132.9,131.1,130.1,130.0,129.3,128.5,127.9,127.3,127.0,125.0,109.3,103.3,70.5,70.4$, $69.3,68.8,67.9,65.4,64.9,58.6,52.8,50.3,47.5,42.7,39.1,34.9,31.3,28.7,22.5,21.6,20.9,15.2$. ESI (MS) 
$m / z: 1031.1(M+\mathrm{H})^{+}$. HRMS (ESI-TOF) calculated for $\mathrm{C}_{51} \mathrm{H}_{56} \mathrm{Cl}_{2} \mathrm{~N}_{6} \mathrm{NaO}_{13}(M+\mathrm{Na})^{+}: 1053.31746$; found: 1053.31881 .

Isopropyl 1-\{14-[4-(\{[(S)-6-(2-chloroacetamido)-2-(4-benzoylbenzamido)hexanoyl]oxy\}methyl)-1H-1,2,3-triazol1-yl]-2-oxo-3,6,9,12-tetraoxatetradecyl\}-4-(2-chlorophenyl)-2-methyl-5-oxo-1,4,5,7-tetrahydrofuro[3,4-b]pyridine -3-carboxylate (31d). HPLC analysis: $90.6 \%$. M.p. $51-52{ }^{\circ} \mathrm{C} .{ }^{1} \mathrm{H}-\mathrm{NMR}\left(400 \mathrm{MHz}, \mathrm{CDCl}_{3}\right): 0.82(\mathrm{~d}$, $J=6.0 \mathrm{~Hz}, 3 \mathrm{H}), 1.18(\mathrm{~d}, J=6.4 \mathrm{~Hz}, 3 \mathrm{H}), 1.42-1.58(\mathrm{~m}, 4 \mathrm{H}), 1.82-2.01(\mathrm{~m}, 2 \mathrm{H}), 2.39(\mathrm{~s}, 3 \mathrm{H}), 3.24-3.33(\mathrm{~m}$, $2 \mathrm{H}), 3.54-3.61(\mathrm{~m}, 8 \mathrm{H}), 3.71(\mathrm{t}, J=4.4 \mathrm{~Hz}, 2 \mathrm{H}), 3.86(\mathrm{t}, J=4.8 \mathrm{~Hz}, 2 \mathrm{H}), 3.95-4.04(\mathrm{~m}, 2 \mathrm{H}), 4.19(\mathrm{~d}$, $J=18.4 \mathrm{~Hz}, 1 \mathrm{H}), 4.31(\mathrm{dd}, J=14.4,7.6 \mathrm{~Hz}, 1 \mathrm{H}), 4.39-4.41(\mathrm{~m}, 2 \mathrm{H}), 4.53(\mathrm{t}, J=4.8 \mathrm{~Hz}, 2 \mathrm{H}), 4.71(\mathrm{~s}, 2 \mathrm{H})$, $4.74-4.79(\mathrm{~m}, 1 \mathrm{H}), 4.82-4.88(\mathrm{~m}, 1 \mathrm{H}), 5.27-5.35(\mathrm{~m}, 2 \mathrm{H}), 5.42(\mathrm{~s}, 1 \mathrm{H}), 6.78(\mathrm{t}, J=5.6 \mathrm{~Hz}, 1 \mathrm{H}), 7.07-7.10$ $(\mathrm{m}, 2 \mathrm{H}), 7.15-7.19(\mathrm{~m}, 1 \mathrm{H}), 7.26-7.28(\mathrm{~m}, 1 \mathrm{H}), 7.39(\mathrm{~d}, J=8.0 \mathrm{~Hz}, 1 \mathrm{H}), 7.50(\mathrm{t}, J=8.0 \mathrm{~Hz}, 2 \mathrm{H}), 7.62(\mathrm{t}$, $J=7.2 \mathrm{~Hz}, 1 \mathrm{H}), 7.80(\mathrm{~d}, J=7.2 \mathrm{~Hz}, 2 \mathrm{H}), 7.82-7.85(\mathrm{~m}, 3 \mathrm{H}), 7.94-7.97(\mathrm{~m}, 2 \mathrm{H}) .{ }^{13} \mathrm{C}-\mathrm{NMR}(100 \mathrm{MHz}$, $\mathrm{CDCl}_{3}$ ): 195.0,171.1, 170.4, 167.1, 165.8, 165.6, 165.5, 156.0, 143.8,141.2, 141.1, 139.3, 135.98, 135.96, 132.2, 131.9, 130.1, 129.1, 129.0, 128.3, 127.5, 126.9, 126.3, 126.1, 124.1, 108.2, 102.2, 69.4, 68.3, 67.7, 66.8, 64.3, 63.9, 57.5, 51.8, 49.3, 46.4, 41.7, 38.1, 34.0, 30.2, 27.7, 21.5, 20.6, 19.9, 14.2. ESI (MS) $m / z: 1075.1(M+\mathrm{H})^{+}$. HRMS (ESI-TOF) calculated for $\mathrm{C}_{53} \mathrm{H}_{60} \mathrm{Cl}_{2} \mathrm{~N}_{6} \mathrm{NaO}_{14}(M+\mathrm{Na})^{+}$: 1097.34368; found: 1097.34555.

\subsubsection{General Procedure for Synthesis of compounds $4 \mathbf{a}-\mathbf{4 d}$}

To a solution of $\mathbf{6 a - 6 \mathbf { d }}(0.32 \mathrm{mmol})$ and $30(0.31 \mathrm{~g}, 0.32 \mathrm{mmol})$ in $\mathrm{CH}_{2} \mathrm{Cl}_{2}(1.5 \mathrm{~mL})$ and $\mathrm{H}_{2} \mathrm{O}$ $(1.5 \mathrm{~mL}), \mathrm{CuSO}_{4} \cdot 5 \mathrm{H}_{2} \mathrm{O}(97.37 \mathrm{mg}, 0.39 \mathrm{mmol})$ and sodium ascorbate $(0.10 \mathrm{~g}, 0.51 \mathrm{mmol})$ were added. The resulting solution was stirred at r.t. overnight. The solvent was evaporated in vacuo, and then the residue was redissolved in EtOAc $(10 \mathrm{~mL})$, washed by water $(10 \mathrm{~mL} \times 2)$, and dried over anhydrous $\mathrm{Na}_{2} \mathrm{SO}_{4}$. The combined organic layer was evaporated, and the residue was purified by preparative-reverse phase HPLC to give the target products of $\mathbf{4 a} \mathbf{a}-\mathbf{4 d}$ as pale yellow solids.

Isopropyl 1-(2-\{2-[4-(\{[(2-[(S)-6-dansylamide-2-(4-benzoylbenzamido)hexanamido]-6-(5-\{(3aS,4S,6aR)-2oxohexahydro-1H-thieno[3,4-d]imidazol-4-yllpentanamido) hexanoyl]oxy\}methyl)-1H-1,2,3-triazol-1-yl]ethoxy\} -2-oxoethyl)-4-(2-chlorophenyl)-2-methyl-5-oxo-1,4,5,7-tetrahydrofuro[3,4-b]pyridine-3-carboxylate (4a). HPLC analysis: 96.6\%. M.p. 93-95 ${ }^{\circ} \mathrm{C} .{ }^{1} \mathrm{H}-\mathrm{NMR}\left(400 \mathrm{MHz}, d_{6}\right.$-DMSO): $0.76(\mathrm{~d}, J=6.4 \mathrm{~Hz}, 3 \mathrm{H})$, $1.11(\mathrm{~d}, J=6.0 \mathrm{~Hz}, 3 \mathrm{H}), 1.28-1.61(\mathrm{~m}, 18 \mathrm{H}), 2.03(\mathrm{t}, J=7.6 \mathrm{~Hz}, 2 \mathrm{H}), 2.24(\mathrm{~s}, 3 \mathrm{H}), 2.55(\mathrm{~d}, J=12.4 \mathrm{~Hz}, 1 \mathrm{H})$, 2.74-2.80 (m, 3H), $2.82(\mathrm{~s}, 6 \mathrm{H}), 2.95-2.99(\mathrm{~m}, 2 \mathrm{H}), 3.04-3.09(\mathrm{~m}, 1 \mathrm{H}), 4.07-4.12(\mathrm{~m}, 1 \mathrm{H}), 4.18-4.23(\mathrm{~m}$, $1 \mathrm{H}), 4.28(\mathrm{t}, J=6.4 \mathrm{~Hz}, 1 \mathrm{H}), 4.40-4.62(\mathrm{~m}, 5 \mathrm{H}), 4.71-4.77(\mathrm{~m}, 3 \mathrm{H}), 4.85(\mathrm{dd}, J=40.0,16.0 \mathrm{~Hz}, 2 \mathrm{H}), 5.12(\mathrm{~s}$, 2H), $5.19(\mathrm{~s}, 1 \mathrm{H}), 6.40(\mathrm{br} \mathrm{s}, 2 \mathrm{H}), 7.17(\mathrm{t}, J=9.2 \mathrm{~Hz}, 1 \mathrm{H}), 7.24-7.36(\mathrm{~m}, 4 \mathrm{H}), 7.55-7.63(\mathrm{~m}, 4 \mathrm{H}), 7.69-7.80$ $(\mathrm{m}, 6 \mathrm{H}), 7.90(\mathrm{t}, J=6.0 \mathrm{~Hz}, 1 \mathrm{H}),, 8.00(\mathrm{~d}, J=8.0 \mathrm{~Hz}, 2 \mathrm{H}), 8.09(\mathrm{~d}, J=7.2 \mathrm{~Hz}, 1 \mathrm{H}), 8.19(\mathrm{~s}, 1 \mathrm{H}), 8.31(\mathrm{t}$, $J=7.6 \mathrm{~Hz}, 2 \mathrm{H}), 8.44(\mathrm{~d}, J=8.8 \mathrm{~Hz}, 1 \mathrm{H}), 8.55(\mathrm{~d}, J=7.6 \mathrm{~Hz}, 1 \mathrm{H}) .{ }^{13} \mathrm{C}-\mathrm{NMR}\left(100 \mathrm{MHz}, d_{6}\right.$-DMSO): 195.4, 172.0, 171.9, 171.7, 170.7, 168.4, 166.2, 165.7, 162.7, 158.1, 150.6, 145.5, 142.7, 141.8, 139.2, 137.4, 136.7, 136.2, 132.9, 132.0, 130.8, 129.7, 129.3, 129.1, 128.9, 128.7, 128.6, 128.1, 128.0, 127.7, 127.3, 125.1, 123.7, 119.6, 115.4, 107.4, 101.2, 66.9, 65.3, 63.6, 61.0, 59.2, 57.6, 55.4, 53.3, 51.9, 48.5, 47.1, 45.1, 42.4, 38.1, 35.2, $34.2,31.0,30.3,29.1,28.7,28.2,28.0,25.3,22.8,22.7,21.3,20.6,14.7$. ESI (MS) $m / z: 1454.5(M+\mathrm{H})^{+}$. HRMS (ESI-TOF) calculated for $\mathrm{C}_{73} \mathrm{H}_{84} \mathrm{ClN}_{11} \mathrm{NaO}_{15} \mathrm{~S}_{2}(M+\mathrm{Na})^{+}:$1476.5176; found: 1476.5171 .

Isopropyl 1-[2-(2-\{2-[4-(\{[(2-[(S)-6-dansylamide-2-(4-benzoylbenzamido)hexanamido] -6-(5-\{(3aS,4S,6aR)-2oxohexahydro-1H-thieno[3,4-d] imidazol-4-ylipentanamido) hexanoyl]oxy methyl)-1H-1,2,3-triazol-1-yl]ethoxy\} ethoxy)-2-oxoethyl]-4-(2-chlorophenyl)-2-methyl-5-oxo-1,4,5,7-tetrahydrofuro[3,4-b]pyridine-3-carboxylate (4b). HPLC analysis: $98.2 \%$. M.p. $133-135^{\circ} \mathrm{C} .{ }^{1} \mathrm{H}-\mathrm{NMR}\left(400 \mathrm{MHz}, \mathrm{d}_{6}\right.$-DMSO): $0.76(\mathrm{~d}, J=6.0 \mathrm{~Hz}, 3 \mathrm{H})$, $1.10(\mathrm{~d}, J=6.4 \mathrm{~Hz}, 3 \mathrm{H}), 1.28-1.61(\mathrm{~m}, 18 \mathrm{H}), 2.03(\mathrm{t}, J=7.6 \mathrm{~Hz}, 2 \mathrm{H}), 2.28(\mathrm{~s}, 3 \mathrm{H}), 2.55(\mathrm{~d}, J=12.4 \mathrm{~Hz}, 1 \mathrm{H})$, 2.75-2.80 (m, 3H), $2.82(\mathrm{~s}, 6 \mathrm{H}), 2.95-3.00(\mathrm{~m}, 2 \mathrm{H}), 3.04-3.09(\mathrm{~m}, 1 \mathrm{H}), 3.66(\mathrm{t}, J=4.4 \mathrm{~Hz}, 2 \mathrm{H}), 3.84(\mathrm{t}$, $J=5.2 \mathrm{~Hz}, 2 \mathrm{H}), 4.08-4.11(\mathrm{~m}, 1 \mathrm{H}), 4.18-4.23(\mathrm{~m}, 1 \mathrm{H}), 4.26-4.30(\mathrm{~m}, 3 \mathrm{H}), 4.38-4.60(\mathrm{~m}, 5 \mathrm{H}), 4.71-4.77$ $(\mathrm{m}, 1 \mathrm{H}), 4.89(\mathrm{dd}, J=34.4,16.0 \mathrm{~Hz}, 2 \mathrm{H}), 5.14(\mathrm{~d}, J=3.2 \mathrm{~Hz}, 2 \mathrm{H}), 5.21(\mathrm{~s}, 1 \mathrm{H}), 6.40(\mathrm{br} \mathrm{s}, 2 \mathrm{H}), 7.17(\mathrm{td}$, $J=8.0,0.8 \mathrm{~Hz}, 1 \mathrm{H}), 7.24-7.28(\mathrm{~m}, 2 \mathrm{H}), 7.32(\mathrm{~d}, J=8.0 \mathrm{~Hz}, 1 \mathrm{H}), 7.40(\mathrm{~d}, J=7.6 \mathrm{~Hz}, 1 \mathrm{H}), 7.55-7.63(\mathrm{~m}$, $4 \mathrm{H}), 7.69-7.80(\mathrm{~m}, 6 \mathrm{H}), 7.90(\mathrm{t}, J=5.6 \mathrm{~Hz}, 1 \mathrm{H}), 8.01(\mathrm{~d}, J=8.0 \mathrm{~Hz}, 2 \mathrm{H}), 8.09(\mathrm{~d}, J=6.0 \mathrm{~Hz}, 2 \mathrm{H}), 8.31(\mathrm{t}$, $J=6.4 \mathrm{~Hz}, 2 \mathrm{H}), 8.44(\mathrm{~d}, J=8.4 \mathrm{~Hz}, 1 \mathrm{H}), 8.55(\mathrm{~d}, J=7.6 \mathrm{~Hz}, 1 \mathrm{H}) .{ }^{13} \mathrm{C}-\mathrm{NMR}\left(100 \mathrm{MHz}, d_{6}\right.$-DMSO): 195.4, 
$172.0,171.9,171.8,170.8,168.7,166.2,165.7,162.7,158.2,150.6,145.6,142.8,141.5,139.2,137.4,136.7$, 136.2, 133.0, 132.0, 130.9, 129.7, 129.3, 129.1, 128.8, 128.7, 128.6, 128.1, 128.0, 127.7, 127.6, 127.3, 124.9, $123.7,119.6,115.3,107.5,101.2,68.5,67.9,66.9,65.4,64.4,61.0,59.2,57.6,55.4,53.2,51.9,49.3,47.3$, $45.1,42.4,38.1,35.2,34.2,31.0,30.3,29.1,28.7,28.2,27.9,25.3,22.8,22.7,21.3,20.6,14.7$. ESI (MS) $m / z$ : $1499.0(M+\mathrm{H})^{+}$. HRMS (ESI-TOF) calculated for $\mathrm{C}_{75} \mathrm{H}_{88} \mathrm{ClN}_{11} \mathrm{NaO}_{16} \mathrm{~S}_{2}(\mathrm{M}+\mathrm{Na})^{+}$: 1520.5438 ; found: 1520.5433 .

Isopropyl 1-\{2-[2-(2-\{2-[4-(\{[(2-[(S)-6-dansylamide-2-(4-benzoylbenzamido)hexanamido] -6-(5-\{(3aS,4S,6aR)-2oxohexahydro-1H-thieno[3,4-d]imidazol-4-yl\}pentanamido) hexanoyl]oxy\}methyl)-1H-1,2,3-triazol-1-yl]ethoxy\} ethoxy)ethoxy]-2-oxoethyl\}-4-(2-chlorophenyl)-2-methyl-5-oxo-1,4,5,7-tetrahydrofuro[3,4-b]pyridine-3-carboxylate (4c). HPLC analysis: 98.9\%. M.p. $119-121^{\circ} \mathrm{C} .{ }^{1} \mathrm{H}-\mathrm{NMR}\left(400 \mathrm{MHz}, d_{6}\right.$-DMSO): $0.76(\mathrm{~d}, J=6.0 \mathrm{~Hz}, 3 \mathrm{H})$, $1.10(\mathrm{~d}, J=6.0 \mathrm{~Hz}, 3 \mathrm{H}), 1.28-1.61(\mathrm{~m}, 18 \mathrm{H}), 2.03(\mathrm{t}, J=7.6 \mathrm{~Hz}, 2 \mathrm{H}), 2.30(\mathrm{~s}, 3 \mathrm{H}), 2.55(\mathrm{~d}, J=12.4 \mathrm{~Hz}, 1 \mathrm{H})$, 2.77-2.80 (m, 3H), $2.82(\mathrm{~s}, 6 \mathrm{H}), 2.95-3.00(\mathrm{~m}, 2 \mathrm{H}), 3.04-3.09(\mathrm{~m}, 1 \mathrm{H}), 3.49(\mathrm{~s}, 4 \mathrm{H}), 3.61(\mathrm{t}, \mathrm{J}=4.4 \mathrm{~Hz}$, $2 \mathrm{H}), 3.78(\mathrm{t}, J=4.8 \mathrm{~Hz}, 2 \mathrm{H}), 4.08-4.11(\mathrm{~m}, 1 \mathrm{H}), 4.18-4.24(\mathrm{~m}, 1 \mathrm{H}), 4.26-4.31(\mathrm{~m}, 3 \mathrm{H}), 4.38-4.61(\mathrm{~m}, 5 \mathrm{H})$, $4.71-4.77(\mathrm{~m}, 1 \mathrm{H}), 4.89(\mathrm{dd}, J=32.4,16.4 \mathrm{~Hz}, 2 \mathrm{H}), 5.14(\mathrm{~d}, J=3.6 \mathrm{~Hz}, 2 \mathrm{H}), 5.21(\mathrm{~s}, 1 \mathrm{H}), 6.40(\mathrm{br} \mathrm{s}, 2 \mathrm{H})$, $7.17(\mathrm{t}, J=7.6 \mathrm{~Hz}, 1 \mathrm{H}), 7.24-7.28(\mathrm{~m}, 2 \mathrm{H}), 7.32(\mathrm{~d}, J=8.0 \mathrm{~Hz}, 1 \mathrm{H}), 7.40(\mathrm{~d}, J=7.2 \mathrm{~Hz}, 1 \mathrm{H}), 7.55-7.63(\mathrm{~m}$, $4 \mathrm{H}), 7.69-7.80(\mathrm{~m}, 6 \mathrm{H}), 7.89(\mathrm{t}, J=6.0 \mathrm{~Hz}, 1 \mathrm{H}), 8.01(\mathrm{~d}, J=8.0 \mathrm{~Hz}, 2 \mathrm{H}), 8.09(\mathrm{~d}, J=4.8 \mathrm{~Hz}, 2 \mathrm{H}), 8.31(\mathrm{t}$, $J=7.6 \mathrm{~Hz}, 2 \mathrm{H}), 8.44(\mathrm{~d}, J=8.8 \mathrm{~Hz}, 1 \mathrm{H}), 8.55(\mathrm{~d}, J=8.0 \mathrm{~Hz}, 1 \mathrm{H}) .{ }^{13} \mathrm{C}-\mathrm{NMR}\left(100 \mathrm{MHz}, d_{6}-\mathrm{DMSO}\right): 195.4$, $172.0,171.9,171.8,170.8,168.7,166.2,165.7,162.7,158.2,150.5,145.6,142.8,141.5,139.2,137.4,136.7,136.2$, 133.0, 132.0, 130.9, 129.7, 129.3, 129.1, 128.8, 128.7, 128.6, 128.1, 128.0, 127.7, 127.6, 127.3, 124.9, 123.7, 119.6, 115.4, 107.5, 101.1, 69.5, 68.6, 68.1, 66.9, 65.4, 64.5, 61.0, 59.2, 57.7, 55.4, 53.2, 51.9, 49.4, 47.3, 45.1, 42.4, 38.1, $35.2,34.2,31.0,30.3,29.1,28.7,28.2,28.0,25.3,22.8,22.7,21.3,20.7,14.7$. ESI (MS) $m / z: 1544.0(M+\mathrm{H})^{+}$. HRMS (ESI-TOF) calculated for $\mathrm{C}_{77} \mathrm{H}_{92} \mathrm{ClN}_{11} \mathrm{NaO}_{17} \mathrm{~S}_{2}(M+\mathrm{Na})^{+}:$1564.5700; found: 1564.5695 .

Isopropyl 1-\{14-[4-(\{[(2-[(S)-6-dansylamide-2-(4-benzoylbenzamido)hexanamido]-6-(5-\{(3aS,4S,6aR)-2oxohexahydro-1H-thieno[3,4-d]imidazol-4-yllpentanamido) hexanoyl]oxy\}methyl)-1H-1,2,3 -triazol-1-yl]-2-oxo3,6,9,12-tetraoxatetradecyl\}-4-(2-chlorophenyl)-2-methyl-5-oxo-1,4,5,7-tetrahydrofuro[3,4-b] pyridine-3 -carboxylate (4d). HPLC analysis: 99.0\%. M.p. 158-160 ${ }^{\circ} \mathrm{C} .{ }^{1} \mathrm{H}-\mathrm{NMR}\left(400 \mathrm{MHz}, d_{6}\right.$-DMSO): 0.77 (d, $J=6.4 \mathrm{~Hz}, 3 \mathrm{H}), 1.11(\mathrm{~d}, J=6.4 \mathrm{~Hz}, 3 \mathrm{H}), 1.23-1.61(\mathrm{~m}, 18 \mathrm{H}), 2.03(\mathrm{t}, J=6.8 \mathrm{~Hz}, 2 \mathrm{H}), 2.30(\mathrm{~s}, 3 \mathrm{H}), 2.55(\mathrm{~d}$, $J=12.8 \mathrm{~Hz}, 1 \mathrm{H}), 2.77-2.80(\mathrm{~m}, 3 \mathrm{H}), 2.82(\mathrm{~s}, 6 \mathrm{H}), 2.95-3.00(\mathrm{~m}, 2 \mathrm{H}), 3.04-3.09(\mathrm{~m}, 1 \mathrm{H}), 3.44-3.50(\mathrm{~m}, 8 \mathrm{H})$, $3.64(\mathrm{t}, J=4.4 \mathrm{~Hz}, 2 \mathrm{H}), 3.80(\mathrm{t}, J=4.8 \mathrm{~Hz}, 2 \mathrm{H}), 4.08-4.11(\mathrm{~m}, 1 \mathrm{H}), 4.19-4.24(\mathrm{~m}, 1 \mathrm{H}), 4.26-4.32(\mathrm{~m}, 3 \mathrm{H})$, 4.40-4.61 (m, 5H), 4.71-4.77 (m, 1H), $4.89(\mathrm{dd}, J=32.4,16.4 \mathrm{~Hz}, 2 \mathrm{H}), 5.14(\mathrm{~d}, J=4.8 \mathrm{~Hz}, 2 \mathrm{H}), 5.21(\mathrm{~s}, 1 \mathrm{H})$, 6.39 (br s,2H), $7.16(\mathrm{t}, J=7.2 \mathrm{~Hz}, 1 \mathrm{H}), 7.25(\mathrm{t}, J=7.6 \mathrm{~Hz}, 2 \mathrm{H}), 7.31(\mathrm{t}, J=8.0 \mathrm{~Hz}, 1 \mathrm{H}), 7.40(\mathrm{~d}, J=7.6 \mathrm{~Hz}$, $1 \mathrm{H}), 7.54-7.62(\mathrm{~m}, 4 \mathrm{H}), 7.71(\mathrm{t}, J=6.0 \mathrm{~Hz}, 2 \mathrm{H}), 7.77(\mathrm{dd}, J=15.2,8.0 \mathrm{~Hz}, 4 \mathrm{H}), 7.88(\mathrm{t}, J=6.0 \mathrm{~Hz}, 1 \mathrm{H})$, $8.01(\mathrm{~d}, J=8.4 \mathrm{~Hz}, 2 \mathrm{H}), 8.09(\mathrm{~d}, J=5.2 \mathrm{~Hz}, 2 \mathrm{H}), 8.30(\mathrm{~d}, J=8.8 \mathrm{~Hz}, 2 \mathrm{H}), 8.44(\mathrm{~d}, J=8.4 \mathrm{~Hz}, 1 \mathrm{H}), 8.54(\mathrm{~d}$, $J=7.6 \mathrm{~Hz}, 1 \mathrm{H}) .{ }^{13} \mathrm{C}-\mathrm{NMR}\left(100 \mathrm{MHz}, d_{6}\right.$-DMSO): 195.4, 172.0, 171.9, 171.8, 170.8, 168.7, 166.2, 165.7, $162.7,158.2,150.8,145.6,142.8,141.5,139.2,137.4,136.7,136.2,133.0,132.0,130.9,129.7,129.3,129.1$, $129.0,128.9,128.7,128.6,128.1,128.0,127.7,127.6,127.3,125.0,123.6,119.4,115.2,107.5,101.1,69.7,69.6$, $69.59,69.50,68.6,68.1,66.9,65.4,64.5,61.0,59.2,57.6,55.4,53.2,51.9,49.4,47.3,45.1,42.4,38.1,35.2$, 34.2, 31.0, 30.3, 29.1, 28.7, 28.2, 28.0, 25.3, 22.8, 22.7, 21.3, 20.7, 14.7. ESI (MS) $m / z: 1586.0(M+\mathrm{H})^{+}$. HRMS (ESI-TOF) calculated for $\mathrm{C}_{79} \mathrm{H}_{96} \mathrm{ClN}_{11} \mathrm{NaO}_{18} \mathrm{~S}_{2}(M+\mathrm{Na})^{+}:$1608.5962; found: 1608.5957 .

\subsubsection{General Procedure for Synthesis of compounds 5a-5d}

A mixture of 31a-31d $(0.37 \mathrm{mmol})$ and $\mathrm{NaN}_{3}(0.56 \mathrm{mmol})$ in $\mathrm{DMF}(8.0 \mathrm{~mL})$ was stirred at r.t. overnight. The mixture was diluted with ice water $(100 \mathrm{~mL})$ and extracted by EtOAc $(100 \mathrm{~mL} \times 2)$. The combined organic phase was washed with brine $(100 \mathrm{~mL} \times 2)$, dried over anhydrous $\mathrm{Na}_{2} \mathrm{SO}_{4}$, and concentrated. The residue was purified by preparative-reverse phase HPLC to give $\mathbf{5 a - 5 d}$ as pale yellow solids.

Isopropyl 1-(2-\{2-[4-(\{[(S)-6-(2-azidoacetamido)-2-(4-benzoylbenzamido)hexanoyl]oxy\}methyl)-1H-1,2,3-triazol -1-yl]ethoxy\}-2-oxoethyl)-4-(2-chlorophenyl)-2-methyl-5-oxo-1,4,5,7-tetrahydrofuro[3,4-b]pyridine-3-carboxylate (5a). HPLC analysis: 91.4\%. M.p. $81-83{ }^{\circ} \mathrm{C} .{ }^{1} \mathrm{H}-\mathrm{NMR}\left(400 \mathrm{MHz}, \mathrm{CDCl}_{3}\right): 0.81(\mathrm{~d}, J=6.4 \mathrm{~Hz}, 3 \mathrm{H})$, $1.17(\mathrm{dd}, J=6.4,2.4 \mathrm{~Hz}, 3 \mathrm{H}), 1.36-1.59(\mathrm{~m}, 4 \mathrm{H}), 1.83-1.98(\mathrm{~m}, 2 \mathrm{H}), 2.33(\mathrm{~s}, 3 \mathrm{H}), 3.23-3.32(\mathrm{~m}, 2 \mathrm{H})$, 
3.85-3.95 (m, 2H), 4.12-4.31 (m, 2H), 4.61-4.69 (m, 7H), 4.81-4.87 (m, 1H), 5.30-5.35 (m, 2H), 5.39 $(\mathrm{s}, 1 \mathrm{H}), 6.56-6.60(\mathrm{~m}, 1 \mathrm{H}), 7.07(\mathrm{tt}, J=8.0,1.2 \mathrm{~Hz}, 1 \mathrm{H}), 7.14-7.22(\mathrm{~m}, 2 \mathrm{H}), 7.25-7.27(\mathrm{~m}, 1 \mathrm{H}), 7.32(\mathrm{~d}$, $J=8.0 \mathrm{~Hz}, 1 \mathrm{H}), 7.50(\mathrm{t}, J=8.0 \mathrm{~Hz}, 2 \mathrm{H}), 7.62(\mathrm{tt}, J=7.2,1.2 \mathrm{~Hz}, 1 \mathrm{H}), 7.74(\mathrm{~d}, J=2.8 \mathrm{~Hz}, 1 \mathrm{H}), 7.78-7.85(\mathrm{~m}$, $4 \mathrm{H}), 7.96(\mathrm{dd}, J=8.4,3.2 \mathrm{~Hz}, 2 \mathrm{H}) .{ }^{13} \mathrm{C}-\mathrm{NMR}\left(100 \mathrm{MHz}, \mathrm{CDCl}_{3}\right): 195.1,171.2,170.7,166.9,166.5,166.0$, $165.8,156.3,143.6,141.9,141.2,139.3,135.9,132.1,132.0,130.1,129.1,128.9,128.2,127.5,127.0,126.4$, 126.1, 123.6, 108.3, 102.0, 67.0, 64.4, 62.7, 57.3, 52.1, 51.4, 47.9, 46.2, 37.7, 33.9, 29.8, 27.7, 21.7, 20.6, 19.9, 14.2. ESI (MS) $m / z: 950.1(M+\mathrm{H})^{+}$. HRMS (ESI-TOF) calculated for $\mathrm{C}_{47} \mathrm{H}_{48} \mathrm{ClN}_{9} \mathrm{NaO}_{11}(M+\mathrm{Na})^{+}$: 972.3060; found: 972.3054 .

Isopropyl 1-[2-(2-\{2-[4-(\{[(S)-6-(2-azidoacetamido)-2-(4-benzoylbenzamido)hexanoyl]oxy\}methyl)-1H-1,2,3-triazol -1-yl]ethoxy\}ethoxy)-2-oxoethyl]-4-(2-chlorophenyl)-2-methyl-5-oxo-1,4,5,7-tetrahydrofuro[3,4-b]pyridine-3carboxylate (5b). HPLC analysis: 94.1\%. M.p. $67-68{ }^{\circ} \mathrm{C} .{ }^{1} \mathrm{H}-\mathrm{NMR}\left(400 \mathrm{MHz}, \mathrm{CDCl}_{3}\right): 0.81(\mathrm{~d}, J=6.4 \mathrm{~Hz}$, $3 \mathrm{H}), 1.16(\mathrm{~d}, J=6.4 \mathrm{~Hz}, 3 \mathrm{H}), 1.34-1.56(\mathrm{~m}, 4 \mathrm{H}), 1.90-1.99(\mathrm{~m}, 2 \mathrm{H}), 2.37(\mathrm{~s}, 3 \mathrm{H}), 3.22-3.29(\mathrm{~m}, 2 \mathrm{H}), 3.68$ $(\mathrm{t}, J=2.8 \mathrm{~Hz}, 2 \mathrm{H}), 3.85-3.91(\mathrm{~m}, 4 \mathrm{H}), 4.20-4.38(\mathrm{~m}, 4 \mathrm{H}), 4.50(\mathrm{t}, J=4.8 \mathrm{~Hz}, 2 \mathrm{H}), 4.68-4.76(\mathrm{~m}, 3 \mathrm{H})$, $4.81-4.88(\mathrm{~m}, 1 \mathrm{H}), 5.31(\mathrm{~s}, 2 \mathrm{H}), 5.41(\mathrm{~s}, 1 \mathrm{H}), 6.62-6.66(\mathrm{~m}, 1 \mathrm{H}), 7.04-7.10(\mathrm{~m}, 1 \mathrm{H}), 7.13-7.22(\mathrm{~m}, 2 \mathrm{H})$, $7.25-7.28(\mathrm{~m}, 1 \mathrm{H}), 7.38(\mathrm{~d}, J=7.6 \mathrm{~Hz}, 1 \mathrm{H}), 7.50(\mathrm{t}, J=7.6 \mathrm{~Hz}, 2 \mathrm{H}), 7.62(\mathrm{t}, J=7.6 \mathrm{~Hz}, 1 \mathrm{H}), 7.74(\mathrm{~s}, 1 \mathrm{H})$, $7.81(\mathrm{dd}, J=15.6,7.6 \mathrm{~Hz}, 4 \mathrm{H}), 7.95(\mathrm{t}, J=8.4 \mathrm{~Hz}, 2 \mathrm{H}) .{ }^{13} \mathrm{C}-\mathrm{NMR}\left(100 \mathrm{MHz}, \mathrm{CDCl}_{3}\right): 195.0,171.2,170.6$, 167.2, 166.4, 165.8, 165.7, 156.3, 143.7,141.3, 141.2, 139.3, 135.9, 135.8,132.1, 132.0, 130.1, 129.1, 128.9, 128.2, 127.5, 127.0, 126.3, 126.1, 123.9, 108.3, 102.0, 68.1, 67.5, 66.9, 64.5, 63.7, 57.4, 52.0, 51.4, 49.1, 46.4, 37.6, 33.9, 30.0, 27.7, 21.6, 20.6, 19.9, 14.2. ESI (MS) $m / z: 994.1(M+\mathrm{H})^{+}$. HRMS (ESI-TOF) calculated for $\mathrm{C}_{49} \mathrm{H}_{52} \mathrm{ClN}_{9} \mathrm{NaO}_{12}(M+\mathrm{Na})^{+}$: 1016.3322; found: 1016.3316 .

Isopropyl 1-\{2-[2-(2-\{2-[4-(\{[(S)-6-(2-azidoacetamido)-2-(4-benzoylbenzamido)hexanoyl]oxy\}methyl)-1H-1,2,3triazol-1-yl]ethoxy\}ethoxy)ethoxy]-2-oxoethyll-4-(2-chlorophenyl)-2-methyl-5-oxo-1,4,5,7-tetrahydrofuro[3,4-b] pyridine-3-carboxylate (5c). HPLC analysis: $93.2 \%$. M.p. $73-74{ }^{\circ} \mathrm{C} .{ }^{1} \mathrm{H}-\mathrm{NMR}\left(400 \mathrm{MHz}, \mathrm{CDCl}_{3}\right): 0.82(\mathrm{~d}$, $J=6.0 \mathrm{~Hz}, 3 \mathrm{H}), 1.18(\mathrm{~d}, J=6.0 \mathrm{~Hz}, 3 \mathrm{H}), 1.38-1.57(\mathrm{~m}, 4 \mathrm{H}), 1.89-2.03(\mathrm{~m}, 2 \mathrm{H}), 2.39(\mathrm{~s}, 3 \mathrm{H}), 3.20-3.29(\mathrm{~m}$, $2 \mathrm{H}), 3.55(\mathrm{~s}, 4 \mathrm{H}), 3.66(\mathrm{t}, J=4.4 \mathrm{~Hz}, 2 \mathrm{H}), 3.84(\mathrm{t}, J=5.2 \mathrm{~Hz}, 2 \mathrm{H}), 3.90(\mathrm{~d}, J=4.0 \mathrm{~Hz}, 2 \mathrm{H}), 4.20-4.39(\mathrm{~m}, 4 \mathrm{H})$, $4.51(\mathrm{t}, J=4.4 \mathrm{~Hz}, 2 \mathrm{H}), 4.69-4.77(\mathrm{~m}, 3 \mathrm{H}), 4.82-4.88(\mathrm{~m}, 1 \mathrm{H}), 5.31(\mathrm{~s}, 2 \mathrm{H}), 5.41(\mathrm{~s}, 1 \mathrm{H}), 6.65-6.71(\mathrm{~m}, 1 \mathrm{H})$, 7.04-7.10 (m, 1H), 7.13-7.18 (m, 1H), 7.22-7.27 (m, 2H), $7.38(\mathrm{~d}, J=7.6 \mathrm{~Hz}, 1 \mathrm{H}), 7.50(\mathrm{t}, J=7.6 \mathrm{~Hz}, 2 \mathrm{H})$, $7.62(\mathrm{t}, J=7.6 \mathrm{~Hz}, 1 \mathrm{H}), 7.79(\mathrm{~d}, J=8.4 \mathrm{~Hz}, 2 \mathrm{H}), 7.83(\mathrm{t}, J=3.6 \mathrm{~Hz}, 3 \mathrm{H}), 7.95(\mathrm{t}, J=8.4 \mathrm{~Hz}, 2 \mathrm{H}) .{ }^{13} \mathrm{C}-\mathrm{NMR}$ $\left(100 \mathrm{MHz}, \mathrm{CDCl}_{3}\right):$ 195.0, 171.1, 170.6, 167.1, 166.3, 165.8, 165.7, 156.2, 143.8, 141.2, 141.1, 139.3, 135.9, 132.1, 132.0, 130.1, 129.1, 129.0, 128.3, 127.5, 126.9, 126.3, 126.1, 124.0, 108.2, 102.1, 69.4, 69.3, 68.2, 67.7, 66.9, 64.4, 63.9, 57.5, 51.9, 51.4, 49.2, 46.4, 37.7, 33.9, 30.2, 27.7, 21.5, 20.6, 19.9, 14.2. ESI (MS) $m / z: 1038.1$ $(M+\mathrm{H})^{+}$. HRMS (ESI-TOF) calculated for $\mathrm{C}_{51} \mathrm{H}_{56} \mathrm{ClN}_{9} \mathrm{NaO}_{13}(M+\mathrm{Na})^{+}:$1060.3584; found: 1060.3578 .

Isopropyl 1-\{14-[4-(\{[(S)-6-(2-azidoacetamido)-2-(4-benzoylbenzamido)hexanoyl]oxy\}methyl)-1H-1,2,3-triazol-1 -yl]-2-oxo-3,6,9,12-tetraoxatetradecyl\}-4-(2-chlorophenyl)-2-methyl-5-oxo-1,4,5,7-tetrahydrofuro[3,4-b]pyridine3-carboxylate(5d). HPLC analysis: 90.7\%. M.p. 66-68 ${ }^{\circ} \mathrm{C} .{ }^{1} \mathrm{H}-\mathrm{NMR}\left(400 \mathrm{MHz}, \mathrm{CDCl}_{3}\right): 0.82(\mathrm{~d}$, $J=6.4 \mathrm{~Hz}, 3 \mathrm{H}), 1.18(\mathrm{~d}, J=6.0 \mathrm{~Hz}, 3 \mathrm{H}), 1.38-1.56(\mathrm{~m}, 4 \mathrm{H}), 1.83-1.93(\mathrm{~m}, 2 \mathrm{H}), 2.39(\mathrm{~s}, 3 \mathrm{H}), 3.23-3.29(\mathrm{~m}$, $2 \mathrm{H}), 3.54-3.61(\mathrm{~m}, 8 \mathrm{H}), 3.71(\mathrm{t}, J=4.4 \mathrm{~Hz}, 2 \mathrm{H}), 3.85(\mathrm{t}, J=4.8 \mathrm{~Hz}, 2 \mathrm{H}), 3.90(\mathrm{~d}, J=4.8 \mathrm{~Hz}, 2 \mathrm{H}), 4.27$ $(\mathrm{dd}, J=51.6,18.8 \mathrm{~Hz}, 2 \mathrm{H}), 4.38-4.41(\mathrm{~m}, 2 \mathrm{H}), 4.53(\mathrm{t}, J=5.2 \mathrm{~Hz}, 2 \mathrm{H}), 4.72(\mathrm{~s}, 2 \mathrm{H}), 4.74-4.77(\mathrm{~m}, 1 \mathrm{H})$, 4.82-4.88 (m, 1H), 5.26-5.35(m, 2H), 5.41 (s, 1H), 6.64-6.69 (m, 1H), 7.05-7.10 (m, 1H), 7.15-7.19 (m, $2 \mathrm{H}), 7.25-7.27(\mathrm{~m}, 1 \mathrm{H}), 7.39(\mathrm{dd}, J=7.6,1.6 \mathrm{~Hz}, 1 \mathrm{H}), 7.50(\mathrm{t}, J=7.6 \mathrm{~Hz}, 2 \mathrm{H}), 7.62(\mathrm{t}, J=7.2 \mathrm{~Hz}, 1 \mathrm{H})$, 7.78-7.85 (m, 5H), 7.94-7.97 (m, 2H). ${ }^{13} \mathrm{C}-\mathrm{NMR}\left(100 \mathrm{MHz}, \mathrm{CDCl}_{3}\right): 195.0,171.1,170.5,167.2,166.3$, 165.8, 165.7, 156.1, 143.8, 141.3, 141.1, 139.3, 136.0, 132.1, 132.0, 130.1, 129.1, 129.0, 128.2, 127.5, 126.9, $126.3,126.1,124.1,108.2,102.1,69.45,69.43,69.41,68.2,67.7,66.8,64.4,63.9,57.4,51.9,51.4,49.3,46.4$, 37.7, 33.9, 30.2, 27.7, 21.5, 20.6, 19.9, 14.2. ESI (MS) $m / z: 1082.1(\mathrm{M}+\mathrm{H})^{+}$. HRMS (ESI-TOF) calculated for $\mathrm{C}_{53} \mathrm{H}_{60} \mathrm{ClN}_{9} \mathrm{NaO}_{14}(\mathrm{M}+\mathrm{Na})^{+}$: 1104.3846; found: 1104.3840 .

3.1.18. (S)-Methyl-6-(2-azidoacetamido)-2-(4-benzoylbenzamido)hexanoate (34)

A mixture of $33(0.11 \mathrm{~g}, 0.25 \mathrm{mmol})$ and $\mathrm{NaN}_{3}(0.25 \mathrm{~g}, 0.38 \mathrm{mmol})$ in DMF $(10.0 \mathrm{~mL})$ was stirred at $75{ }^{\circ} \mathrm{C}$ for $2 \mathrm{~h}$. The mixture was diluted with ice water $(20 \mathrm{~mL})$ and extracted by EtOAc $(20 \mathrm{~mL} \times 2)$. 
The combined organic phase was washed with brine $(20 \mathrm{~mL} \times 2)$, dried over anhydrous $\mathrm{Na}_{2} \mathrm{SO}_{4}$, and concentrated. The residue was purified by flash silica gel column chromatography [petroleum ether-EtOAc (4:1)] to obtain $34(83.0 \mathrm{mg}, 61 \%)$ as a white solid product. HPLC analysis: $96.0 \%$. M.p. 121-122 ${ }^{\circ} \mathrm{C} .{ }^{1} \mathrm{H}-\mathrm{NMR}\left(400 \mathrm{MHz}, \mathrm{CDCl}_{3}\right): 1.36-1.54(\mathrm{~m}, 2 \mathrm{H}), 1.62(\mathrm{tt}, J=14.1,7.0 \mathrm{~Hz}, 2 \mathrm{H}), 1.88$ (ddd, $J=22.8,11.4,7.4 \mathrm{~Hz}, 1 \mathrm{H}), 1.96-2.07(\mathrm{~m}, 1 \mathrm{H}), 3.24-3.39(\mathrm{~m}, 2 \mathrm{H}), 3.80(\mathrm{~s}, 3 \mathrm{H}), 3.88-4.00(\mathrm{~m}, 2 \mathrm{H}), 4.81(\mathrm{dd}$, $J=12.2,7.2 \mathrm{~Hz}, 1 \mathrm{H}), 6.44(\mathrm{~s}, 1 \mathrm{H}), 6.97(\mathrm{~s}, 1 \mathrm{H}), 7.50(\mathrm{t}, J=7.6 \mathrm{~Hz}, 2 \mathrm{H}), 7.62(\mathrm{t}, J=7.4 \mathrm{~Hz}, 1 \mathrm{H}), 7.80(\mathrm{~d}$, $J=7.6 \mathrm{~Hz}, 2 \mathrm{H}), 7.85(\mathrm{~d}, J=7.6 \mathrm{~Hz}, 2 \mathrm{H}), 7.96(\mathrm{~d}, J=8.2 \mathrm{~Hz}, 2 \mathrm{H}) .{ }^{13} \mathrm{C}-\mathrm{NMR}\left(100 \mathrm{MHz}, \mathrm{CDCl}_{3}\right): 195.9$, $172.8,166.9,166.4,140.4,137.0,136.9,132.9,130.1,128.5,127.2,52.7,52.5,38.7,31.8,28.9,22.4$. ESI (MS) $m / z: 450.2(M-H)^{-}$. HRMS (ESI-TOF) calculated for $\mathrm{C}_{23} \mathrm{H}_{24} \mathrm{~N}_{5} \mathrm{O}_{5}(M-\mathrm{H})^{-}: 450.1777$; found: 450.1783 .

3.1.19. Isopropyl 1-(14-\{4-[(\{(S)-2-(4-benzoylbenzamido)-6-[2-(4-\{[(5-\{(3aS,4S,6aR)-2-oxohexahydro-1Hthieno[3,4-d]imidazol-4-yl\}pentanoyl)oxy]methyl\}-1H-1,2,3-triazol-1-yl)acetamido]hexanoyl\}oxy) methyl]-1H-1,2,3-triazol-1-yl\}-2-oxo-3,6,9,12-tetraoxatetradecyl)-4-(2-chlorophenyl)-2-methyl-5-oxo1,4,5,7-tetrahydrofuro[3,4-b]pyridine-3-carboxylate (36)

To a solution of $5 \mathrm{~d}(0.39 \mathrm{~g}, 0.36 \mathrm{mmol})$ and $35(0.12 \mathrm{~g}, 0.43 \mathrm{mmol})$ in $\mathrm{CH}_{2} \mathrm{Cl}_{2}(4 \mathrm{~mL})$ and $\mathrm{H}_{2} \mathrm{O}$ ( $4 \mathrm{~mL}), \mathrm{CuSO}_{4} \cdot 5 \mathrm{H}_{2} \mathrm{O}(0.10 \mathrm{mg}, 0.40 \mathrm{mmol})$ and sodium ascorbate $(0.10 \mathrm{~g}, 0.51 \mathrm{mmol})$ were added. The resulting solution was stirred at r.t. overnight. The solvent was evaporated in vacuo, and then the residue was redissolved in EtOAc $(10 \mathrm{~mL})$, washed by water $(10 \mathrm{~mL} \times 2)$, and dried over anhydrous $\mathrm{Na}_{2} \mathrm{SO}_{4}$. The organic layer was evaporated, and the residue was purified by preparative-reverse phase HPLC to give $36(66.0 \mathrm{mg}, 13 \%)$ as a pale yellow solid. HPLC analysis: $93.6 \%$. M.p. $71-73{ }^{\circ} \mathrm{C} .{ }^{1} \mathrm{H}-\mathrm{NMR}$ (400 MHz, $d_{6}$-DMSO): $0.76(\mathrm{~d}, J=6.0 \mathrm{~Hz}, 3 \mathrm{H}), 1.11(\mathrm{~d}, J=6.0 \mathrm{~Hz}, 3 \mathrm{H}), 1.29-1.56(\mathrm{~m}, 10 \mathrm{H}), 1.79-1.84$ $(\mathrm{m}, 2 \mathrm{H}), 2.30-2.33(\mathrm{~m}, 5 \mathrm{H}), 2.57(\mathrm{~d}, J=12.4 \mathrm{~Hz}, 1 \mathrm{H}), 2.81(\mathrm{dd}, J=12.4,5.2 \mathrm{~Hz}, 1 \mathrm{H}), 3.06-3.10(\mathrm{~m}, 3 \mathrm{H})$, $3.44-3.52(\mathrm{~m}, 8 \mathrm{H}), 3.64(\mathrm{t}, J=4.4 \mathrm{~Hz}, 2 \mathrm{H}), 3.80(\mathrm{t}, J=5.2 \mathrm{~Hz}, 2 \mathrm{H}), 4.10-4.13(\mathrm{~m}, 1 \mathrm{H}), 4.28-4.32(\mathrm{~m}, 3 \mathrm{H})$, $4.43-4.61(\mathrm{~m}, 5 \mathrm{H}), 4.71-4.77(\mathrm{~m}, 1 \mathrm{H}), 4.89(\mathrm{dd}, J=32.0,16.8 \mathrm{~Hz}, 2 \mathrm{H}), 5.06(\mathrm{~s}, 2 \mathrm{H}), 5.12(\mathrm{~s}, 2 \mathrm{H}), 5.21(\mathrm{~s}$, $3 \mathrm{H}), 6.34(\mathrm{br} \mathrm{s}, 1 \mathrm{H}), 6.40(\mathrm{br} \mathrm{s}, 1 \mathrm{H}), 7.17(\mathrm{td}, J=7.6,1.6 \mathrm{~Hz}, 1 \mathrm{H}), 7.27(\mathrm{td}, J=7.6,1.2 \mathrm{~Hz}, 1 \mathrm{H}), 7.31(\mathrm{dd}$, $J=8.0,1.2 \mathrm{~Hz}, 1 \mathrm{H}), 7.40(\mathrm{dd}, J=7.6,1.6 \mathrm{~Hz}, 1 \mathrm{H}), 7.58(\mathrm{t}, J=7.6 \mathrm{~Hz}, 2 \mathrm{H}), 7.71(\mathrm{t}, J=7.6 \mathrm{~Hz}, 1 \mathrm{H}), 7.76$ $(\mathrm{d}, J=7.2 \mathrm{~Hz}, 2 \mathrm{H}), 7.82(\mathrm{~d}, J=8.0 \mathrm{~Hz}, 2 \mathrm{H}), 8.03(\mathrm{~d}, J=8.4 \mathrm{~Hz}, 2 \mathrm{H}), 8.07(\mathrm{~s}, 1 \mathrm{H}), 8.12(\mathrm{~s}, 1 \mathrm{H}), 8.32(\mathrm{t}$, $J=5.6 \mathrm{~Hz}, 1 \mathrm{H}), 8.95(\mathrm{~d}, J=7.2 \mathrm{~Hz}, 1 \mathrm{H}) .{ }^{13} \mathrm{C}-\mathrm{NMR}\left(100 \mathrm{MHz}, \mathrm{CDCl}_{3}\right): 195.1,172.4,171.6,170.7,167.3$, 165.9, 165.8, 164.6, 156.3, 143.9, 141.9, 141.3, 141.1, 139.2, 136.0, 135.9, 132.1, 131.9, 130.1, 129.1, 129.0, 128.2, 127.5, 126.9, 126.5, 126.1, 124.6, 124.1, 108.1, 102.0, 69.4, 69.3, 68.2, 67.7, 66.8, 64.5, 63.9, 60.7, 59.2, 57.4, 56.4, 54.5, 52.2, 51.6, 49.3, 46.4, 39.5, 38.0, 33.9, 32.7, 29.9, 27.3, 27.1, 27.0, 23.6, 21.7, 20.7, 19.9, 14.2. ESI (MS) $m / z: 1364.1(M+\mathrm{H})^{+}$. HRMS (ESI-TOF) calculated for $\mathrm{C}_{66} \mathrm{H}_{78} \mathrm{ClN}_{11} \mathrm{NaO}_{17} \mathrm{~S}(M+\mathrm{Na})^{+}$: 1386.4884; found: 1386.4879 .

\subsection{Glycogenolysis Inhibition in Liver HL-7702 Cells and HepG2 Cells}

The inhibition of hepatic glycogenolysis was monitored by the measurement of liver glycogen using a microplate reader (BIO-RAD, Bio-Rad Laboratories, Hercules, CA, USA), which was done quantitatively by the anthrone reagent (Sigma, Saint Louis, MO, USA) colorimetric method based on the published method [11]. Primary human liver HL-7702 cells or HepG2 cells (Sigma) were treated with the test compound or DMSO solvent (final concentration, $0.10 \%$ ), followed by 60 min incubation with $0.3 \mathrm{nM}$ glucagon (GGN). Assays were terminated by centrifugation, and cells were digested with $30 \% \mathrm{KOH}$ followed by glycogen determination. The $\mathrm{IC}_{50}$ values were estimated by fitting the inhibition data to a dose-dependent curve using a logistic derivative equation.

\subsection{Photoaffinity Labeling Experiment}

(1) According to our previous report [10], a complete Dulbecco's Modified Eagle's Medium (DMEM) (100 U/mL penicillin, $100 \mathrm{mg} / \mathrm{mL}$ streptomycin, $12 \%$ fetal bovine serum, $\mathrm{pH} 7.4)$ was used to culture the HepG2 cells in standard incubator conditions $\left(37^{\circ} \mathrm{C}, 5 \% \mathrm{CO}_{2}\right)$ until about $80 \%$ confluence. HepG2 cells were harvested by trypsinization and washed twice with phosphate buffered saline (PBS). HepG2 cells were lysed in a lysis buffer (7 M urea, 2 M thiourea, $4 \%(w / v)$ CHAPS, $40 \mathrm{mM}$ Tris, $65 \mathrm{mM}$ 
DTT, 2\% (v/v) IPG Buffer pH 3-10, 1\% (v/v) Protease Inhibitor cocktail), and then centrifuged using a Soniprep instrument with $100 \mathrm{~W}, 5 \times 10 \mathrm{~s}$ pulses and short pauses in between; these cells were kept on ice for $1 \mathrm{~h}$. The resulting lysate was centrifuged at $100,000 \times g$ at $4{ }^{\circ} \mathrm{C}$ for $1 \mathrm{~h}$ to remove cell debris. Finally, the precipitate was resuspended in 5 volumes of $50 \mathrm{mM}$ Tris. $\mathrm{HCl}$ buffer $(\mathrm{pH} 7.4)$ and stored at $-80{ }^{\circ} \mathrm{C}$. The protein concentration of the suspension was measured according to the Bradfor method. (2) The soluble proteomes prepared from HepG2 cells were diluted to $2.0 \mathrm{mg} / \mathrm{mL}$ with $50 \mathrm{mM}$ Tris· $\mathrm{HCl}$ buffer ( $\mathrm{pH}$ 7.4). The labeling reation was initiated by incubating proteomes with the probe (dissolved in DMSO) at $4{ }^{\circ} \mathrm{C}$ for $8 \mathrm{~h}$, and then exposing them to UV $365 \mathrm{~nm}(220 \mathrm{v}, 6 \mathrm{~W}, 365 \mathrm{~nm})$ at a distance of $3 \mathrm{~cm}$. The reaction mixture was centrifuged at $48,000 \times g$ for $10 \mathrm{~min}$, and then the supernatant was removed, and the precipitate was resuspended in a lysis buffer (urea $480 \mathrm{mg} / \mathrm{L}$, chaps $40 \mathrm{mg} / \mathrm{L}$, Tris-base $4.8 \mathrm{mg} / \mathrm{L}$, DTT $10 \mathrm{mg} / \mathrm{L}$, Ampholate $50 \mathrm{~mL} / \mathrm{L}$, and bromophenol blue $0.002 \%$ ) at $4{ }^{\circ} \mathrm{C}$ for $1 \mathrm{~h}$ and centrifuged at $18,000 \times g$ for $2 \mathrm{~h}$. The supernatant was dialyzed against $50 \mathrm{mM}$ Tris. $\mathrm{HCl}$ buffer ( $\mathrm{pH} 7.4)$. To detect the proteins photo-cross-linked by test probe, the homogenate photolabeled with the probe was subjected to SDS-PAGE electrophoresis and then transferred onto a polyvinylidene fluoride membrane. The membrane was blocked with 1\% BSA in PBS with $0.05 \%$ Tween 20 at room temperature for $1 \mathrm{~h}$, washed using PBS with 0.05\% Tween 20 for 5 min two times, and then incubated with a streptavidin-HRP polymer conjugate (Sigma, Cat. S 2438) diluted 1:10,000 in PBS with 0.05\% Tween 20 at room temperature for $1 \mathrm{~h}$. After six washes for 5 min each using PBS with $0.05 \%$ Tween 20, the membrane was treated with Enhanced Chemiluminescence (ECL, Amersham, Boston, MA, USA) detection reagents. Biotinylated proteins were visualized by exposure to X-ray and imaging development.

\subsection{Protein Digestion and Mass Spectrometry}

(1) The $170 \mathrm{kDa}$ band was excised from the blot and processed for internal sequence analysis as described [13]. Briefly, in situ digestion was done using $0.01 \mu \mathrm{g} / \mu \mathrm{L}$ trypsin (in $100 \mu \mathrm{L}$ of $25 \mathrm{mM}$ $\mathrm{NH}_{4} \mathrm{HCO}_{3}$ ) for $30 \mathrm{~min}$ at $4{ }^{\circ} \mathrm{C}$, until the trypsin was completely absorbed by the gel particles. Then, the resulting mixture was added to $100 \mu \mathrm{L}$ of $25 \mathrm{mM} \mathrm{NH}_{4} \mathrm{HCO}_{3}$, the supernatant was collected by centrifugation and transfered in another Eppendorf tube. The extraction buffer $\left(5 \% \mathrm{TFA}, 95 \% \mathrm{ddH} \mathrm{H}_{2} \mathrm{O}\right)$ was added into the pellets for $1 \mathrm{~h}$, and then treated with an extraction buffer $(2.5 \% \mathrm{TFA}, 50 \% \mathrm{ACN}$, $47.5 \% \mathrm{ddH}_{2} \mathrm{O}$ ) for $1 \mathrm{~h}$ and stored at $-20^{\circ} \mathrm{C}$. (2) Mass Spectrometry analysis was carried out using the Tanon-6100 Chemiluminescent Imaging system (Tanon Science and technology Co., Ltd., Shanghai, China). The band densities were calculated with Quantity One software 4.6.2 (Bio-Rad Laboratories, Inc., Hercules, CA, USA). The excised gel was digested with trypsin and subjected to LC-MS/MS. The data were recorded on an LTQ-Orbitrap Fusion mass spectrometer (ThermoFisher Scientific Inc., Waltham, MA, USA) coupled to an Easy-nLC 1000 LC System (ThermoFisher Scientific Inc., Waltham, MA, USA). Label-free MS analysis was performed by Thermo Q-Exactive mass spectrometry, and the MS raw data were processed using MaxQuant software with the Uniprot-Orytolagus cuniculus database.

\section{Conclusions}

In summary, this work described the design and synthesis of novel photoaffinity probes of dihydropyridine derivatives, BAY R3401, and evaluated their potency in an inhibition assay of glycogenolysis. Probe $2 \mathrm{~d}$ exhibited the best inhibitory activity, with an $\mathrm{IC}_{50}$ value of $4.45 \mu \mathrm{M}$ and $28.49 \mu \mathrm{M}$ in primary human liver HL-7702 cells and HepG2 cells, respectively. Photoaffinity labeling experiments were also performed, and protein bands larger than $170 \mathrm{kDa}$ were tagged by probe $\mathbf{2 d}$ in crude proteomes. These data suggest that the synthesized probe $\mathbf{2 d}$ might be used to label, identify, and purify the potential target enzymes of BAY R3401. Mass spectrometric analysis was used to detect protein bands larger than $170 \mathrm{kDa}$, and we hypothesise that the $\mathrm{PH}$-interacting proteins, histone $\mathrm{H} 4$, hexokinase-2, and solute carrier family 2 might be the target proteins of BAY R3401 based on the results. We are now in the process of verifying these proteins.

Supplementary Materials: Supplementary materials associated with this article are available online. Contents: Data of Coomassie brilliant blue (CBB) and NMR spectra of the prepared compounds. 
Author Contributions: Conceived and designed the study: L.Z. and Z.Y. Performed the experiments: L.Z., Z.Y., Y.W., C.S., and G.M. Analyzed the data: Z.Y. and Y.W. Contributed reagents/materials/analysis tools: L.Z., Z.Y., Y.W., C.S., and G.M. Wrote the manuscript: L.Z. and Z.Y.

Funding: This work was supported by the National Natural Science Foundation of China (No. 81473101 and 81001401), the Natural Science Foundation of Hebei Province (No. H2017406049), and Key Program of Education Department of Hebei Province (No. ZD2018080).

Conflicts of Interest: The authors declare no conflict of interest.

\section{References}

1. Goldmann, S.; Ahr, H.; Puls, W.; Bischoff, H.; Petzinna, D.; Schlossmann, K.; Ben-der, J. Dihydropyridine compounds and their use in reducing blood sugar. U.S. Patent 4,786,641, 22 November 1988.

2. Kurukulasuriya, R.; Link, J.T.; Madar, D.J.; Pei, Z.; Richards, S.J.; Rohde, J.J.; Souers, A.J.; Szczepankiewicz, B.G. Potential drug targets and progress towards pharmacologic inhibition of hepatic glucose production. Curr. Med. Chem. 2003, 10, 123-153. [CrossRef] [PubMed]

3. Kato, A.; Nasu, N.; Takebayashi, K.; Adachi, I.; Minami, Y.; Sanae, F.; Asano, N.; Watson, A.A.; Nash, R.J. Structure-activity relationships of flavonoids as potential inhibitors of glycogen phosphorylase. J. Agric. Food Chem. 2008, 56, 4469-4473. [CrossRef] [PubMed]

4. Bergans, N.; Stalmans, W.; Goldmann, S.; Vanstapel, F. Molecular mode of inhibition of glycogenolysis in rat liver by the dihydropyridine derivative, BAY R3401: Inhibition and inactivation of glycogen phosphorylase by an activated metabolite. Diabetes 2000, 49, 1419-1426. [CrossRef] [PubMed]

5. Sakurai, K.; Hiraizumi, M.; Isogai, N.; Komatsu, R.; Shibatal, T.; Ohta, Y. Synthesis of a fluorescent photoaffinity probe of OSW-1 by site-selective acylation of an inactive congener and biological evaluation. Chem. Commun. 2017, 53, 517-520. [CrossRef] [PubMed]

6. Pan, S.; Zhang, H.; Wang, C.; Yao, S.C.; Yao, S.Q. Target identification of natural products and bioactive compounds using affinity-based probes. Nat. Prod. Rep. 2016, 33, 612-620. [CrossRef] [PubMed]

7. Smith, E.; Collins, I. Photoaffinity labeling in target - and binding-site identification. Future Med. Chem. 2015, 7, 159-183. [CrossRef] [PubMed]

8. Ogawa, A.K.; Willoughby, C.A.; Bergeron, R.; Ellsworth, K.P.; Geissler, W.M.; Myers, R.W.; Yao, J.; Harris, G.; Chapman, K.T. Glucose-lowering in a db/db mouse model by dihydropyridine diacid glycogen phosphorylase inhibitors. Bioorg. Med. Chem. Lett. 2003, 13, 3405-3408. [CrossRef]

9. Rowland, M.M.; Bostic, H.E.; Gong, D.; Speers, A.E.; Lucas, N.; Cho, W.; Cravatt, B.F.; Best, M.D. Phosphatidylinositol 3,4,5-trisphosphate activity probes for the labeling and proteomic characterization of protein binding partners. Biochemistry 2011, 50, 11143-11161. [CrossRef] [PubMed]

10. Zhang, L.; Zhang, Y.; Dong, J.; Liu, J.; Zhang, L.; Sun, H. Design and synthesis of novel photoaffinity probes for study of the target proteins of oleanolic acid. Bioorg. Med. Chem. Lett. 2012, 22, 1036-1039. [CrossRef] [PubMed]

11. Martin, W.H.; Hoover, D.J.; Armento, S.J.; Stock, I.A.; McPherson, R.K.; Danley, D.E.; Stevenson, R.W.; Barrett, E.J.; Treadway, J.L. Discovery of a human liver glycogen phosphorylase inhibitor that lowers blood glucose in vivo. Proc. Natl. Acad. Sci. 1998, 95, 1776-1781. [CrossRef] [PubMed]

12. Olivo, H.F.; Perez-Hernandez, N.; Liu, D.; Iruthayanathan, M.; O’Leary, B.; Homan, L.L.; Dillon, J.S. Synthesis and application of a photoaffinity analog of dehydroepiandrosterone (DHEA). Bioorg. Med. Chem. Lett. 2010, 20, 1153-1155. [CrossRef] [PubMed]

13. Erdjument-Bromage, H.; Lui, M.; Lacomis, L.; Grewal, A.; Annan, R.S.; McNulty, D.E.; Carr, S.A.; Tempst, P. Examination of micro-tip reversed-phase liquid chromatographic extraction of peptide pools for mass spectrometric analysis. J. Chromatogr. A 1998, 826, 167-181. [CrossRef]

Sample Availability: Samples of the compounds are available from the authors.

(C) 2019 by the authors. Licensee MDPI, Basel, Switzerland. This article is an open access article distributed under the terms and conditions of the Creative Commons Attribution (CC BY) license (http://creativecommons.org/licenses/by/4.0/). 